University of Louisville

ThinkIR: The University of Louisville's Institutional Repository

Electronic Theses and Dissertations

$12-2018$

\title{
Arab-Islamic and folk health models: new perspectives on Syrian refugee resettlement in the US.
}

Ghina Kheir

University of Louisville

Follow this and additional works at: https://ir.library.louisville.edu/etd

Part of the Arts and Humanities Commons

\section{Recommended Citation}

Kheir, Ghina, "Arab-Islamic and folk health models: new perspectives on Syrian refugee resettlement in the US." (2018). Electronic Theses and Dissertations. Paper 3100.

https://doi.org/10.18297/etd/3100

This Doctoral Dissertation is brought to you for free and open access by ThinkIR: The University of Louisville's Institutional Repository. It has been accepted for inclusion in Electronic Theses and Dissertations by an authorized administrator of ThinkIR: The University of Louisville's Institutional Repository. This title appears here courtesy of the author, who has retained all other copyrights. For more information, please contact thinkir@louisville.edu. 


\title{
ARAB-ISLAMIC AND FOLK HEALTH MODELS: NEW PERSPECTIVES ON SYRIAN REFUGEE RESETTLEMENT IN THE US
}

\author{
By \\ Ghina Kheir \\ B.A., Lebanese University, 2005 \\ M.A., University of Balamand, 2010 \\ A Dissertation \\ Submitted to the Faculty of the \\ College of Arts and Sciences of the University of Louisville \\ in Partial Fulfillment of the Requirements \\ for the Degree of
}

Doctor of Philosophy in Humanities

Department of Comparative Humanities

University of Louisville

Louisville, KY

December 2018 
Copyright 2018 by Ghina Kheir

All rights reserved 



\title{
ARAB-ISLAMIC AND FOLK HEALTH MODELS: NEW PERSPECTIVES ON SYRIAN REFUGEE RESETTLEMENT IN THE US
}

\author{
By \\ Ghina Kheir \\ B.A., Lebanese University, Lebanon, 2005 \\ M.A., University of Balamand, Lebanon, 2010
}

A Dissertation Approved on

November 12, 2018

by the following Dissertation Committee:

Doctoral Committee Chair, Prof. Julie Peteet

Prof. Fabian Crespo (Member)

Prof. Gul Marshall (Member)

Prof. Brad Bowman (Member) 


\section{DEDICATION}

This dissertation is dedicated to

my God who enabled me to accomplish this work

my parents, Mazhar Kheir and Maha Kanj, for their endless and unconditional

love and encouragement

to my husband, Mohamed El Kheir, for his continuous support and patience

to my sisters, Jana, Judy, and Farah, for their making me feel high always

to my children, Majd, Leen, Rahaf, and Yazan, for being always the inspiration

to every person who believes in the power of humanness 


\section{ACKNOWLEDGEMENTS}

Thanks to my Creator who armed me with His love and mercy to achieve my goal. I would like to express my deepest thanks and appreciation to my love, Mohamed ElKheir, for his patience as I worked to fulfill the responsibilities for this research study. You have been there for me each step of the way and for that I am forever grateful. I am appreciative of my family: Mazhar, Maha, Jana, Judy, and Farah Kheir, for their love, support, and encouragement during this doctoral journey. It has not been an easy excursion, but my progress is largely due to your persistent motivation to keep me going when times were tough. I am grateful to my kids: Majd, Leen, Rahaf, and Yazan for providing the motivation for this work to be successfully accomplished. Special thanks to my friend Yaman Babi for always being there to help with my children. This dissertation is made possible through the commitment and encouragement of my committee members. Words are powerless to express my gratitude for my chair and faculty mentor Professor Julie Peteet for her guidance, constructive criticism, support, kind words, and broad-scope perspective which made this a better interdisciplinary project. I have grown professionally and personally as a result of this work. You recognized my potential and never gave up on me. Also, I would like to thank Professor Gul Marshall for her thoughtprovoking comments and Professors Simona Bertacco and Fabian Crespo for their collaboration. Thank you for every Syrian refugee who made this research journey eye opening to many aspects of our humanness. 


\section{ABSTRACT \\ ARAB-ISLAMIC AND FOLK HEALTH MODELS: NEW PERSPECTIVES ON SYRIAN REFUGEE RESETTLEMENT IN THE US \\ Ghina Kheir}

November 12, 2018

This research builds upon the framework of the Health Traditions Model (HTM) as described in 1994 by Rachel Spector, a scholar and practitioner of a cultural care model of health among multicultural populations. I integrate this model into a study of Syrian refugees' resettlement experience in Louisville, Kentucky. Syrian refugees' voices and narratives of their corresponding Arab-Islamic and folk approaches to health, illness, and healing are the launch site for this project. I argue that approaching the resettlement experience from the refugees' own cultural and Arab-Islamic perspectives toward health, illness, and healing aids in achieving a pluralistic health care system and also has the capacity to start a new trend in studying refugees' resettlement experiences. This trend would distance itself from the standard approaches to refugees encompassing mostly negative mental health outcomes and psychic disorders such as depression, anxiety, posttraumatic stress disorder, and suicide. An abductive methodology is adopted in this study which came up with new findings. Data analysis and interpretation revealed fundamental concepts related to various aspects: the existence of Arab/Islamic and folk health beliefs and practices in the daily lives of Syrian refugees, the positive impact of 
these practices and beliefs on their lives post-resettlement, and the problems these refugees encounter in the US biomedical health care system as they try to retain their health beliefs and practices. This study allowed Syrian refugees the opportunity to voice their personal experiences of dealing with health and illness upon resettlement in the US, and it revealed health-related issues that inspire and illuminate a process that can guide health care delivery and refugee resettlement research. 


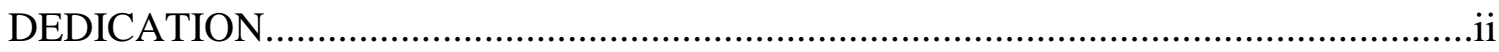

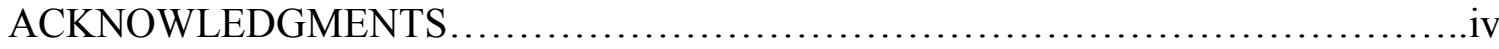

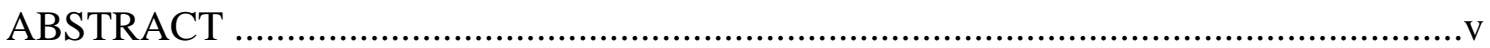

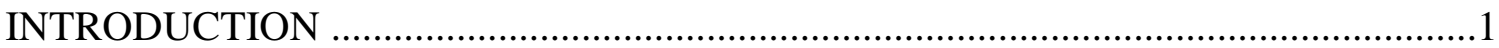

Research Problem and Background.........................................11

Spector's Theory of Cultural Competency ..................................20

Research Design and Methodology.......................................25

CHAPTER I LITERATURE REVIEW AND METHODOLOGY .................28

Application of Theory in Refugee Research................................. 30

Critical Analysis of Refuge Research................................... 35

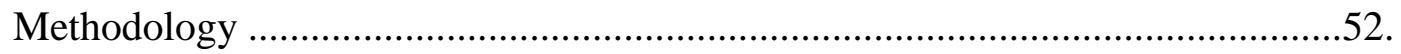

CHAPTER II A COMPARATIVE APPROACH: ISLAMIC MEDICINE\&WESTERN

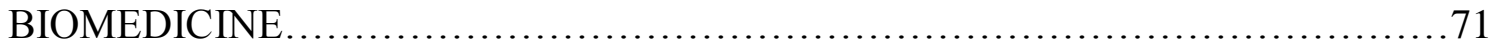

Islamic Medical System................................................ 90

Western Biomedicine...................................................... 99

Critiques of Western Biomedical System....................................132

Critiques of Islamic Medical System.....................................138 
Need for Medical Pluralism............................................141

CHAPTER III THE SYRIAN REFUGEES $\quad$ T................................ 147

The Syrian Refugee Crisis...........................................147

Syria's Demographics and Ethnic Groups.............................156

Syria's Health System and Health Traditions............................ 157

Overview of Syrian Refugees' Health in Hosting Countries.................170

US-Bound Refugees' Medical Screenings............................. 175

Syrian Refugees in Kentucky: Demographics and Health Profile.............178

CHAPTER IV RESULTS.............................................. 184

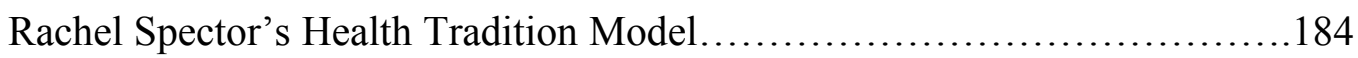

Acculturation and Adaptation.........................................189

Data Analysis and Results.......................................... 193

CHAPTER V SUMMARY AND IMPLICATIONS..........................219

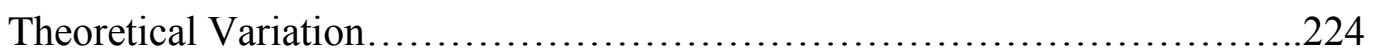

Recommendation..................................................227

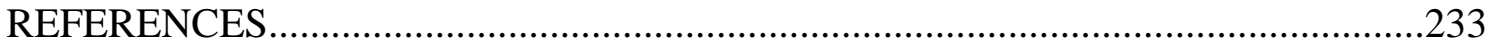

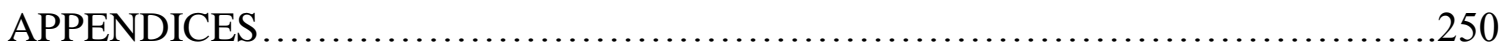

CURRICULUM VITAE..................................................254 


\section{INTRODUCTION}

While doing an internship at Kentucky Refugee Ministries, I met a Syrian refugee whom I was helping with directions to reach a downtown clinic. While chatting, he asked me about my ordinary treatment of headache. I answered that I endure sometimes and other times I use some over the counter drugs. He looked at me with much eagerness and said that he can prepare a massage oil for headaches and that he tried it before in Syria with many relatives and it 'worked'. To end the chat, I promised him to ask for that the next time I have any headache. Quickly, he affirmed: "Believe me, I tried it before, you would be more than happy, and I would be SO HAPPY to share with you this healing recipe." He delivered his promise with high tone of voice and sparkling eyes. His voice, tone, smile, mood, and facial expressions were all rejuvenated and brightened by his description of 'what he knows and what he uses'. This serendipitous encounter sparked my curiosity about the juxtaposition of medical systems and I decided to launch this study.

This research builds upon the framework of the Health Traditions Model (HTM) as described in 1994 by Rachel Spector, a scholar and practitioner of a cultural care model of health among multicultural populations. ${ }^{1}$ I integrate this model into a study of

\footnotetext{
${ }^{1}$ The terms 'HEALTH', 'ILLNESS', and 'HEALING' are written in this way when referring to the holistic view of health as adopted by Rachel Spector. It is worth noting that my use of the word 'traditional' in this context is as adopted by Spector. I find the terms 'folk' and 'ethno-religious' more appropriate than 'traditional', a somewhat nebulous and imprecise term.
} 
Syrian refugees' resettlement experience in Louisville, Kentucky. The resettlement experience challenges and propels the host community's health care system to be a pluralistic one. The research project proposes that Syrian refugees' resettlement experience and coping strategies in terms of their health substantially serves and feeds into the concept of pluralistic health care which recognizes the existence of multiple health and healing systems and options within a society. Facione describes pluralistic medical systems as culturally sensitive i.e. they display an "awareness and utilization of knowledge related to ethnicity, culture, gender, or sexual orientation in explaining and understanding situations and responses of individuals in their environment" (50). Syrian refugees' voices and narratives of their corresponding Arab-Islamic and folk approaches to Health, Illness, and Healing are the launch site for this project. I argue that approaching the resettlement experience from the refugees' own cultural and ArabIslamic perspectives toward Health, Illness, and Healing aids in achieving a pluralistic health care system and also has the capacity to start a new trend in studying refugees' resettlement experiences. This trend would distance itself from the standard approaches to refugees encompassing mostly negative mental health outcomes and psychic disorders such as depression, anxiety, posttraumatic stress disorder, and suicide. My study will investigate whether and how refugees' health folk and Arab-Islamic practices and beliefs enable their adaptation as they encounter a new culture and health care system. Globalization has become a fact of life since the late twentieth century, with issues of unparalleled displacement since WWII continuing to shape the new century's overall uncertainty and volatile changes. Members of the European Union (EU) fear that immigrants and refugees will compete for work and lower wages and change the racial 
and ethnic demographics; xenophobic nationalism is on the rise. Another fear is that they will pinch the public purse of European countries. Some claim refugees are destabilizing the EU, exposing the limits of the 1951 UN Convention on Refugees, and stretching humanitarian organizations to their limits. ${ }^{2}$ For instance, in Syria alone, the number of displaced people since the beginning of war till present is estimated to be around 12 million i.e. almost half of the population. Around 6.5 million have sought refuge in neighboring countries or abroad and another six million are internally displaced. Refugees leave their countries of origin because of wars, persecution, environmental crises, poverty, and lack of opportunities. These displaced populations are forced to move from one place to another and from one culture to another. Mobility brings with it the encounter of various cultures which in turn sparks culture shock, ethnocentrism, prejudicial beliefs and behaviors, and cultural conflicts. From age, gender, race and ethnicity to social class, language, spiritual beliefs, and mental and physical abilities, the breadth and depth of differences found in the people populating our single planet are limitless.

The United States (US) is one of many countries witnessing the growth of ethnocultural diversity. While failure to acknowledge, respect, and address these differences can divide, and while the assumption that "the US is the melting pot of all cultures" is detrimental, pluralism in health care has the capacity to shrink the gap, while enabling better communications and health outcomes and ultimately, uniting people in spite of,

\footnotetext{
${ }^{2} \mathrm{~A}$ refugee is someone who has been forced to flee his or her country because of persecution, war or violence. A refugee has a well-founded fear of persecution for reasons of race, religion, nationality, political opinion or membership in a particular social group.
} 
and sometimes because of, their differences. An understanding and awareness of Health and Illness within the ethno-cultural context is fundamental to the development and practice of medical pluralism. Therefore, striving for effectiveness and a pluralistic medical system is a must for practicing the moral art of ethics and responsibility in health care. While 'pluralistic medical systems' are sometimes romanticized, diversity awareness can actually be lifesaving in a health care setting. Refugees often have a 'different' set of cultural and religious beliefs concerning health practices which should be considered by health care professionals. There is a compelling need to recognize and incorporate pluralistic health care in response to the current and projected demographic changes in the United States.

The profile of the American population has undergone profound changes as a result of immigration patterns since 1965. Significant racial, ethnic, and cultural diversity characterizes this population. Health care organizations, programs, and staff and federal, state, and local governments are facing these demographic changes. They will be compelled to implement systemic change in order to meet the health needs of this diverse population. The results of the 2010 American Community Survey showed that over 40 million foreign-born people, representing 13 percent of the population, resided in the US. Currently, the US foreign-born population comprises a larger segment than at any time in the past five decades, a trend expected to continue. Therefore, health care professionals should be aware of these 'culturally-different' populations so that effective and quality health outcomes can be achieved.

Syrians are one recent group of refugees who has resettled in the US since 2015, and their religious and cultural beliefs about health differ in some significant ways from 
the Western view of health and illness. Yet they are not unfamiliar with the Western biomedical model of health knowledge and practices. The 'biomedical' or 'scientific' model of health draws upon biochemical explanations of ill health as the basis for treatment and intervention. By and large, it focuses on the purely biological to the exclusion of possible psychological, environmental, and social factors. Syrian refugees come from a country where folk and Arab- Islamic health practices are integrated in varying degrees with the Western biomedical models of health care. To better enhance the encounter of Syrian refugees with the Western biomedical health care systems, practices, and beliefs, and to guarantee a smooth acculturation process, it is vital to start the journey from the refugees' health care system background and their folk and ArabIslamic perspectives on health and illness.

Syria has been under the authoritarian rule of Bashār Al Assad since 2000. When Al Assad came to power he implemented reforms lifting some of the restrictions on freedom of the press and liberalizing trade, reforms that benefitted a growing urban business elite. Government support for education and health care continued with health care provided at little or no cost. In pre-conflict Syria, the government emphasized primary health care, but in a country with a high rate of population growth, funding could not keep up with demand or maintain quality. Syria's rural areas were a contrast with the wealth and services concentrated in the urban areas like Damascus. While rural communities are the country's breadbasket, the Syrian regime in the last 25 years has directed its resources toward urban areas and has not invested as much in rural development. In other words, access to health care was uneven along regional and class lines. Syria’s health care system, after 2000 i.e. when President Bashār Al Assad came to 
power, has been characterized with disparity in health care access and scarcity of resources in rural areas. For example according to the World Health Organization (WHO), in Damascus in 2009, there was one doctor per 339 people, while in rural $\mathrm{Al}$ Hasakah governate, the ratio was one doctor per 1,906 people. The health care system in Syria consists of a government-run public system that provides mostly primary care services, while the majority of advanced care services and facilities belong to the private sector and are concentrated in major urban centers such as Damascus and Aleppo. According to Mershed et al., out-of-pocket payments for private providers and copayments for public hospitals accounted for 60 percent of health expenditures of Syrians in 2008 (168-70). Attempts to liberalize the health care system and to provide more autonomy for the private sector in recent years, state Kherallah et al., resulted in a widening of inequality in access to care and increased the financial burden of those least able to pay (52). With cost and access issues, many Syrians turned to folk and herbal medicine.

Syria is known for its herbal-friendly environment, and folk medicine has been used frequently even before the uprising. In 1998, the Ministry of Health issued decisions on the manufacture and distribution of herbal medicines and on a system of controls. The manufacture of herbal medicines has been included in the national drug policy. According to WHO report "Legal Status of Traditional Medicine and Complementary/Alternative Medicine: A Worldwide Review: Eastern Mediterranean: Syrian Arab Republic", the Ministry of Health in Syria gave preliminary approval for the establishment of laboratories to manufacture herbal medicines and both public and private laboratories have been active in processing medicinal herbs. In addition, a 
syllabus on treatment with herbal medicines has been recommended for inclusion in the curricula of faculties of medicine (82). Many Syrians had recourse to herbs and folk ways of healing because they trusted them more than biomedical drugs, they have fewer side effects, and are more accessible. The resort to herbal medicine and folk cures is grounded in cultural and Islamic medical beliefs. Others invest in these remedies due to the high costs of chemically-based medicines or perhaps due to inequality in access to health care. Many Syrians integrated both the folk and Arab-Islamic health practices with the biomedical ones.

'Atțārinn (traditional Syrian druggists), are popular with Syrian patients especially those with cancer, hypertension, and obesity. This is not to say that Syrians are not familiar with Western biomedicine, but they also have a kit of folk and Arab Islamic beliefs, preferences, and expectations regarding diagnosis, causation, treatment, preventions, and practices regarding health and illness. Components of this kit sometimes overlap with the Western biomedical mainstream and other times depart from it. Due to war in the past five years, the absence of medical monitoring and inspection in Syria, as well as the huge drop in the number of medical staff due to displacement, death, and migration, have pushed many people to seek the help of folk treatments and Arab Islamic cures. Today, as Syria's war and economic crisis grinds on, the collapse of medical systems along with the absence of medical personnel, unavailability of drugs, and the skyrocketing prices of any if available, has fueled a recourse to folk medicine and ArabIslamic remedies. For example, many herbal treatments like brewing sage leaves in tea are being used to treat severe coughs and throat inflammation. Many Syrian refugees prefer to use olive oil in their dietary habits and for soothing their muscles. Several of the 
major Syrian pharmaceutical companies are located in battle zones; many of the factories have been completely destroyed and those that still stand have been forced to suspend operations due to failing finances and the logistical nightmare of distributing drugs. The price of imported drugs has increased in line with the value of the US dollar to the Syrian pound. Some people search the Internet for herbal medication for a certain disease they suffer from because they want to avoid seeing the doctor to save on check-up fees.

Syrians' cultural identity includes religion which plays a major role in preserving the values, beliefs, and practices within Syrian society and in fostering a sense of belonging. ${ }^{3}$ Religion is not only part of cultural identity, but also Syrians, as many Muslims do, rely on Qur'an-based and worship practices as healing and preventive measures in maintaining their health and treating illness. Not surprisingly, Syrian refugees take their folk and Arab-Islamic health beliefs and preferences with them wherever they go. However, to what extent do these beliefs and preferences gain recognition and value in the West? One of the aims of this study is to highlight the folk and Arab-Islamic perspectives of Syrian refugees in Louisville regarding their health and illness.

The examination of Syrian refugees' resettlement experience from a fairly new stance and the development of a hypothesis concerning their empowerment and validation via recognizing their folk as well as Arab-Islamic beliefs with respect to their Health and Illness would contribute to making a medically pluralistic system viable. It would also narrow the gap in knowledge about the experience of resettlement for Syrian

\footnotetext{
${ }^{3}$ Of the Syrian population, $74 \%$ are Sunnis, $13 \%$ are Shias including Alawites, $3 \%$ are Druze, while the remaining $10 \%$ are Christians.
} 
refugees, propel their adaptation in terms of health and wellness, and diminish the stress associated with this process. For successful adaptation to take place, the Western culture must be aware of refugees' perspectives and beliefs. Since acculturation involves a dynamic and reciprocal process between the newcomers and the host community, medical pluralism could be celebrated and inevitably realized. This research will also contribute to reducing the pervasive biases and stereotypes with regard to non-Western, here Muslim patients.

As Islamophobia is on the rise and as US President Trump's executive orders regarding the suspension of Refugee Admission Program in 2017, it is crucial to know what Muslim people, particularly Syrian refugees, think about Health and Illness and what folk and Arab Islamic beliefs and customs they bring with them. Knowing these issues is one way of building trust and finding common ground between the two cultures. Health care is one vital point of contact between diverse ethnicities and cultures in the US. Sometimes, it can bear negative outcomes if any of the two parties disrespect or mistrust the beliefs and preferences of the other. Here, I cannot but cite Fadiman's The Spirit Catches You and You Fall Down, a true story involving the life of Lia Lee, a Hmong child who was epileptic. After suffering severe grand mal seizures, she ends up in a persistent vegetative. The key point of the book, however, is not Lia's epilepsy as much as it is about the cultural barriers and clash that led to her vegetative state. The proper bio-medical treatment and compliance with it becomes the basis of a tug-of-war for Lia's life between her doctors and her parents. The author uses this battle as a way of framing the distinctions between Western and Eastern medicine, cultures, and family, and how each group views the patient in radically different ways. 
Syrian patients have a series of cultural and religious preferences and expectations that are put into relief during clinical encounters with Western health care providers. For example, many Syrians prefer to be examined by same-sex health care providers. This is an example of how one's core beliefs and values, if not recognized, may cause discomfort, misunderstanding, and mistrust. For health care, the link between ethics and professional conduct is vital. Health care providers' modes of reasoning and moral norms are largely grounded in European and Anglo-American culture. Refugees in the US constitute different racial, ethnic, and religious groups whose values systems (one) sometimes are congruent with, and sometimes at odds with, Western European cultural values. Ethics and culturally sensitive knowledge are highly valued in a pluralistic medical system, as they contribute to health care providers' moral development and professional decision making. They can also foster the ability to offer effective and quality health care to a wide spectrum of diverse populations. It is highly critical for health care providers, practices, and policies to be sensitive to the Syrian refugees' cultural beliefs and religious practices. This sensitivity would aid in better health outcomes, sometimes in integrating pluralistic approaches to certain health conditions, and in empowering refugees in their resettlement and adaptation process. This research project aims to elicit the voices of these refugees who could potentially enrich the health care system and render it more pluralistic. Moreover, their voices could guide policies in health care systems dealing with diverse communities and promote a positive image of a culturally diverse health care system. Accordingly, this research project advocates for a new perspective of studying refugees' resettlement and acculturation in terms of their health and wellness. 


\section{Research Problem and Background}

The US had increasingly become a resettlement site for refugees from various cultural, religious, and ethnic backgrounds. Recently, it has begun to host a relatively small number of Syrian refugees fleeing civil war since 2011. Over the past decade, the US annually accepted around 70,000 refugees from around the world. In September 2016, the US government has set a refugee admission target of 110,000 for FY 2017. This group includes people fleeing violence, religious persecution and war. In 2015, the Obama administration announced that the number of people to be admitted to the US as refugees would be increased to 85,000 in 2016, including about 10,000 Syrians. When compared to Europe, this number is exceedingly minimal. For example, in 2015 , Germany opened its doors to nearly one million asylum-seekers. More than half of these - about 484,000 — came from Syria. This number exceeds by far the numbers of Syrian refugees admitted to the US by the end of 2016. However, after the 2017 presidential election, refugees' admission policies have changed rather dramatically. President Trump signed an executive order in January 2017 suspending the refugee program and entry to the US for travelers from several Muslim-majority countries. In response to objections from the courts, the order was revised but still suspended refugee entries. However, it did not suspend Syrian refugees indefinitely and no longer includes Iraq in the named countries. As a reaction to the harsh rhetoric pervading some of the political stances regarding hosting refugees in Europe and the United States, it is vital to know more about these refugees since little is known about Syrian refugees resettling in the US. 
To enhance adaptation, refugees should be active players in shaping the communities they are resettled in and in nourishing the spirit of multi-culturalism. While the United States is currently witnessing a small but steady influx of Syrian refugees, we still know little of their resettlement process and the challenges, obstacles, and conflicts they face. What has been their experience of resettlement? It is apparent that this influx may be continuous; thus, in ten years the Syrian refugees will include first and second generations living in the US. ${ }^{4}$ It is crucial for the future of both the refugees and the US social and health sector to mutually cultivate culturally sensitive knowledge and awareness and help in realizing a pluralistic medical system.

This research adds to the expanding body of knowledge about refugee resettlement in the US such as Rumbaut and Portes's Immigrant America: A Portrait and Inhorn's America's Arab Refugees: Vulnerability and Health on the Margins. However, it builds upon and departs from the literature on refugee resettlement. Refugees' health and wellness issues post-resettlement are approached from a different perspective; the refugees' folk and religious beliefs and preferences concerning their Health, Illness, and Healing are the building blocks of this study. My research complements research aimed at studying refugees' perspectives on adaptation and folk remedies. My research brings Syrian refugees to the fore since they are a recent refugee population, not yet wellresearched, and also carries forward previous studies about refugees' resettlement experience and health needs expanding upon them to highlight the health beliefs and traditions of these refugees. It is inspired by a model of cultural competency (Health

\footnotetext{
${ }^{4}$ In 2019, the numbers of refugee admissions will be reduced to 30,000
} 
Traditions Model by Spector) and applies it to the specificity of Syrian refugees' resettlement process. Moreover, my research elicits refugee voices to inform a culturallycompetent health care system as part of medical pluralism in a country which has long hosted refugees and migrants from across the globe.

This research is a qualitative study of the Syrian refugee resettlement process in Louisville, Kentucky with a focus on folk and Arab Islamic beliefs, preferences, and practices concerning health and integration. This study adopts Rachel Spector's Health Traditions Model as the conceptual framework for cultural competency in health care delivery. In this way, refugee voices are positioned as a key factor in shaping and bringing forth culturally competent health care as part of medical pluralism, and, I argue, would suffer less stress as they acculturate. Listening to refugees' health beliefs, practices, and preferences can be empowering. Recognition of these practices and beliefs by the Western health care system, on one hand, and the refugees' experiences of less stress and more comfort upon clinging to their ethno-religious beliefs as part of preserving their identity, on the other hand, constitute a form of empowerment. Empowerment is strongly intertwined by one's ability to use his/her resources and render them discernible. Studies on the refugee acculturation process illustrate a direct relationship between loss of identity and traditions during the process of acculturation and the on-set of depression. Successful contact and participation in host societies and maintenance of heritage culture and identity were associated with less psychological distress (Fassaert et al., 2011 and Kamperman et al., 2007). Refugees are expected to acclimatize themselves very quickly to the host country culture and to integrate themselves through language acquisition and employment, as well as navigate the social 
and health service systems. Integration within the domain of health for refugees

sometimes does not meet the expectations of the bio-medical health care systems due to many cultural beliefs and preferences which dominate the issue of health for these refugees. Syrian refugees may encounter significant barriers to culturally-sensitive health care resources which are not yet explored. Therefore, to better afford a culturallycompetent health care facilities and to practice medical pluralism, we need to conduct a qualitative exploration of refugee, here the Syrians, experiences regarding health issues, preferences, and beliefs.

The number of refugees and their origins is affected by a number of factors shaping US refugee policy. By and large, these factors are economic and security issues. The US considers for resettlement at least half of the refugees referred by the United Nations High Commissioner for Refugees (UNHCR) for resettlement worldwide each year, depending on the availability of funding. The attacks of September 11, 2001 had a significant impact on the US refugee program. In the aftermath of those attacks, a review of refugee-related security procedures was undertaken, refugee admissions were briefly suspended, and enhanced security measures were implemented. As a result of these and other factors, actual refugee admissions, which had totaled about 70,000 in FY2001, plunged to historically low levels in the years following the attacks. In FY2002, for example, actual admissions totaled 27,131. According to the Congressional Report, the FY2015 refugee ceiling of 70,000 includes 68,000 admissions numbers allocated among different regions of the world and an unallocated reserve of 2,000 numbers. The FY2015 regional allocations are intended to cover previously approved refugees in the pipeline as well as new cases. An unallocated reserve is to be used if, and where, a need develops for 
refugee slots in excess of the allocated numbers. Africa has been allocated 17,000 refugee admissions numbers for FY2015. The FY2014 allocation to the region was originally 15,000 but was increased to 17,500 to accommodate additional admissions. FY2014 admissions totaled 17,476. FY2015 admissions are expected to come primarily from East Africa and to include Somalis, Eritreans, and Congolese, among others. East Asia's FY2015 allocation is 13,000, compared to a revised FY2014 allocation of 14,700 . FY2014 admissions totaled 14,784. FY2014 admissions consisted primarily of Karen Burmese refugees living in Malaysia and Thailand. Europe and Central Asia have a combined FY2015 allocation of 1,000 refugee numbers, the same as the FY2014 allocation. FY2014 admissions for this region totaled 959. The 2015 allocation includes projected admissions of "Lautenberg Amendment" cases from the former Soviet Union (see "Lautenberg Amendment and Specter Amendment"). The FY2015 allocation for Latin America and the Caribbean is 4,000, compared to a revised FY2014 allocation of 4,300. FY2014 admissions totaled 4,318. Cubans account for the vast majority of admissions from this region. The Near East/South Asia FY2015 allocation is 33,000, compared to a revised FY2014 allocation of 32,500. FY2014 admissions totaled 32,450. FY2015 admissions include Iraqis, Bhutanese, Iranians, Syrians, Pakistanis, and Afghans. $^{5}$

\section{Who are the Syrian Refugees?}

Many alleged dangers and frustrations have been woven around the Syrian refugees resettled in the US and fueled anti-refugee sentiments. Some of these claims are:

\footnotetext{
${ }^{5}$ Bruno, Andorra. "Refugee Admissions and Resettlement Policy" Congressional Research Service, 2015.
} 
"the majority of Syrian refugees are young males", "they could easily be people who are being infiltrated by terrorists" and "once you bring them in, then you have got to bring other members of the family in and that will exceed the numbers initially allowed". A profile of Syrian refugees resettled in the US is not yet well-developed. There is little evidence-based knowledge and a paucity of published research about Syrian refugees' resettlement process and adjustment strategies. Studies conducted in the field of refugee resettlement and adjustment do often navigate through the concepts of mental health, adaptation, and integration; however, there is a scarcity of research detailing the folk and ethno-religious preferences, practices, and beliefs that refugees bring with them regarding health and wellness. So far, there is no single research addressing these preferences and beliefs post-resettlement among Syrian refugees. So, there is a need to develop a profile of Syrian refugees, the context of their plights, the process of their resettlement, their physical and psychological status upon and after resettlement, and their coping strategies as they resettle. Health care professionals need to know more about this population's health beliefs, practices, preferences, and conflicts. Bringing to the fore knowledge about these Syrian refugees in terms of the above mentioned areas would facilitate more efficient and culturally-competent health care that reflects a positive image of medical pluralism.

Demographic information on all 2,234 Syrian refugees admitted to the US from October 2010 through November 2015, according to the Refugee Processing Center indicates that in terms of gender and age, the refugees are overwhelmingly young: 43 percent of all Syrian refugees are children under age 14. The gender ratios are more balanced: 53 percent are male and 47 percent are female. Males aged 14-30, often 
considered the most potentially dangerous group, are 13 percent of all Syrian refugees. Data on religion was collected for all Syrian refugees admitted from fiscal year 2011 to November, 2015. About 96 percent of the refugees are Muslims, about three percent are Christians of several denominations, and about one percent are nonreligious or of other faiths. Concerning their level of education, since 43 percent of the Syrian refugees are under 14 and 56 percent are under 20, Syrian refugees tend to be less educated than the US population; only 9.4 percent have a technical, university, college or graduate school level of education. Syrians resettled in the US are highly concentrated in a few states. Six states (California, Texas, Michigan, Illinois, Arizona and Pennsylvania) have together received more than half of Syrian refugees. In 2014, Kentucky had about one hundred Syrian refugees, and it was among the first ten states with the highest number of Syrian refugees. These refugees often arrive with significant medical problems and psychological trauma. Upon arrival in the US, they start struggling with the aftermath of their horrific journey as they attempt to build healthier lives in their new home. So, health care providers urgently need to provide culturally appropriate mental and physical health services that take refugees' cultural beliefs and preferences into consideration and promote medical pluralism in its practical form.

\section{Literature Review}

The literature of refugee resettlement spans nearly three decades, beginning with the inception of the Refugee Act in 1980, which created the Federal Refugee Resettlement Program as an amendment to the Immigration and Nationality Act of 1952. Refugees resettling in the US during the 1970s until 1999 primarily originated from Vietnam, Cambodia, Laos (the Hmong), Bosnia, Africa, and Afghanistan; hence most 
research studies conducted during these years focused on these populations (Haines, 1993 and Mghir et al., 1995). Arrival data according to the US Department of Health and Human Services (USDHHS) indicate that the largest number of refugees received in the US since 2000 have been from Somalia, Burma, Bhutan, Congo, and Iraq. Substantial research was done with these populations covering their mental health, socio-economic status, and adaptation strategies (Kia-Keating and Ellis, 2007; Benson et al., 2011 etc.). Since 2011, the US has accepted around 13,000 Syrian refugees. Although this number is relatively small in comparison with other numbers of refugees across the US, this is not a matter of numbers only. So far, there is no single research conducted about Syrian refugees in particular who have resettled in the US and the problems and concerns they have faced since resettlement. A book about the plight of resettled Arab refugees in the ethnic enclave community of 'Arab Detroit', Michigan by Marcia Inhorn was published during my study (2018). It explores the physical and emotional experiences of suffering Lebanese and Iraqi refugees manifest as they navigate the US health care system. A goal of the Center for Disease Control and Prevention (CDC), a world leader in health promotion and disease prevention, is to promote the health of refugees in the US; yet very little is known about Syrian refugees' health and its role in their adaptive process. Therefore, further research on their coping strategies and health beliefs and preferences is of paramount importance.

Research on the topic of refugee resettlement and health is most prevalent in the fields of sociology, psychology, nursing, anthropology, and medicine; yet the theoretical basis for existing research is rarely made explicit and clearly outlined in the research projects. A vast majority of these studies adopted top-down methods, experimenting with 
a specific hypothesis and treating refugees as numbers and phenomena in the hypothetical equations. These studies tend to focus on refugee behaviors, attitudes, problems, reactions, and even words. The body of research on refugee resettlement includes multiple theoretical frameworks, such as adaptation (Keyes and Kane, 2004), acculturation adaptation (Oh, Koeske and Sales, 2002), integration (Beiser, 2009), and self-efficacy (Kia-Keating and Ellis, 2007). Other frameworks included transcultural nursing care (Keyes and Kane, 2004; Rashidi and Rajaram, 2001). Few studies concern the cultural and ethno-religious beliefs of refugees and their role in the process of acculturation and coping. Of these, Ai et al. (2003) conducted a study about the effect of religious-spiritual coping on positive attitudes of adult Muslim refugees from Kosovo and Bosnia. The study methods included mixed methods, quantitative, qualitative, case study, historical research, and participatory action research. Most of the quantitative studies were descriptive surveys or utilized a correlational research design. They aimed to enumerate the refugees suffering from certain mental disorders post-resettlement. The qualitative works were case studies or phenomenological in nature. Although critical of the above theoretical frameworks, calling for culturally-sensitive tools of measurement and study, and advocating for the voices of refugees in shaping and modifying certain theoretical frameworks (Ryan et al., 2008, Strang and Ager, 2010, and De Vries and Van Heck, 1997), no studies related to refugee experiences of resettlement have been guided by the conceptual frameworks of cultural competency in a medically pluralistic system. Most of the above studies, qualitative and quantitative in nature, are descriptive in design. To date, no study has been conducted that elucidates a theory advocating refugees' voices 
and narratives in shaping culturally-competent health care, promoting medical pluralism, and in achieving a peaceful acculturation process.

\section{Spector's Theory of Cultural Competency}

In this project, I adopt Spector's Health Tradition Model/Framework (HTM) of cultural competency as a theoretical basis for my study of Syrian refugee experiences and to advocate for future interventional practice and research about refugees' resettlement and culturally-sensitive and medically pluralistic systems. Spector's model is intended originally as part of cultural-competency and transcultural nursing models, but I will be using it in the broader context of medical pluralism. Medical pluralism is an umbrella term and concept which includes cultural competency as one aspect. As described by Spector (1994), the HTM deploys the concept of holistic health and explores what people do from a 'traditional' perspective to maintain and protect Health, prevent Illness, and restore Health. The 'traditional' methods of Health maintenance, protection, and restoration are not alternative methods of health care because they are methods that are an integral part of a person's ethno-cultural and religious heritage. Health is perceived as the balance of the person, both within one's being- physical, mental, and spiritual- and in the outside world- natural, communal, and metaphysical. Illness is perceived as the imbalance of the person, both within one's being and in the outside world. Healing is the restoration of balance, both within one's being and in the outside world- natural, communal, and metaphysical. Within many 'traditional' settings (defined as 'old' or 'not contemporary') people tend to define Health, Illness, and Healing in this manner. The HTM is comprised of nine interrelated 'traditional' methods of maintaining, protecting and restoring health. All three of these 'traditional' methods are focused on physical, 
mental and spiritual health. These 'traditional' methods include this state of balance for the individual, their family, and surrounding community. The 'traditional' methods of health maintenance, protection and restoration require the understanding of one's own cultural health background. Spector argues that in order to understand Health and Illness beliefs and practices, it is necessary to see each person in his or her unique sociocultural world. These 'traditional' methods should be addressed to the health care professional as multi-cultural encounters take place in the medium of a pluralistic health care.

Spector assigns a major role to the sociocultural and ethnic backgrounds of people (patients) from a 'different' culture than the mainstream Western one. These backgrounds include sets of beliefs and perceptions about health and illness often at odds with the US health care providers' perceptions. Spector also proposes a useful tool in setting the stage for assessing and understanding a person's traditional Health and Illness beliefs and practices and in helping determine the community resources that will be appropriate to target for support when necessary. This tool helps determine how much a person identifies with his/her 'traditional' heritage; thus indicating the degree of heritage consistency. In the case of Syrian refugees, who are recently resettled in the US (starting 2015), their heritage consistency is definitely high since the period of time since resettlement has been short. However, some of the questions in the heritage assessment tool are used in the interviews. For example, questions like: "How long have you been in the US?" and "What setting did you grow up in?" illuminate the effect of sociocultural factors on the traditional beliefs and perceptions.

Spector's theory is highly workable with the certain aspects of the Arab Islamic views of Health as a balance of the physical, mental, and spiritual parts of a person. 
Spector's advocacy for examining the ethno-cultural and religious perspectives on Health, Illness, and Healing distinguishes between what is cultural and what is religious and places great value for the uniqueness of each person's sociocultural world; the issue that fosters refugees' individuality and agency. This distinction is important in Muslims' beliefs about Health and Healing. Many beliefs assumed to be adopted from the religion of Islam are in fact cultural and folk. The diagnosis of many Muslims of their respective Illness as a spiritual purification from God (Allah) is a religious belief and perspective. I am not assuming that all Muslims, including the Syrian refugees to be studied here, exclusively adopt either folk, Arab-Islamic, or Western bio-medical views of Health and Illness. It is a continuum where many Muslims use either one as primary, secondary, or integrative.

Refugees' health behaviors are shaped by many factors which health care systems and professionals should be aware of. These factors include trust in the host health care system, cultural beliefs and preferences, spiritual modes of healing, and linguistic barriers. "The Process of Cultural Competence in the Delivery of Health care Services" is a model of cultural competence that defines cultural competence as "the process in which the health care professional continually strives to achieve the ability and availability to effectively work within the cultural context of a client" (Campinha-Bacote, 181). Cultural competence encompasses the ability to provide care to patients with diverse values, beliefs, and behaviors, including tailoring delivery to meet patients' social, cultural, and linguistic needs (Betancourt, Green, \& Carillo, 2003). However, this cultural competency is best implemented in a pluralistic medical system where people with the help of health care providers choose from various systems which remedies and which preventive 
practices work the best for them. Individual values, beliefs, and behaviors about health and well-being are shaped by various factors such as race, ethnicity, nationality, language, gender, socioeconomic status, physical and mental ability, sexual orientation, and occupation. Cultural competence in health care is broadly defined as the ability of providers and organizations to understand and integrate these factors into the delivery and structure of the health care system. The goal of culturally competent health care services is to provide the highest quality of care to every patient, regardless of race, ethnicity, and cultural background to better serve a medically pluralistic system which matches diversity and multi-culturalism.

My argument, which has an applied approach, is that refugees' voices and narratives should not be the end point, rather their voices must be heard and taken into serious consideration in order to implement culturally appropriate and sensitive health care, social support systems, and medical pluralism. In this dissertation, I argue that, contrary to many social scientists such as Giorgio Agamben reducing refugees to icons of 'bare' humanity, refugees can be the force behind implementing medically pluralistic health care in their communities of resettlement. Findings from this research, obtained through exploring Syrian refugees' ethno-cultural and religious beliefs about their Health, could guide the US health care system to provide culturally-congruent and holistic care. Indeed, refugees' voices and narratives concerning health preferences and beliefs, if tolerantly elicited and heeded, can contribute to developing and modifying health care systems to better serve multi-cultural constituents. Refugee voices, though often not incorporated in decision-making and policies, are vital to enhance better communication with host communities and humanitarian aid workers and to yield better aid and 
integration outcomes. Refugees, when granted the opportunity to talk about their ethnocultural and religious perspectives of Health and Illness feel less stress and more powerful, and can acculturate more easily.

\section{Research Design and Methodology}

To illustrate my argument, I adopted a qualitative research method to examine the Syrian refugees' resettlement process and coping strategies in terms of their health and wellness and identify the ethno-cultural and religious Health and Illness beliefs they adhere to. Methods of data collection, largely ethnographic, included: participatory observation and semi-structured interviews with Syrian refugees. The research design encompassed open-ended questionnaires and in-depth interviews. Grounding the Syrian refugees' resettlement experience and acculturation process in terms of their Health and Illness in Spector's Health Traditions Model, I employed abductive analysis, moving back and forth between Spector's HTM, the literature review, and the data collected. New concepts emerged informing my hypothesis: refugees when allowed to express their own beliefs and expectations about health issues once resettled, can be expected to acculturate with less stress and more agency and sense of control. I situate this hypothesis in the Syrian refugees' own narratives and personal experiences.

This dissertation has a strong applied component. Developing new concepts and themes like refugees' power based on qualitative research can enhance the participatory interaction between Syrian refugees, on one side, and the US health care providers, on the other side and allow a less stressful, more trustful, and productive encounter between the two sides. It will also guide health care providers to be aware of and attuned to the cultural sensitivities and personal narratives of Syrian patients. This theory-driven and 
theory-developing research replaces former depictions of refugees as passive, pathologic, and in need for help and support (Malkki, 1996). In other words, this dissertation is a call for the active participation of refugees in the delivery of pluralistic and culturallysensitive health care and simultaneously for allowing more advocacy for refugees, especially those who are underserved and unheard. The sampling used in this study included adult Syrian men and women participants over 18 years of age and willing to voluntarily address and discuss their cultural and religious beliefs and preferences regarding their health. Some interviews were conducted with health care providers dealing with refugees. Questions covered the categories of acculturation, stressors, and access to health care.

Field research took place in Louisville, Kentucky over the course of 2017. I conducted ethnographic field research, consisting of participatory observation and openended interviews at the refugees' local residences and at some medical offices and clinics where encounters with Syrian refugees occur. I also visited the Muslim Community Center and some houses of worship where refugees go to pray. During my internship at KRM (Kentucky Refugee Ministries), I started meeting informally with some newly resettled Syrian families. KRM has been in operation for twenty six years and has helped in resettling 14000 + refugees distributed between Lexington and Louisville. Kentucky has taken in 89 refugees from Syria in a little more than a year (2015), most of them in Louisville, and about half of whom are children. Kentucky is home to thousands of refugees from across the globe which makes it among the top states welcoming refugees. Louisville also has a large number of Arab immigrants, a high percent of which are 
Syrians, which makes it an appropriate field site to study the contextual factors shaping the resettlement process and to translate theory into practice and intervention. 


\section{CHAPTER ONE}

\section{LITERATURE REVIEW AND METHODOLOGY}

\section{Introduction}

The literature of refugee resettlement spans nearly three decades, beginning with the inception of the Refugee Act in 1980, which created the Federal Refugee Resettlement Program as an amendment to the Immigration and Nationality Act of 1952. This chapter begins with a brief introduction to the research literature on refugee populations. It then turns to the theoretical frameworks that have guided refugee research. A critical analysis of the current state of the research and literature on refugee resettlement will follow. The chapter concludes with a summary of what is known and not known in order to identify gaps in knowledge and, thereby contextualize and promote a rationale for the proposed research study.

\section{Sources}

Research for this review was accessed mainly from the University of Louisville Library website. The library offered sources in a range of fields-e.g., anthropology, medical anthropology, refugee studies, and bioethics — with databases that included Dissertation Abstracts, JSTOR, Google Scholar, PubMed, Elsevier Health, and ProQuest. Keyword queries included refugee resettlement, health traditions, Islamic medicine, biomedicine, and resilience of refugees. Research studies or opinion articles examining refugee resettlement were included in this review if they met the following criteria: 
1. Published in English during the timeframe of 2000 to 2017; and

2. examined refugee health, health care, resettlement, and acculturation

Numerous research studies were utilized for this review ranging from those carried out in Australia, Canada, and the Netherlands to Sweden, and the United States. Study methods included mixed methods, quantitative, qualitative, case study, action research, and historical research. Most of the quantitative studies were descriptive surveys or utilized a correlational research design. The qualitative works were case studies or phenomenological in nature.

Studies and articles comprising this review were found in professional journals in the fields of medical anthropology, nursing, refugee studies, medicine, mental health, public health, and social work. Government documents relevant to refugee resettlement programs and refugee data and resources were also included.

\section{Diversity of Refugee Groups Examined in the Literature}

Refugees resettling in the US during the late 1970s primarily originated from Vietnam, Cambodia, South Asia, and Afghanistan. Thus, most research studies conducted between 1980 and 1999 focused on these populations. According to Pew Research Center Report of 2017, historically, waves of refugees to the US have ebbed and flowed with

global conflict. In the 1990s, waves of refugees came to the US in large numbers from the former Soviet Union. However, refugee admittance dropped off steeply in the wake of the terrorist attacks in 2001. The total annual number of refugees has trended upward 
since then. In the last five years, the largest numbers came from the Democratic Republic of Congo, Syria, Burma (Myanmar) and Iraq.

The diversity of refugees received in the US and other host countries is increasing; however, there is limited current research reflecting the expansion of refugees in the US. Syrian refugees in particular started resettling in the US since 2011. In total and according to the Refugee Processing Center (RPC) “Admissions and Arrivals", 21,060 Syrian refugees were resettled in the United States between 2012 and 2018. Minimal research has been conducted with Syrian refugees in particular. Little is known about Syrian refugees' health care problems upon resettlement and their health traditions and beliefs as part of their resettlement experience, identity formation, and resilience process in the US. Therefore, further research on Syrian refugee resilience and their health perspectives and traditions is of paramount importance.

\section{Application of Theory in Refugee Research}

Research on the topic of refugee resettlement is most prevalent in the fields of psychology, sociology, nursing, and medicine. The body of research on refugee resettlement is more theoretically oriented and includes multiple theoretical frameworks, such as adaptation (Keyes \& Kane, 2004), acculturation adaptation (Oh, Koeske, \& Sales, 2002), integration (Beiser, 2009), social support (Simich, Beiser \& Mawani, 2003), selfefficacy (Kia-Keating \& Ellis, 2007) and (Corvo \& Peterson, 2005), and ecosystem (Guruge \& Knanlou, 2004). Other frameworks include models of health care utilization (Drummond, Mizan, Brocx \& Wright, 2011), and a socio-ecological model of health behavior (Pavlish, Noor, and Brandt, 2010; Wahoush, 2009). 
From a mental health perspective, Kia-Keating and Ellis (2007) examined psychosocial adjustment and belonging based on the theory of self-efficacy with a sample of 76 Somali adolescents who had resettled in the Northeast region of the US. The Multidimensional Scale of Perceived Self-efficacy was one of the measurement instruments used in the quantitative study. It was hypothesized that exposure to adversities would result in increased levels of PTSD and depression as well as lower levels of self-efficacy. A critical finding of the study was that adolescents had significantly lower self-efficacy, greater adjustment difficulties, and higher levels of stress and depression when they had experienced greater exposure to war, violence, and displacement adversity.

The desire to have a sense of belonging was also evident in the study by Keyes and Kane (2004). Supported by the theory of adaptation, the phenomenological study of seven female Bosnian refugees revealed that they simultaneously struggle with the loss of belonging in their old culture while striving to establish footing in their new cultural environment. Bosnian refugee participants in that study revealed that they find ways to adapt and cope, such as focusing on their past accomplishments and envisioning hope for the future, in order to survive in their new homes.

Refugees' survival in their new residence depends on negotiating the old and new. Oh, Koeske, and Sales suggest that two modes of acculturative adaptation exist: assimilation and integration (512). According to the acculturative adaptation model, assimilation is the process of adopting greater elements of the host culture, whereas integration is a blending of host and native cultures. Their quantitative study of 157 
Korean refugees revealed that those who try to adapt via an assimilative mode may have greater depressive symptoms due to loss of their own native culture; yet, adaptation via an integrative mode results in greater acculturative stress from trying to strike a balance between two cultures.

A mixed method study conducted by Beiser (2009) was guided by integration theory, which has its origins in behavioral science. The research was the largest and most comprehensive refugee study of Southeast Asian refugees resettling in Canada. Qualitative interviews of 1,348 participants complemented the quantitative survey questionnaire results. The lesson learned from the Canadian Refugee Resettlement Project was that individuals who retain their own cultural identity while integrating elements of the new culture by participating fully in the political, economic, social, and cultural life are more successful than those who primarily assimilate in the adaptation process. The results suggest that integration should be promoted to facilitate psychosocial adaptation to resettlement.

A conceptual framework for integration was developed by Ager and Strang (2008) through a comprehensive literature review, secondary data analysis, and inductive fieldwork. As a result of the conceptual analysis, key domains of integration were identified: employment, housing, education, health, and strong social connections facilitated by language and cultural knowledge. Acquisition of rights and citizenship was considered the foundation domain of integration. Refugees are expected to acclimatize themselves very quickly to the host country culture and to integrate themselves through 
language acquisition and employment as well as seek care through health and social services.

Social support was found to facilitate greater integration and to positively affect the refugees' mental and physical health and well-being in a study conducted by Simich, Beiser, and Mawani (2003). The study was guided by social support theory, which suggests that social ties with family and community strengthen one's ability to overcome the stressors encountered during life-changing experiences. Lack of social support was found to be one of the barriers to healthy integration in the study by Drummond et al. (2011) where participants revealed their preference to cope with psychological or physical health problems alone out of fear of what others may think about their cultural beliefs and values related to health care practices. According to Ryan, Benson, and Dooley, negative health outcomes may be an unfortunate result if social support for refugees is lost, constrained or devalued; therefore, the goal of health care professionals should be to identify resources lost and promote resource gain for refugee integration. (17-18).

\section{Conceptual Framework}

Spector's HEALTH Traditions Model provides concepts that serve as a foundation for considering further studies and research about refugees' resettlement experience in terms of their health beliefs and traditions and how these resources help them in achieving a positive resettlement experience and successfully integrate in the host society. No studies related to refugee experiences and resettlement have been guided by Spector's model, which originated in 1994; however, this conceptual HEALTH 
Traditions Model has significant relevance and value to the proposed research. Accessing health issues through refugees' own voices and perspectives not only informs policy makers and social workers of things that comfort refugees, but also helps in conceptualizing and attaining a pluralistic medical system. Integration is a two-way process; therefore, to achieve an effective resettlement process, reciprocity is key. It is a process that is dynamic and two-way: it places, as Penninx asserts, demands on both receiving societies and the individuals and/or the communities concerned (2013). Unfortunately, successful integration within the domain of health for refugees is not well understood or defined. Research about health issues encountered by refugees often covers topics related to pathology (mental and physical well-being) and mechanical problems with health care (translation, insurance, language etc.). However, topics like refugees' own health beliefs and perspectives and their own religious and folk health traditions are overlooked. Refugees may encounter many systematic, community, and ideological challenges that impede successful health integration, yet indicators for health integration remain to be identified. Significant barriers to health care and resources have largely been unexamined particularly with Muslim refugees. Therefore, qualitative exploration of refugee experiences regarding their health concerns and access to care deserve to be considered. A bottom up approaches to refugees' belief systems and perspectives regarding their own health traditions are vital to obtain a successful resettlement experience. Failure to achieve integration in the host society can lead to future physical and mental health. According to Roy, a "lack of integration represents lack of health" (33). These approaches are also required for a pluralistic medical system 
to be fully realized. Refugees have a basic need to create meaning and purpose as they deal with the transition of resettlement. Therefore, preservation of psychological and spiritual integrity can strengthen the refugee's sense of self-concept and identity.

\section{Critical Analysis of Refugee Research}

Four recurring themes emerge from the refugee resettlement literature - mental health, physical health, health care, and adaptation/acculturation. Research on the psychological well-being of refugees has focused on deficiencies within individuals either in terms of psychiatric symptoms or feelings of distress. We need to examine the limitations of the theoretical models that have guided research on the psychological status of refugees. In the area of mental health, more bottom up approach studies need to be conducted with refugees in order to reach out for their personal perspectives about their physical and mental health status, as well as their personal perspectives of what makes their resettlement less stressful and what grants them more resiliency upon resettlement. Studies related to each identified theme will be critically analyzed to depict the current state of refugee resettlement research.

\section{1-Mental Health}

Though the dominant frameworks of enquiry in refugee studies and health have focused on examining psychopathology as the major outcome of the refugee experience, many unanswered questions regarding psychological disorders, PTSD in particular, in refugee populations remain, including: why population prevalence rates of psychological conditions remain relatively low, despite the often considerable traumata refugees have endured?, is the use of PTSD and other associated westernized paradigms of mental 
health is appropriate and cross-culturally applicable to ethnically diverse populations?, what are the mechanisms behind the lack of psychosocial functional impairment in those who do meet clinical criteria for PTSD and other disorders?, and what if the focus on psychopathology in general, and PTSD in particular, as a major outcome of the refugee experience fails to explicate broader psychosocial factors (such as language proficiency, employment, health, and social support that may interact with an individual's psychological functioning after trauma to influence the development of psychopathology) and adaptive processes that may be impacted by the refugee experience? The majority of the refugee research literature is focused on mental health needs and pathological conditions of refugees often with quantitative methods, top bottom approaches, and western-guided scales. Indeed, most of the studies about groups who have resettled in Western countries are infused with a trauma discourse that focuses on high-impact events that occurred in the pre-resettlement environment and overshadows the basic needs in the present lives of resettled refugees. With resettlement continuing, although at much reduced levels, the reality of mental health care needs of refugees can no longer be ignored. Much of the current literature on refugee mental health suggests that depression, anxiety, PTSD, substance abuse, fear, and even suicidal tendencies are prevalent within the refugee population.

One of the largest comprehensive research studies investigating the risk and protective factors for refugee mental health was conducted in Canada. Beiser (2009) provides a report of lessons learned from the decade-long study titled 'The Ryerson University Refugee Resettlement Project' (RRP). The sample for the study consisted of 
1348 Southeast Asian refugees resettled in Canada between 1979 and 1981. At that time, war and conflict were prevalent in Southeast Asia, and many persons had been displaced from their homes, resulting in a large-scale migration of refugees to various host countries. Funding was provided from the National Health Research Directorate Program to study the adaptation of Southeast Asian survivors of war, displacement, migration, and resettlement in Vancouver, British Columbia.

The sample consisted of three ethnic refugee groups - Chinese, Vietnamese, and Laotian. Participants were selected based on a combination of the snowball method and probability sampling techniques. Questionnaires translated into the appropriate ethnic language were used to obtain demographic statistics, resettlement experiences, acculturation, health and mental health information. Surveys were taken in 1981, 1983, and 1991, and a 50-percent attrition rate was found by the time of the last survey, which is noted as a weakness of the study. To complement quantitative data, qualitative interviews were conducted with two similarly sized cohorts of refugees - those who seemed to be adapting well and those who were experiencing psychological distress.

The longitudinal design of the study provided valuable information that strengthened the knowledge base regarding resettlement and mental health well-being of refugees. Results of that study indicate that men have higher degrees of depression than women during the early stages of resettlement, but that depression becomes more predominant in women refugees as time passes that is during the latter stages of resettlement and post-resettlement. Social support and language fluency positively 
impacted mental health well-being, whereas discrimination and disparities in equitable access to care negatively impacted mental health of refugees.

Current research suggests that refugees experience psychological distress due to lack of support. A literature review conducted by O'Mahony and Donnelly (2010) suggests that refugee women are susceptible to depression, specifically post-partum depression, due to social isolation and lack of social support. Social and emotional support from family members, community, and health care providers were suggested as being instrumental in promoting psychological well-being; however, research examining social and emotional support for refugees remains limited.

Simich, et al. (2003) conducted a qualitative study exploring the underlying reasons for secondary migration of refugees. For this study, purposive sampling was used to recruit participants from refugee reception centers in Ontario, Canada. ${ }^{6}$ Refugees are often placed in certain geographic regions distant from members of their own ethnic or national group; this separation can exacerbate their feelings of anxiety and stress, and refugee participants in the study revealed a desire to seek co-ethnics with cultural similarities to their native heritage. Thus, refugees actively sought social support even if it meant relocating, that is secondary migration, in order to strengthen their ability to cope and adapt. The contribution of that study is the expansion of knowledge regarding the influence of social support on decision-making processes of refugees. That research

\footnotetext{
${ }^{6} \mathrm{~A}$ purposive sample is a non-probability sample that is selected based on characteristics of a population and the objective of the study.
} 
focused on newly arrived refugees but not on refugees who had been resettled for longer periods of time, which constitutes a weakness of the study.

During the resettlement process, refugees struggle with the fragile balance between two cultures - their native culture of origin and their new cultural home. Such cultural conflict may be experienced as refugees strive to learn the culture of their new society while at the same time striving to preserve cultural practices of their native homeland. Acculturative stress can result from cultural collision as refugees strive to cope with resettlement. Oh, et al. (2002) conducted a quantitative study examining acculturation, acculturation stress, and depression. The cross-sectional survey design consisted of a sample of 157 Korean immigrants residing in Pennsylvania, and a response rate of 90.8 percent was achieved. All questionnaires were translated into Korean language, and psychometric analysis was performed on study instruments revealing adequate reliability and validity, which is a strength of the study. Results of that study indicate that acculturative stress was positively related to depression. Moreover, results supported the theory that assimilation strategies to incorporate host culture language, values, and practices are more effective in reducing life stress and strengthening mental health than trying to integrate both cultures. A limitation of the study is a populationspecific focus on Korean immigrants, making generalizability to other populations difficult. Also, the cross-sectional design limits the study as well.

A study conducted by Corvo and Peterson (2005) examined post-traumatic stress symptoms, language acquisition, and self-sufficiency in a non-experimental quantitative study with 34 Bosnian refugees in Syracuse, New York. The small sample size was a 
weakness of this study; therefore, its results provided only weak empirical support that trauma-related problems interfered with self-sufficiency. Findings, however, indicated that there were issues of concern related to reported symptoms of sleep disturbance, loneliness, and hopelessness about the future for the Bosnian refugees.

In an exploration of the experiences of Bosnian refugees in the US, Keyes and Kane (2004) conducted a qualitative study of phenomenological design with seven adult female Bosnian refugees. Belonging and adapting were two major themes identified in the data analyses. It is often assumed that refugees are burdened with the negative realities of resettlement; however, both negative and positive aspects of their experiences were recognized in that study. Embedded in their experiences were states of culture shock, loneliness, psychic numbness, grief, nostalgia, and feelings of dejection, humiliation, inferiority as well as feeling as if they belonged nowhere. Inherent in their experiences, however, were feelings of relief, safety, gratefulness, and a newfound freedom to hope for a better life as well. The study is one of the few acknowledging both grief and a sense of hope for the future.

Grief was evident in the experiences of traumatized refugees hospitalized in a psychiatric facility in the Netherlands. A convenience sample was recruited to participate in the mixed-method study conducted by Strijk, van Meijel, and Gamel (2011) using a survey questionnaire and interview method. ${ }^{7}$ Results of that study revealed that 86.7 percent of respondents felt that their psychological needs were unmet at the time of the

\footnotetext{
${ }^{7}$ Convenience sampling (also known as availability sampling) is a specific type of non-probability sampling method that relies on data collection from population members who are conveniently available to participate in study
} 
study. Displacement and the associated sense of loss were found to be directly related to expressions of grief, gloom, and loneliness. One respondent remarked: "When I look around me, I see so many people who feel happy and safe, and I think, 'Why not me? Why can't I be that person, why can't I have what they have?' It makes me want to cry all the time" (50).

Participants in the study were in a state of severe psychological distress that influenced their quality of life and well-being. The assessment-of-need questionnaire used in the study was not specifically designed for use with refugees; therefore, reliability and validity of the instrument for this population is uncertain.

A review of quantitative and qualitative literature on refugee mental health suggests that psychological distress is not uncommon among refugees. Social support has been recognized as being crucial to mitigating the effects of mental disorders associated with stress and trauma. Refugee mental health research has been limited to pre-resettlement conflicts and violence, yet there is a growing body of research focusing on stressors in the post-migration period (Miller, et al., 2002; Miller \& Rasmussen, 2010; Norris, Aroian, \& Nickerson, 2011; Rasmussen et al., 2010).

A common finding of these studies is that persistent challenges or stressors from day to day within the post-migration and resettlement periods can have substantive effects on mental health outcomes. Stressors such as lack of social support, limited income, and unemployment have been shown to mediate psychological distress among refugees. Although Rasmussen et al. (2010) included only Darfuri refugees, their findings may be relevant for refugees of other ethnic origins. 
One important implication for future research is to include a temporal dimension. Stress does not subside with resettlement. It simply takes a new form, triggered by the challenges of adaptation to a new country and culture. In other words, stressors in the everyday social world during the post-migration and resettlement periods can have significant mediating effects on refugee mental health; therefore, the social ecology of the post-migration experience needs to be considered in order to understand psychological distress from a broader temporal and spatial perspective. This social ecology includes many areas of struggle for refugees in the host country upon resettlement. One of these area which is not yet researched is the ideological and systematic encounter with the host country's medical system. The difference between health beliefs and perspectives along with views of pain, the role of the doctor, and the emotional comfort from the health care staff contributes to adding more stressors on refugees' resettlement experience. These struggles can harm the refugees' mental well-being and often cause discomfort in refugees until they start the health integration process. Other areas of struggle or challenges such as inability to access care, lack of health insurance (medical, dental, and vision), minimal income (to afford prescription medications, co-pays, and healthy food), transportation, trust in translation services, time factor in appointments, communication barriers, and minimal health literacy also contribute to psychological distress during the resettlement period. These potential stressors related to the encounter with the health care culture in the US have been largely unexplored in relation to Muslim refugees. Therefore, this gap in knowledge needs to be addressed.

\section{2-Physical Health}


Many refugees arrive in the United States with pre-existing physical health conditions and needs. According to Bruno (2011), circumstances of inadequate access to medical care, poor sanitation, and poor nutrition in refugee camp settings has left refugees with chronic untreated medical conditions that are often a threat to public health. Refugees are screened for communicable diseases in the early stage of the resettlement process. However, for Syrian refugees, they scored negative for many communicable diseases according to CDC 2017 report (14-16). Yet, there is a dearth of research on the physical health needs of Muslim refugees resettling in the United States.

A retrospective quantitative descriptive study was conducted by Museru et al. (2010) that examined the prevalence of Hepatitis B virus infection among refugees who resettled in the State of Georgia over a five-year period between the 2003 and 2007. The number of refugees testing positive for Hepatitis B surface antigen comprised an overall prevalence of 10.7 percent of the refugee population resettling in Georgia during the fiveyear period. Those who tested positive were referred for follow-up care, but there was no formal mechanism to ensure that the refugees received access to the recommended medical care. Although the research was retrospective and descriptive in design, the results provided valuable information regarding the extent of Hepatitis B in the Georgia refugee population.

An additional retrospective descriptive study design was also conducted by Barnes and Harrison (2004) to examine reproductive health practices of refugee women. Medical charts were reviewed from 1996 to 2000, and the frequency of reproductive health problems and breast and cervical screening rates were measured. Twenty-five 
percent of the women in the sample had reproductive health problems, and 86 percent of women over the age of 40 had never had a mammogram, while only 24 percent reported having had a Pap smear test within the previous three years. Fifteen percent of the women were pregnant but had not received prenatal care. Although that study was of a retrospective descriptive design, results of the study provide much insight to the reproductive health care and screening practices of refugee women.

A community-based participatory qualitative research study conducted by Doyle, Rager, Bates, and Cooper (2006) revealed behavioral, psychological, access/treatment, environmental, and social/economic factors that affected the health of migrant workers. Although migrant workers are different from refugees by definition, factors identified are implications of what refugees may experience when resettling in the US, such as poor diet/nutrition, low resource awareness, lack of insurance, illiteracy, stress, language difficulties, and limited income to afford medications or treatments.

Despite the documented threat of communicable diseases, such as tuberculosis, intestinal parasites, Hepatitis B, HIV and potential chronic health conditions associated with poor living condition and lack of care, there has been little research exploring the impact of such threats to health and the process of health care access for refugees. Also, no studies were found that examined the physiologic impact of stress upon resettlement on refugees.

\section{3-Health Care}

In a health care system already burdened with complex problems and in need of reform, the addition of growing numbers of refugees can challenge the ability of the 
public health care system to provide equitable access to health care. Thus, many health disparities may prevail due to lack of insurance and inadequate access to primary care and needed resources for preventative care. Refugee medical assistance is provided during the first 6-8 months of resettlement while the refugee seeks employment. If no employment is acquired by the end of the covered medical assistance time period, then the refugee is left with no insurance, thereby limiting access to health care. If the refugee is employed and receives a salary that exceeds the limits set by Refugee Medical Assistant programs and Medicaid, he/she should switch to his/her employment insurance which usually costs more.

Focus groups and semi-structured interviews were conducted with refugees in New York City as well as health care providers over a 30-month period by Asgary and Segar (2011) to examine perceived barriers to health care access. Results of the study identify several barriers, including (a) mistrust and perceived discrimination of Western medicine, (b) affordability, (c) lack of knowledge regarding health care resources, (d) the fact that health care is for urgent care only and not preventative care, (e) linguistic differences, (f) resettlement stressors and other priorities, and (g) lack of community social support. A limitation to the study is that 30 of the 34 participants in the study were male; therefore, the gender imbalance suggests perceived barriers to health care access by women were not adequately addressed. Also, no specific ethnic group was targeted; it was a study about refugee asylum seekers. However, this study highlights some of the issues that refugees encounter in the health field which are not pathological and which are to some extent systematic differences. 
Health care barriers for refugees were also examined by Morris et al. (2009) in a qualitative study examining the health care access experiences of 40 participants of various ethnic backgrounds in San Diego. Additional barriers were identified in the study, including 1) transportation issues, 2) financial hardship and lack of insurance, 3) acculturation difficulties, 4) communication barriers, and 5) cultural differences in health care practices and beliefs. Findings of that study were consistent with existing literature regarding challenges to health care access for refugees and pinpointing a new category of barriers: cultural differences in health care beliefs and practices. This study, though not targeting specific ethnic identities, is eye opening for future research into refugees' own health beliefs, perspectives, and expectations.

An additional qualitative study conducted by Pavlish, et al. (2010) examined the experiences of Somali refugee women and their health care interactions as they sought care for their health needs. Questions regarding health concerns, utilization of health care resources, and barriers to health care access were posed during focus group interviews, and the researchers report that the participants were eager to share their experiences. Results of the study revealed that the Somali women's experiences consisted of unmet expectations regarding holistic health care as American health care providers concentrated primarily on their physical needs while disregarding their social and mental well-being. Deficiencies in culturally appropriate care were also identified.

Additionally, the Somali refugees expressed frustration with trying to communicate their health care concerns to US health care providers who did not seem to take the time to listen or explain details to them. 
A strength of the studies examining barriers to health care is that both refugees and health care providers were recruited to provide their perspectives of health care access for refugees. Convenience sampling was a limitation to the studies, but overall, the information gained is valuable to understanding obstacles that may prevent adequate health care for refugees in the US. Inadequacy of health care for mental and physical health needs of refugees as revealed in the analyzed studies thus far can impede the ability of refugees to successfully resettle in an integrative way.

\section{4-Adaptation}

Few research studies were identified that focused specifically on refugee adaptation. Adapting was a major theme recognized in the study conducted by Keyes and Kane (2004). In response to the loss of family and friends, refugees sought to establish and strengthen new social networks as a way of promoting adaptation to their new way of life. A strength of this study is its exploratory approach in examining both positive and negative elements associated with refugee adaptation. Therefore, a broader view of refugee adaptation experiences is evident in the research. The phenomenological method used for the study provides much needed insight into the lived experiences of refugees and reinforces the need to better understand a broader array of factors influencing refugee adaptation.

Cultural adaptation and refugee social interactions were examined by Jorden, Matheson, and Anisman (2009) in a mixed-method study with Somali refugees in Canada. Findings from that study indicate that refugees who had experienced traumatic life events pre-resettlement had greater stress sensitivity and reduced social relations that 
negatively impacted cultural adaptation. Social support was found to mitigate symptoms related to psychological distress. The sample population included 169 participants for the quantitative component and 23 participants for the qualitative aspect of the study. An additional strength is that both men and women were included as study participants. The examination of the correlational effect of social support on cultural adaptation is a strength of this study.

Physical and mental well-being is predominantly discussed in the refugee literature; however, social well-being is minimally addressed. Two studies were located that specifically focused on social support and the impact on adaptive patterns for refugees (Schweitzer, Melville, Steel \& Lacherez, 2006 and Simich, et al., 2003). Results of both qualitative studies indicate that social support had a significant influence on adaptive outcomes, such as positive mental health and well-being when social support was strong; however, neither study was performed in the US. Little is known about refugee social and relational well-being for those who have resettled in the US.

\section{Summary}

In spite of the dearth of studies that examine the effect of religious and folk health beliefs on the resettlement process, there have been some studies that highlighted the role of religious beliefs in positive attitudes upon resettlement and which took refugees' voices into consideration. The research on the relationship between religiosity and posttraumatic growth (PTG) among refugees is in its infancy. In a sample of Somali refugees in Hungary (Kroo and Nagy, 2011), religiosity was positively correlated with PTG. According to Tedeschi and Calhoun, PTG is "the positive psychological changes 
experienced as a result of the struggle with highly challenging life circumstances" (1). Another study on religious coping in Muslim refugees from Bosnia and Kosovo by Ai, Tice, Huang, \& Ishisaka (2005) found a correlation between coping and religiosity. Refugees were more hopeful and optimistic if they had a religious belief system. Accordingly, this study investigated private prayer among Muslim refugees from Kosovo and Bosnia $(N=138)$. Results showed that these refugees were highly traumatized and most counted on private prayer for coping with their wartime difficulties. A structural equation model indicated that war-related trauma was associated directly only with negative religious coping but indirectly with positive coping. Also Thomas, Roberts, Luitel, Upadhaya, and Tol (2011) examined the needs of refugee populations in a study completed on Nepalese refugees and their strengths and struggles. Some of the findings indicated that refugees benefited from close relations, emotional support, and religion; these three as a combination served refugees well throughout their struggles. Schweitzer et al. (2007) found in a study about refugees from Sudan that belief in God has helped refugees cope with their experiences; it has assisted them in reacquiring some of the stability and constancy lost throughout trauma. Adhering to their beliefs in God also helped refugees in dealing with feelings of depression, loneliness, and unhappiness. Refugees often resorted to their beliefs in times of emotional turmoil; praying to God was often a frequent form of relief for refugees when they felt the need to cope with their struggles. Additionally, refugees' spirituality and belief systems helped them in forming social relationships. Refugees reported that attending places of worship assisted them in 
forming contacts and helped them to locate others who shared their beliefs and other cultural similarities.

Refugees present unique mental and physical health needs that deserve attention from health care providers. However, on equal grounds with mental and physical health, and in strong correlation with these two, are the refugees' religious and folk health beliefs and their perspectives regarding health. These beliefs, if well-known and considered by health care staff dealing with refugees, would enhance the health encounter, promote medical pluralism, and make refugees' experience of resettlement less stressful. Little is known about the health care needs of Muslim refugees particularly Syrian refugees. The atrocities of war, violence, displacement, and uncertainty precipitate the deterioration of mental health and wellbeing of Syrian refugees. Depression, stress, anxiety, fear, and psychological distress are often the mental health consequences. Chronic health conditions and some communicable diseases are physical health needs prevalent among Syrian refugees. However, health beliefs, traditions, and perspectives of Syrian refugees are not yet known and examined.

Syrian refugees may not have the level of knowledge and support needed to help compensate for the challenges they may face. However, their Arab/Islamic and folk health practices and beliefs are one tool that helps them compensate for the stressors they face upon resettlement; thus to show resiliency in their resettlement and to aid the US medical system in being more pluralistic.

After this critical review, gaps in the literature can be summarized as follows: 
1) Much of the research conducted in the US, both quantitative and qualitative in nature, has been highly descriptive in design. Accordingly, theoretical abstractions building upon previous theories, are underdeveloped.

2) Few studies have examined the conceptual interrelation of health and integration.

3) No studies have yet examined the basic social process of resettlement for Syrian refugees.

4) Few studies have included both men and women in the sample.

5) No interventional research could be located for Syrian refugee populations in the US.

In view of the identified gaps, this dissertation research sought to advance knowledge regarding health beliefs and perspectives of Syrian refugees to serve as toolkit in the resettlement process, comforting them in this stressful period, and, at the same time providing valuable information for the US health care system if and when it adopts a more pluralistic approach. 


\section{Methodology}

In this study, I adopted abductive reasoning as my methodology. I employed Rachel Spector's theory of Health Traditions Model as a basis of my study, and my data analysis revealed new observations that added to this theory in addition to findings that were in conversation with Spector's theory. This next section addresses four major sections: the philosophical underpinning of abductive reasoning; the researcher's role; study procedures; and finally, equipment used for the study.

Abductive reasoning is a form of synthetic inference through which meaningful underlying patterns of selected phenomena are recognized to comprehend a complex reality and expand scientific knowledge. Abductive reasoning is a creative inference, which involves integration and justification of ideas to develop new knowledge. According to Denzin, interpretation in qualitative research is a productive process that sets forth the multiple meanings of an event, object, experience, or text. Thus, it is transformative (502). While abductive reasoning allows one to conceive ideas from vague, possible or potentially possible phenomena, deductive and inductive reasoning allow for the consequent processing of those ideas. Raholm states that this process can be explained as such: (1) Surprising phenomena emerge and require an explanation because they do not follow an accepted hypothesis; (2) a new hypothesis that predicts these phenomena is adopted through abduction; (3) necessary and probable experimental consequences of the hypothesis are traced out through deduction; and (4) when tests verify prediction after prediction, the hypothesis is situated among scientific result through induction (36-40). According to Eriksson and Lindstrom, abductive reasoning 
guides the generation of hypotheses, the consequences of which are explicated logically through deductive reasoning and empirically through inductive reasoning (196). Abductive reasoning is a new approach to generate theory from qualitative observations grounded in the work of pragmatist Charles S. Peirce. It is the most creative form of theorizing. Abductive analysis harnesses the notion of abduction for qualitative researchers, offering methodological guidance on how to structure research to cultivate anomalous findings against a background of existing theory/ies and to work with such observations to generate new theoretical insights. Abduction differs from grounded theory method in that its users, as Timmermans and Tavory suggest, are neither theoretical atheists nor avowed monotheists, but informed theoretical agnostics (169).

Therefore, abductive reasoning was the chosen methodological approach for this study since the act of discovery of new theoretical insights against a background of existing theories: Spector's theory, theories guiding refugee studies (adaptation, acculturation adaptation, etc.) Through data analysis, I was led to new theoretical insights regarding refugee studies. Abductive analysis allowed me, as Shank describes it, to work inductively observing one thing and wondering if it is a sign of something else, broader, more general, and more theoretical (22). My research started with a background of theories in refugees' health, acculturation, and resettlement. Upon collecting my data and observing the results, findings were partly in conversation with some of these theories and partly new findings emerged which gave me insights to theoretical variations. Creativity, which is inherent to abductive reasoning, was the triggering factor for me to choose abductive reasoning since my research is not exclusively phenomenological, 
descriptive, or exploratory. Creativity in abductive analysis starts with surprise when you analyze your data or record your observations and involves a self-organizing process in which abductive reasoning occurs allowing the expansion or alteration of well-structured set of beliefs and hypotheses.

\section{Role of the Researcher}

Denzin and Lincoln describe the role of the researcher in qualitative research as a "bricoleur" who fashions meaning and interpretation out of ongoing experience (2). When following an abductive approach, a researcher seeks to choose the 'best' explanation among many alternative in order to explain 'surprising facts' or 'puzzles' identified at the start of the research process. In the course of explaining 'surprising facts' or 'puzzles', the researcher can combine both numerical and cognitive reasoning. The researcher's main task is the transformation he/she makes when making sense of a sign. Timmermans and Tavory claim that the researcher in abductive reasoning is given the opportunity to reflect on his/her role of reasoning, beliefs, and convictions in his/her interpretation of qualitative data through the community of inquiry. This community is a group of colleagues, examiners, reviewers, editors, etc.; anyone who has the capacity or desire to question the researcher's theoretical approach to explaining observed social phenomena. The researcher's creativity lies in his/her ability to make sense of the data and come up with more interesting theorization than the one started with. He/she moves back and forth between a set of observations and theoretical generalizations (13-15). Thus, the roles of the researcher in abductive reasoning is summarized in these four intertwined activities: a) gathering observations and data; b) reading a broad range of 
theories; c) working systematically with observations; and d) participating in a community of inquiry.

\section{Study Procedures}

I approached the proposed study as a self-reflective being during the data collection and analysis process. Being a Lebanese, I reflected on the days when borders between Syria and Lebanon were open and many Lebanese went to Syria for shopping and food obtained in low prices. Lebanon and Syria had more than common geographical borders; they had many common historical and cultural features. Also, living in Louisville and witnessing lots of refugees arriving and in need of social, financial, health, and emotional support made me noticeably sympathetic with and aware of their needs and problems. According to Corbin and Strauss, reflexivity is an important component in qualitative research (23).

My research is interview-based qualitative research; therefore all data collected and analyzed is the product of the interviewees' experiences and worlds. This body of data was analyzed so as to productively make sense of what is spoken and expressed by the Syrian refugees. Ruthellen Josselson states that the aim of interviewing is to document people's experience, self-understanding, and working models of the world they live in so that we may later attempt to make meaning of these phenomena at levels of analysis beyond simple descriptions of what we heard. She claims that interviews allow us to encounter the mental sets of interviewee - the subjectively created reality in which the interviewee experiences life (Preface viii). 
Abductive reasoning was the chosen methodological approach for this study. As the experiences, words, and worlds of Syrian refugees were explored and discovered, the methods suggested by Timmermans and Tavory guided the approach. A theoretical understanding of refugee resettlement health problems and solutions and new insights into integrating refugees' health perspectives and beliefs with US medical system was crafted. This theoretical variation helps in attaining medical pluralism and in approaching refugees' resettlement experience in terms of health in a new and more positive way. These insights were ascertained by discovering the processes by which Syrian refugees experience illness, seek treatment and look for comfort as portrayed by their own perspectives. The procedural method was as follows.

\section{Ethical Considerations}

An application for the research study was submitted to the Institutional Review Board (IRB) at the University of Louisville for review. Approval was obtained after requested revisions to the original submission were made. During the course of the study, two modifications to the original IRB approval form were submitted due to changes in the names and affiliations of some clinical offices for refugees. Both modifications were reviewed and approved.

I was the investigator and the interpreter for the research interviews due to my native Arabic language in addition to English. Thus, I conducted interviews in Arabic and translated them in English. Informed consent was requested from all participants and all potential participants were allowed to ask questions or discuss study participation with the investigator prior to consent. The informed consent form was translated into Arabic 
and approved by the IRB. I read the informed consent form to the participant to obtain permission if the participant was illiterate.

Privacy and confidentiality were maintained throughout the entirety of the study. Records for the study were kept confidential. All transcripts were identified by code numbers known only to the primary investigator. No individual names have been used in any research reports, presentations, or publications regarding the study. All informed consents, tapes, transcripts, and research information have been kept in a locked file and will be kept in the office of Prof. Julie Peteet, chairperson for the doctoral committee. All electronic information has been kept on a password-protected computer owned by the principal investigator. Research information has only been available to research personnel and will not be revealed except as requested by the IRB or required by law.

Participation in the study was voluntary, and participants were free to decline to respond to questions that they preferred not to answer. Additionally, participants were allowed to withdraw from the study at any time but none did so.

Reflecting on experiences could have elicited painful memories and emotions; therefore, the researcher was cognizant of counseling resources to offer to each participant. I monitored for signs and symptoms of stress related to the expressions of each refugee participant's experiences and memories, and I was prepared to offer referral for follow-up if needed and to change the topic if needed too. In some of the interviews, the participants became anxious or emotionally distressed. The interview was paused to allow the participants to regain composure. When participants expressed emotions, such as crying, the interviewer offered reassurance. When the interview resumed, the focus of 
the discussion was changed to a less stressful topic with the intent to return to the difficult topic later if deemed appropriate by the interviewer. The interviewer was prepared to ask the participant if he/she would like to stop the interview if the distress continued or increased, but none of the interviews progressed to that point. If the participant wished to have stopped the interview, he/she may have done so without recrimination. I was prepared to offer the contact information for some outpatient mental health support for follow-up if needed. I did recognize loss of confidentiality would have been a risk if the participant required mental health crisis intervention. Pseudonyms are used to protect the identities of all research participants in this dissertation and will be used in articles submitted for publication.

\section{Study Sample}

A purposeful sampling strategy was used to enroll a homogenous sample (all Syrian) men and women participants for the study. Initial informal recruitment of study participants was conducted at Kentucky Refugee Ministries (KRM). Upon IRB approval, the study purpose, design, method, and intended use of study findings were communicated to KRM personnel, so they could inform their Syrian refugee client population about the study and support study recruitment. I requested that an informational flyer about the study be posted at KRM main hall. Advertisement for the study was in English and translated into Arabic as well. I also had the opportunity to communicate the study purpose, design, method, and intended use of study findings to refugees who attended some informal community gatherings at some parks and the 
Muslim Community Center on Westport Road. Thus, I had known most of the participants before my formal interviewing process started.

Research participants were gathered through a snowball approach. Persons who were interested in participating in the study were contacted by me in person or through one woman who was in charge of helping Syrian refugees resettle in Louisville, by phone. WhatsApp was the main tool of communication between me and the potential participants where I contacted them to establish a date/time to meet in person for the interview and at a location of their choice.

Inclusion criteria for the study sample were as follows:

1) A Syrian person (male or female) who had resettled in the US as a refugee within the last three years;

2) A Syrian refugee 18 years and older; and

3) A Syrian refugee who can speak either Arabic or English.

As significant concepts emerged and the new observations were detected, additional study participants were recruited by asking study participants to recommend persons who could help the researcher learn more about the research questions pertaining to Syrian refugees' religious and folk health perspectives and beliefs. Sample recruitment in this manner continued until data saturation was achieved and no new additional information or observation were needed to understand a given category. Saturation is defined by Creswell and Poth as the point where one "no longer finds new information that adds to the understanding of a category"; therefore, a point of data saturation has been obtained (318). 


\section{Data Collection}

Individual semi-structured interviews were conducted face-to-face with recruited study participants in a private naturalistic setting. Participants were allowed to choose the location for the interview, such as their home, local mosque or local library. A small number of participants preferred to be interviewed on phone.

The informed consent was provided in both English and Arabic. If the participant was illiterate, the informed consent document was read in its entirety by the investigator. Persons who acknowledged agreement to the informed consent were requested to sign the document using their legal names. If a person objected to signing his/her legal name, then he/she was given an option to give verbal consent prior to an interview in lieu of providing written consent. The verbal consent was audio recorded separately at the beginning of a recorded interview and kept confidential with all research documents.

In order to protect privacy and identity of the participants, each Syrian participant was given a pseudonym and a number that will be used in reporting the findings of this research and in identifying him/her. This approach protects the real names of the participants since many refugees have fears regarding their safety. In other words, they would not want their real identities known. Even though their identities would be protected, early selection of numbers and pseudonyms helped to increase their comfort level. A master list was kept by the researcher that matched the consent name with the recorded number and kept confidential with all research documents.

During the analysis process, it was determined that recruiting community partners as participants would be valuable to understanding Syrian refugee resettlement in a 
broader way. Approval was granted by the University of Louisville IRB to recruit community partners as participants as well. These were persons from the community who have a vital role in helping Syrian refugees transition to resettlement in the US (health care staff and mental health therapists). They are actively involved as employees of the refugee agency or as health care staff in charge of Syrian refugees' health like the 550 Clinics which were then moved to another place with a different name; MedCenter One. Support provided by the refugee agency and community partners is a vital component of the refugee resettlement process. Therefore, interviewing employees of the refugee agency and/or members of the community helped the researcher broaden and verify the new observations and situate them in the suitable theoretical variation.

\section{Interview Process}

The original intent for all interviews was to be individual and face to face. However, as the study progressed this was not always possible. Family and social support is important during the transition of resettlement for Syrians, and some volunteers requested couple interviews, and were unwilling to agree unless spouse or other family support was present. Allowing participants to interview with the presence of family members provided them a better sense of emotional safety and security. Therefore, there were two possible forms of interviews:

1) Individual: This was the preferred format mode, and the one that was encouraged. However, if a volunteer indicated a strong desire to participate but felt it is important to have support person present, the following alternative approach was allowed:

\section{2) Couple's Interview with spouse or partner:}


Whether Individual or Couple, only persons who met the inclusion criteria for the study were allowed to participate. A total of 37 interviews were conducted, with a total participant $\mathrm{N}$ of 30 refugees and seven community partners

(Total N=37): 24 interviews were conducted in the Syrian refugees' own homes and six interviews were conducted on phone upon the participants' request. Interviews with the community partners were conducted at their work place, local coffee shops, or on phone.

\section{Table 1. Face to Face Interview composition}

\begin{tabular}{|l|l|l|}
\hline Type of Interview & Number of Interviews & Number of Participants \\
\hline Individual & 6 & 6 \\
\hline Couple Interview with spouse & 9 & 18 \\
\hline or partner & & \\
\hline Total & 4 & 4 \\
\hline
\end{tabular}

In allowing for couple-interviews, there was a possibility that the interviews could have been dominated by a spouse or family member. The researcher was sensitive to this risk throughout the interview process and the issue of dominance was considered during data analysis. Observations of non-verbal language, vocal intonations, physical expressions and gestures, were made during the interview process, and recorded in memo writing step. The researcher's thoughts and impressions were documented after each 
interview session. A demographic profile was completed for the Syrian participants. Table 2 provides a synthesis of this data. Syrians may differ from other ethnic refugee groups in the following domains: English fluency, education and occupation.

First of all, English was not been taught in the Syrian educational system until 2002 with the educational reforms of President Bashār Al Assad; therefore, many Syrian refugees who arrive in the US have little or no English fluency. Only two of the thirty Syrian participants had some fluency in the English language.

Secondly, Syrian refugees often have mid-levels of education prior to resettlement. Twenty two out of the 30 Syrian participants had completed middle, secondary, and post-secondary school education. This is because education is free and compulsory from ages seven to fifteen. In contrast, refugees from other countries may not have this education pre-migration. The third differing characteristic may be the occupational or career stature. Syrians, even from rural areas, hold manual and vocational positions in construction, commerce, and business. Many of the Syrian participants, in my study despite being in rural areas, had private businesses like electricians, traders, chefs, etc.

Table 2: Demographic Profile Summary (Syrian refugees, $N=30$ )

\begin{tabular}{|l|l|l|}
\hline Age & $<30$ & \multicolumn{1}{|c|}{$\geq 30$} \\
& years: 3 people & years: 27 \\
people
\end{tabular}




\begin{tabular}{|c|c|c|}
\hline Gender & $\begin{array}{l}17 \\
\text { Female }\end{array}$ & Male \\
\hline Marital Status & \multicolumn{2}{|c|}{$\begin{array}{l}\text { 1 Single } \\
1 \text { Widow } \\
\text { 28Married }\end{array}$} \\
\hline English Fluency & & $\begin{array}{l}\text { glish } \\
\text { lish }\end{array}$ \\
\hline Length of Time in US & & $\begin{array}{l}8 \text { people } \\
22 \text { people }\end{array}$ \\
\hline Reason for Coming to US & $\begin{array}{r}\text { Fol } \\
\text { any family } \\
\text { Fol } \\
\text { of children } \\
\text { Saf } \\
\text { Hu } \\
\text { Im } \\
\text { status: } 14\end{array}$ & $\begin{array}{l}\text { ent for self or } \\
\text { ion and future } 16 \\
\text { n in Jordan: } 4 \\
\text { financial }\end{array}$ \\
\hline
\end{tabular}




\begin{tabular}{|l|l|}
\hline & \\
\hline Urban or Rural Background & \\
\hline Education Level & Urban: 20 \\
& Rural: 10 \\
\hline Health Insurance & Elementary:7 \\
\hline & Middle: 12 \\
\hline & No school: 1 \\
\hline & University: 2 \\
\hline & High School: 8 \\
\hline
\end{tabular}

As I entered the participant's homes, I was made to feel very welcome. The Syrians demonstrated genuine hospitality by offering water, tea, or juice to drink and oftentimes a spread of fruit, vegetables and/or sweet treats prior to or during the interviews. Participants were informed that the interview would last approximately between half and one hour. . 


\section{Interviews}

Open-ended questions were used to encourage participants to elaborate on their experiences with US health care system and their beliefs and traditions regarding health and illness. As discussion progressed in the interviews, further questions were posed to explore emerging concepts that arose through the participants' descriptions of their experiences with the health care system and their folk and religious treatments when sick in addition to their definitions of 'health' and 'illness'. Additional questions were posed to encourage participants to clarify their expressions and to further explore concepts that emerged in the interview process. . Interviews with community partners were conducted in English and began with the following introduction: Tell me about your experience of working with Syrian refugees' health as they resettle in the United States. During the process of all interviews, observations were made of details such as participants' nonverbal language, vocal intonations, physical expressions and gestures, and were recorded in memo. All interviews with the Syrian refugees were digitally audio voice recorded. The interviews with community partners were conducted face-to-face or on phone and lasted 1 to 1 1/2 hour each. Community-partner interviews were also recorded but not all were transcribed.

All refugee interviews were transcribed verbatim. Transcripts, audiotapes, informed consents, and confidentiality statements are to be kept in the office of Prof. Peteet for three years and then will be destroyed by shredding all paper documents as well as deleting all digital recordings. Electronic computer files related to the research study are to be kept on a password protected computer owned by the principal 
investigator until the study is completed. At that time, all electronic computer files will be placed on a data storage device that will be given to Prof. Peteet to keep in her office.

\section{Data Analysis}

Once individual interviews were transcribed, an inductive process was used for analysis. The central process for analyzing the interview data followed the recommendations of Johnny Saldana's (2016) model of analysis to deconstruct, conceptualize and re-construct the data in order to thereby develop a core category that captures the story and all the categorical complexity within the data. Data analysis began after the first interview so that unanticipated and surprising concepts could be identified in order to guide subsequent data collection for theoretical variation that follow abductive analysis methodology. As the researcher, I immersed myself in the data to search beyond the surface in order to gain a deeper understanding of Syrian refugee resettlement in the US and their health problems, solutions, and ways sought for comfort. I was sensitive to their non-verbal expressions (tears, sighs, pauses, etc.).

Transcribed interview data and memos were sources of evidence that were analyzed. Memo-ing, according to Corbin and Strauss, is an essential part of the analytic process as it is a way to record thoughts and ideas that transpire as data is explored (10708). The researcher considers the language that participants used to tell their stories, the metaphors that they used, the emotions expressed, as well as words that reflected temporal or spatial influences. Also, contextual factors expressed in the data such as social, political, cultural, and environmental influences that either facilitate or hinder actions and interactions were considered in the analytic process. I noted my impressions 
of the various dimensions that could be considered in the data in order to establish a progressive audit trail of how the concepts, categories, and the thematic story lines were developed.

I manually managed and organized the data into coded categories as well as documented memos of my impressions of the emerging concepts and patterned relationships among them. Memos were recorded after each analytic session and each memo was labeled with a concept code. The conceptual labels applied to the memos were reflective of the researcher's interpretation of the data. Memos are conceptual in nature, and the researcher compared memos for similarities and differences as further analysis continued.

During the analysis process, three types of coding were used simultaneously open coding, axial coding and selective coding - as I interpreted and constantly compared the emerging and surprising concepts, relationships, and hypotheses derived from the data. Open coding of the data was performed as interview transcripts were read to distinguish an overall impression of the interview data as a whole; detailed line-by-line readings were performed to identify significant categories, often called "in vivo" codes, that were derived from the words and phrases of the informants themselves; and axial coding was performed as provisional categories were identified to recognize and establish relationships and patterns among the identified categories. At this point, constant comparisons were made to determine similarities and differences of conceptual codes. Conceptual similarities were ordered as one category or theme. As emerging categories were formed, theoretical comparisons and sampling facilitated the further refinement and 
development of multiple categories. Additional perspectives of community partners were explored to yield rich and relevant information to broaden the expanse of the new findings in data analysis and to act as confirmation for these findings. Eventually, a core central category emerged that ultimately served as the discovery or theoretical variation of the refugee resettlement and health research approaches. All other categories were related to this core category and bore new insights to fully explain the process. A central theme which acted as the new finding unified the whole data collected for the research. Constant comparisons were made between the new theoretical abstractions elicited from data analysis and the pre-existing theories about refugees' resettlement and their health issues.

\section{Equipment}

The equipment needed for this study were as follows: digital recording device and computer (laptop).

\section{Conclusion}

This study provides a foundation for constructing new knowledge on Syrian refugee resettlement experiences especially regarding health and their own perspectives about health problems they encounter in the US. Also, the study provides a new, positive, and promising image of refugees that is not exclusively negative, pathological, or problematic. Refugees employ different strategies to acculturate and have various resources that help them to be resilient through the stresses of resettlement. Instead of focusing only on diagnosing them with mental or physical health problems, we can approach these refugees in more optimistic and positive ways through exploring the 
richness of their own cultures and what they bring with them to the US. Syrian refugees' Arab/Islamic and folk health traditions proved to play a positive role in their resettlement process, offering comfort and resort amid the problems they encounter. These traditions and beliefs enrich the US medical system and render medical pluralism easier to be realized and implemented. As a result, future implications for refugee research, and health care education, practice, and policy advocacy can be ascertained. The realities of Syrian refugees who resettle in the US shed light on the ways in which the process of Syrian refugee resettlement occurs on real grounds and how it can be improved for Syrian refugees who relocate to the US in the future. 


\section{CHAPTER TWO}

\section{A COMPARATIVE APPROACH: ISLAMIC MEDICAL SYSTEM AND WESTERN BIOMEDICINE}

\section{Introduction}

There is an increasing interest in Islamic medicine in the West. However, it is "challenging to define clearly the exact composition of modern Islamic medicine" (Adib, 697). Nonetheless, some practices and ideas associated with the classical Islamic medicine can be observed in many Muslim-majority states whether by people or health care staff. Islamic medicine started to flourish in the Middle Ages during what is termed the Islamic Golden Age, spanning the $8^{\text {th }}$ to the $15^{\text {th }}$ centuries. This Islamic Golden age saw many significant advances in scientific fields, as Islamic scholars gathered texts, and thus knowledge from across the known world and added their own findings. One of these important fields was Islamic medicine. Islamic medicine also known as 'Arabic', 'Galeno-Arabic', or 'Galeno-Islamic' medicine is a textual corpus written in Arabic. Islamic medicine faithfully preserved, systematized, and further developed the medical knowledge of classical antiquity. During the post-classical era, Islamic medicine was the most advanced in the world, integrating concepts from the Greco-Roman and Persian eras, as well as the ancient Indian traditions of Ayurveda. Medicine was a central component of medieval Islamic culture and thought. Responding to circumstances of time and place, Islamic physicians and scholars developed a large and complex body of 
medical literature discovering, exploring, analyzing, and synthesizing theories and practices of medicine. Initially, Islamic medicine was built on tradition; chiefly the theoretical and practical knowledge in Arabia at Muhammad's time, ancient Hellenistic medicine known as Unani, ancient Indian medicine known as Ayurveda, and ancient Persian medicine of the Academy of Gundishapur. The works of ancient Greek and Roman physicians like Hippocrates and Galen also had a lasting impact on Islamic medicine. Islamic medicine, thus, combines the humoral approach of Galen and Hippocrates with the practices of Persians, Hindus, and the pre-Islamic Arabs in order to fulfill Islamic injunctions to heal the sick and comfort the ill.

Muslim physicians pursued the study of human anatomy, which they believed was a result of God's infinite wisdom and power. Muslim doctors subscribed to the Hippocratic Oath, and the traditions of their art stressed that the true physician, like the true philosopher, must be pious and upright. Farage explains that the traditional figure of the hakim (physician) is one who combines medical skill with an intimate knowledge of the other sciences, natural philosophy, and metaphysics. In the Galeno-Islamic tradition, philosophy and medicine were wedded as implied by the term hakim which in Arabic means both doctor and sage. Physicians were trained in three aspects of philosophy: logic, so as to speak and judge better; ethics, so as to act appropriately; and physics, so as to understand one's place in the cosmos. The medical encounter in the Galeno-Islamic tradition involved three stages: direct sense perception (aesthesis), an extensive questioning of the patient, and deduction through keen reasoning. The shared experience of both patient and doctor of flowing humors, as expressed in the pulse, permitted the 
physician to empathize with the patient. The hakim, adds Farage, aimed to cure not only ailments of the body but also disorders of the soul. To pronounce a verdict on the condition of the patient, the hakim required an elaborate consultation which in all its aspects centered on a relation of trust and compassion. His success depended on an "intimate knowledge of the particular nature of the patient and an understanding of cosmic forces" (22-25). Thus, we can see that the relationship between the physician and patient was built on trust and infused with empathy.

The pulse, according to Farage, was a keystone of the medical arts since it revealed the condition of health, disease, and the states in between; thus it was a fundamental diagnostic, prognostic, and therapeutic aid to the physician. She asserts that to the trained physician's discriminating touch, the pulse sounded imbalances in both body and soul. Hence, "physical ailments, inflammations, fevers, and even the onset of death, no less than secret loves, hidden pregnancies, festering angers, and debilitating melancholia, were narrated by the pulse". The pulse uniquely embodied the intimate correspondence between microcosm and macrocosm (23). Therefore, the soul was seen as strongly affected by the balance of the bodily humors which was particular to each person and influenced his/her temperament. In contrast to the mind-body dualism of contemporary medicine, body and soul were interrelated as matter and form in the Galeno-Islamic tradition. 
Central to Islamic medicine two primary texts: the Qur'an and Hadīth, ${ }^{8}$ Muslims had a duty to care for the sick; this was often referred to as "Medicine of the Prophet." According to the sayings of the Prophet Muhammed, Allah (God) had sent a cure for every ailment, and it was the duty of Muslims to take care of the body and spirit. This certainly falls under the remit of improving the quality of health care and ensuring that there is access for all, with many of the Hadiths laying down guidelines for a holistic approach to health. If Islamic medicine is closely bound up with the principles of the faith, so too is it tied directly to the other sciences, to philosophy, and to the notion that knowledge is legitimate so long as it remains within the framework of the Muslim worldview and does not contradict Islam as indicated in the Qur'an.

Religion, ethics, and science converged to produce one of the most fruitful eras in the history of medicine, the era of Islamic medicine. Various developments including theories of diagnosis and treatment were discovered and advanced. Not surprisingly Islam's emphasis on social well-being fostered significant advances in public health - the creation of vast urban hospital complexes, as well as intricate systems of sanitation, public baths, and the provisioning of fresh-water supplies. Changes in diet and regimen were the preferred path to restored health, and Muslim physicians were skilled observers and diagnosticians who relied heavily on listening to the pulse or analyzing the color of urine. They were the first to have diagnosed smallpox, measles, and hemophilia. Pharmacology, as well as advanced surgical techniques, many to treat eye ailments were

\footnotetext{
" "Hadith" has acquired in Islamic literature the very specific meaning of reports about what the Prophet said, did, approved, and disapproved of, explicitly or implicitly. Indeed, Hadith is considered as the main source of the "Sunna" or "customary behavior" of the Prophet.
} 
also developed in the event that less invasive techniques proved inadequate. Among the innovations in medical technology were the development of the vaginal speculum and forceps, the use of animal gut in sutures, the use of cotton to dress wounds, and even a “concealed" surgical knife to allay patients' anxieties as long as possible. The scientific and medical achievements made during the classical Islamic period had a significant influence on the formation and development of modern medicine in Europe.

Over the years, both Muslim and non-Muslim health care providers have shown an increasing interest in an Islamic viewpoint when it comes to medical research and practice to, as Rassool claims, better understand and respond to the culturally specific outlook and needs of patients from Muslim-majority states residing or seeking treatment in the Western world (5). Islam is the fastest growing religion in the world; currently there are nearly 3.5 million Muslims in the US. Therefore, it would be beneficial for the modern Western scientific health care system to have some knowledge of the religious and folk sources to which many Muslims refer when sick and when seeking treatment.

Modern Western scientific medicine is often called "biomedical" because it explains health in terms of biology. It attaches importance to learning about body structure (anatomy) and systems (physiology), in particular to understanding mechanisms like the heart, arteries, nerves, brain and so on. Health is seen as a state where all the parts of the body function normally, like a newly repaired car. If parts go wrong - if the body is struck down by a virus, internal changes damage it, or parts wear out - it goes in for repair by specialists. This view offers a particular and distinctive way of 'seeing' and understanding bodies and health, a set of guidelines about relating to them and dealing 
with them — to look after them as systems which need care and proper maintenance by their owners. So a biomedical account is one which gives a physical or biological explanation for health, and offers physical/biological methods for 'repairing' bodies when they are not working properly. Certain diagnostic tests establish what is wrong. Then medicines, such as antibiotics, act as a cure, or surgery can repair or replace body parts. The biomedical model is an integral part of Western cultures and the way the health care system is organized. Given the cultural plurality of the contemporary US population, this medical system should recognize, evaluate, and integrate, where possible and effective, components of various systems including the Islamic medical system in order to more effectively deal with a diverse population.

In this chapter, the term 'Islamic medicine,' defined above, refers to the system that comprises health-related teachings of the Qur'an, medicine of the Prophet (his ways of treatment and prevention) and the vast literature developed by early Muslim scholars and inherited over the centuries including theories of prevention, treatment, and diagnosis. This term is not the same as 'folk medicine' inherited by people from generation to generation as customs and beliefs and which varies from one place to another. It is worth noting, however, that many Muslims who resort to Islamic medicine integrate folk health practices and cures with it. In fact, the emergence of Islamic medicine must be understood against the background of two trends: the indigenous Arab tradition and foreign influence, mainly Greek and Persian. Islam, states Al Khayat, considers health as one of the greatest blessing given by God to human beings (7). Devout Muslims "use holy texts as the key source of the prayers for curative purposes" 
(AlRawi et al., 490). Many Muslims believe that God sends illnesses down and is the one who cures them although this does not prevent them from seeking bio-medical interventions and various treatments. ${ }^{9}$ On the other hand, Western biomedicine is grounded on the assumption that every disease has a particular cause that materially influences the human body in a foreseeable, fairly predictable, and uniform manner. This implies that there are universal cures or treatments for specific diseases. It should be noted that many fundamentalist Christians believe as do many Muslims that illness and calamity come from God. It should be noted that not all Muslims abide by the theories developed earlier in Islamic medicine together with teachings of the Qur'an and recommendations set by Prophet Muhammad.

Muslims today approach medicine and health care in various ways. There are some Muslims, particularly those in rural areas, who have limited access to modern medical facilities or who completely reject modern medicine. Many of these people prefer to rely on a combination of supplications and traditional medical treatments. Accordingly, it is quite common to find traditional healers working today who continue to rely on a mixture of Qur'anic verses, water, local herbs, ornaments, oil, or honey for their medical treatments. Unfortunately, some of these practitioners have no medical or professional training, and some become involved in superstitious practices that contradict Islamic norms and values. On the other end of the spectrum, there are secular Muslims (non-practicing), who do not abide by Qur'anic injunctions and Prophetic statements in

\footnotetext{
${ }^{9}$ Sometimes I will say "Muslim" to refer to those raised in a culturally Muslim environment and self-identify as Muslims but are not necessarily devout. In other words, "being a Muslim" exists on a broad spectrum from devout and practicing to non-practicing and atheist.
} 
the medical sphere, who prefer to rely completely on modern medicine. The vast majority of Muslims, however, fall somewhere between these two groups. They believe that prayer, supplications, herbal and folk health traditions, taking preventive measures, Qur'anic recitation, and $d h i k r$ (remembrance of Allah) play an important role in healing and recovery while also recognizing the benefits of modern medicine.

The practice of the Galeno-Islamic medicine still flourished as late as the midnineteenth century across the Near East and South Asia. However, the colonial rule of the eighteenth and nineteenth-century Europe was decisive in eradicating much of the practices and theories advanced by this system of medicine. Though thoroughly eclipsed by modern medicine or biomedicine, the last few decades have witnessed a renewed interest in reviving traditional Islamic medical knowledge and combining it with the latest advancements in modern medicine especially in India and Pakistan. Many seminars, conferences, books, publications, and medical associations have been devoted to this revival, as well as to generating a precise definition of "Islamic medicine." For some, the term means a return to classical Islamic medicine as it was implemented in the Middle Ages. Accordingly, institutes such as the Hamdard Foundation in Pakistan and the National Research Center and the Desert Institute, both in Egypt, were established to undertake clinical studies on the efficacy of the medical teachings found in the Sunnah.

For some Muslims, however, Islamic medicine entails applying Islamic values and paradigms to any type of medical phenomenon, thereby "Islamizing" it. Omar Kasule, the deputy dean of the Faculty of Medicine at the International Islamic University Malaysia, defines Islamic medicine as a system of basic paradigms, concepts, values, and 
procedures that conform to, or do not contradict, the Qur'an and Prophetic traditions. It is universal and can be defined only in terms of values and ethics, not as specific medical procedures or therapeutic agents (qtd. in Hermansen, 410). In understanding of 'Islamic medicine', the most common today, there is no clear-cut scientific distinction between Islamic medicine and other systems due to globalization, acculturation, wars, colonialism, and Western medical advancements. Many Muslims, particularly the devout ones, carry remnants of this system as it was implemented thousands years ago. For example, the role of the physician, the examination (pulse), the relationship between patient and physician, the meaning of pain and suffering, the holistic view of health, the role of spirituality in healing, in addition to the Qur'anic teachings and Prophetic ways of treatment and prevention, all these are still engraved in the lives of these Muslims and form their beliefs and perspectives regarding health and illness. Therefore, today the term Islamic medicine tends to be comprised mostly of the religious and ethical components and less of the scientific.

Islamic medical systems follow a biopsychosocial approach that takes into consideration a patient's sociological, psychological, physical, and spiritual needs. Under this system Lovering claims, a patient is treated as a whole human being rather than only focusing on the physical symptoms of the disease in question (112). On the contrary, Western biomedicine conceptualizes the human body in a more technical fashion as a machine composed of interconnected parts such as the circulatory, respiratory, skeletal and nervous systems. The role of a physician, therefore, is similar to that of technician who identifies and repairs broken parts. For centuries, health practice, training, and 
research have concentrated on trying to recognize and eradicate particular diseases, and thus has moved away from the social perspective of medicine and social origins of diseases. This chapter provides a comparison between the Islamic medical system as it was classically implemented and the Western biomedicine system. It provides a brief comparison of the two systems followed by a discussion of the major theories and aspects of each system that constitute their differences.

\section{A Comparative Approach: The Islamic Medical System (400AD-1400 AD) and}

\section{Western Biomedicine}

During the Middle Ages, religion played a key role in everyday life both in the Western and Islamic worlds. The Christian Church in Europe established monasteries, which also served as hospitals, and later started to provide training for doctors. The Church considered it the responsibility of all Christians to help the needy and the sick. To qualify as a Doctor of Medicine took ten years, so the numbers of such fully qualified physicians remained comparatively small during the Middle Ages and there were not enough qualified doctors to treat the population. Medicine was administered by different people during the Middle Ages. In the Middle Ages, medicine was basic, and doctors had limited knowledge. Medieval doctors had little idea what caused the terrible illnesses and diseases which plagued the era. Many people relied on local healers, who were in most cases women. During the Middle Ages, priests and monks most often carried the responsibility of tending to the sick when there was no physicians available or when the sick could not afford to pay the physician. Taking care of the sick and poor was mainly the role of religious leaders who provided spiritual care and satisfaction. During the $6^{\text {th }}$ 
century, people with mental disorders were taken care of in monasteries administered by the Church. All in all, the Middle Ages were a terrible time to get sick.

The Catholic Church controlled medical care, and propagated the idea that God inflicts disease as punishment for immoral behavior, and through prayers, God could be pacified to withdraw or ease the punishment. The main religious teaching then included balancing the four humors for good health which was inherited from the ancient Egyptians and later systematized by the Greeks and will be explained in detail later in this chapter. The humoral system used purging and bloodletting as the main interventions. While these treatment methods did not kill the sick, in most cases, they also did not do much good. The medical practitioners of the time also had recourse to herbs as treatments. Though some illnesses were treated with a degree of efficacy, a good number were beyond both cure and explanation. For about ten centuries, the Church had the primary responsibility of running hospitals and licensing doctors to practice. However, after $1400 \mathrm{AD}$ and with the onset of the Renaissance, Koeing states that the certification process came under the purview of the state, marking an emerging separation between religion and medicine in the Western world (388).

In the Islamic world, the middle Ages were more positive and productive in terms of scientific developments as well as literature which reached the peak of its civilization in $1000 \mathrm{AD}$. Islamic texts (Qur'an and Ḥadīth) provided clear instructions on social responsibilities such as the rich providing for the unwell and the poor and the paying of dhakat (taxes) as a duty on all Muslims. Dhakat, the giving of alms to the poor and needy, is one of the five pillars of Islam. The individual must own a specific amount of 
wealth or savings (after living costs, expenses etc.) in order for the zakat to be payable. In addition, the waqif system endowed many hospitals. Waqif is an endowment that sets aside a property or a sum of money to be dedicated to a charitable endeavor such as a hospital, school, bath, mosque, or fountain and the devotion of its profits or usufructs to charity, the poor, or other good deeds. Based on these principles of charitable donations and waqif, as well as Muslim advances in medicine, "many hospitals were built" (Koeing and Saad, 14).

Throughout medieval Islamic societies, medical pluralism can be conceptualized as a continuum running from the scholarly theories and practices of scientific medicine to those of local custom and magic. Intense cultural exchange among Arabs (Muslims, Christians, and Jews), Persians, and Hindus characterized this period. In fact, late medieval and early Renaissance European medical education owe much to the medieval Islamic medical tradition. The origins of the approaches and methodology of modern Western medicine can be traced in large part to medieval Islamic medicine through its Latin translations, while the institutionalization of both teaching and the provision of medical care was foreshadowed by Islamic institutions. Islamic medicine emerged and flourished during this period due to vast translation movements accompanied by innovation on the theoretical, social, and practical levels. The Islamic medical tradition built on the translations of Greek medical texts; both medical theory and practice were overwhelmingly a continuation of the Greek one. However, it was not merely a 'watereddown' and corrupt version of glorious medical achievements, as some scholars from the Renaissance onward have often claimed. It, as Pormann and Smith argue, incorporated 
other elements such as Syriac, Persian, and Indian medical concepts into the general framework of humoral pathology (6).

Muslims developed the institution of the hospital in the eighth century. Many of these hospitals had their own gardens in which medicinal plants were cultivated, and most significantly, many of these hospitals were sites for the transmission of medical knowledge and training. In other words, they were the first teaching hospitals. The rules for the practice of medicine were very progressive. According to Al Rāzī, a physician had to be well versed in new and old medical literature and have worked in hospitals as a house surgeon before he could be employed in one. Al Rāzī was the most outstanding physician of the ninth century. The first hospital in the history of Baghdad was established on his advice under the rule of the Abbasid Khalifa Harun al-Rashid. In order to find a suitable site for the hospital, Al Razi hung pieces of meat around the city and chose the site based on where the meat rotted last. There were also a large number of traveling hospitals in the Muslim world.

Islamic medicine and biomedicine share a number of things in common. To begin with, these two medical approaches are analytical and are based on examination, diagnosis, theories of causation, prevention, and treatment, and inquiry, and thus are scientific systems. As mentioned before, Islamic medicine, as it was practiced in the medieval times, comprised religion, ethics, and science. Both systems' investigative nature has brought about peculiar insights into the human body. For example, Muslim clinicians held considerable knowledge on the treatment and etiology of metabolic diseases. As demonstrated by Al-Rāzī and other Muslim clinicians, the Islamic medical 
system was an evidence-based approach. Islamic medicine signaled a disciplinary and institutional model that included, hospitals (with quarantine units), and systematic training. Another point of comparison is that both medical systems acknowledge the fitra (nature) of the human body. Islamic medicine recognizes the symmetry and beauty of the human body as a microcosm since humankind (al-insān) is considered to be a microcosm ('âlam șaghìr). The human body was essentially a miniature of the cosmos (al-'ālam), wherein its morphology and organization corresponded with those elements which "make up the wholeness of the universe" (El Bizri, 4). Whereas Western biomedicine attributes to human body a number of adaptations like the immune system and the brain which endows people with consciousness.

Both the Islamic medical system and Western biomedicine promote the welfare and health of human beings through lifestyle and diet. The Prophet advised Muslims to be mindful of their eating habits and of the adverse effects of gluttony on the spiritual heart: "Don't indulge in over-eating because it would quench the light of faith within your hearts" (Al-Mustadrak, Vol.3; 81). The concept of human agency which entails that human actions be dictated by reason ('aql) is encouraged in Islam. Humans should be in a state of health and consciousness to take their own decisions rightly and effectively. Muslims understand that while sovereignty belongs to God it has also been delegated in the form of reason and human agency. "And when your Lord said to the Angels: 'I will create a viceroy on the earth'. They said: 'will You put there one who will do evil, and shed blood?' We celebrate Your praise and sanctify You. He said: I know what you do not know" (Qur'an, 2.30). 
The verse explains the reason why the Prophet has been sent to this world and the significance of his appointment as the vice-regent of God on this earth. God intends to appoint a vice-regent in the earth in order that the said vice-regent should represent God by celebrating His praise and glorifying His holiness through his worthy presence. Under the gift of human agency and reason bestowed to Muslims, maintaining a sound physical as well as mental state is a prerequisite to executing Islamic duties and acting in accordance with God's commands. This point is illustrated by the following hadith: "No one will be allowed to move from his position on the Day of Judgement until he has been asked how he spent his life... and in what pursuits he used his health." (Jāmi 'AtTirmidhi, Vol.4; Hadith 117). Therefore, Islam holds Muslims accountable for preserving their health and ameliorating it through seeking the best choices as long as they are not in conflict with Islamic order.

Islam prohibits Muslims from consuming particular foods and drink, especially intoxicating substances. The loss of reason ('aql), as a consequence of alcohol consumption, inhibits prayer; in addition, the prohibition on alcohol is related to the social good as well. Family resources are squandered on alcohol and this has a negative impact on the economic, moral, health, and safety status of the family which in turn will affect society as a whole. The Qur' an encourages Muslims to consume food in moderation and to cultivate their psychological, spiritual, and physical well-being. In addition, the Qur'an highlights specific foodstuffs for medicinal treatment such as black seeds, olive oil, vinegar, and honey. Honey is described as a source of healing: "There 
comes forth from their [bees'] bellies, a drink of varying color wherein is healing for mankind. Verily, in this is indeed a sign for people who think" (Qur'an, 16.69).

Prophet Muhammad commanded various foods for their health benefits as well as the benefits of exercises such as swimming. Prophet Muhammad was also an advocate of dental hygiene and recommended the use of the miswāk (toothbrush), especially one made from a twig from Salvadora persica tree, to clean teeth. "Make the (brushing with) miswāk a must - for it cleans the mouth, and the Lord also gets pleased" (Sunan An Nasā 'i, Vol. 1; Hadith 5). He also used cupping (al hijāma) to cure some diseases. According to Azaizeh et al., the Islamic medical system incorporates a collection of chemo-protective medicines that stimulate the human immune system (231). Moreover, it possesses "anti-bacterial, anti-viral, anti-inflammatory, anti-cancer, and antioxidant properties" (Cragg and Newman, 129). Some diseases require non-invasive healing processes such as the natural healing process of the body coupled with proper diet and herbs. The use of natural herbs, foods, and spices like olive products, black seed, dates, honey, turmeric, melon, pomegranate, ginger, wheat bread, and onions are used increasingly in Muslim-majority states. Some of these practices and dietary habits have folk origins; people inherited them and continued their use as they proved to be effective while others are religiously recommended. For example, many Syrians rely on thyme and sage tea to alleviate the symptoms and treat coughs and sore throats. These folk practices are not part of Prophetic or Islamic medicine. Many of these herbs like thyme and turmeric have been proven by recent scientific researches to possess anti-cancer properties (Cragg et al., 3020-29). A number of Western biomedicine researchers have 
written extensively on the role modern diets play in the onset of chronic diseases. Overuse of unrefined sugars, refined carbohydrates, trans-fats, and sodium, coupled with sedentary lifestyle have been identified as significant factors in chronic diseases. Some scholars in nutrition such as Lindeberg et al. have recommended a Paleolithic diet for optimal health. They argue that a decrease in consumption of cereal and dairy-based foods and an increased consumption of lean meat, legumes, leafy green vegetables, nuts, and fruits are important in promoting human health (150-55). Increasingly people in the West are beginning to favor diets based on olive oil, dates, honey, and less consumption of high-fructose corn syrup, fats, and alcohol.

Despite the above similarities, the Islamic medical system is critical of the biomedical view that medication alone is solely responsible for treating and curing diseases. To many devout Muslims, no illness can be cured without the approval and kindness of God (Allah). In fact, the principle of pre-determination (al qadar) or fate applies to disease causation, progression, and resolution. Therefore, treatment and prevention of disease are not against qadar but are subsumed under the principle that qadar can reverse another qadar. The Qur'an states that God is the one who cures. Humans try, but ultimately it is God who cures. Indeed, one of God's 99 names is al shāf $\bar{\imath}$ (the Healer). For believers, the Qur'an itself serves as a spiritual cure and healing for all types of ailments and not only a guidance for humankind. This includes treatment of all worldly problems: physical, psychological, and spiritual ailments in addition to the effects of evil eye. The evil eye is the name for a sickness or misfortune transmitted, usually with or without intention, by someone who is envious, jealous, and covetous or 
even a pious person. However, the evil eye does not affect except with the will and decree of God. In the Qur'an, God says: “And We send down of the Quran that which is a healing and a mercy to those who believe-" (Qur'an, 17.82).

Thus, even with the appropriate application of the proven practices of treatment, the cure is only achieved after God's intercession. This implies that it is God who endows medicine with its curative effects. In other words, medical intervention, even if compulsory or recommended in certain cases, cannot be seen as the cause of healing. Rather, it may lead to healing with the permission of God. Therefore, all that a physician performs is done with God's permission and is therefore part of fate or pre-determination. This view is in accordance with the basic Islamic creed that God is the Creator of all things and is the master of cause and effect; therefore, people should do their part and have a sense of tawakkul (trusting God's plan). With reason and the human agency granted to Muslims as exercisers of the delegated power on behalf of their sovereign, God (Allah), Muslims are required to take care of their health and their bodies. Seeking good health is an obligation in Islam and Muslims are accountable for it on the Day of Judgement. God has ordered his followers to protect their bodies and preserve them in the perfect form He has fashioned. This is illustrated by the following Qur'anic verses: “O mankind! What has enticed you from your gracious Lord who has created and wellproportioned you, and given you a perfect moulding?" (Qur'an, 82.5).

Prophet Muhammad encouraged the women of his household to learn medicine from those who knew it. In the time of the Prophet, women excelled in medical practices. The Prophet had installed a tent in the yard of his mosque in Madina and appointed a lady 
named Rufaidah to run it as a field hospital, nurse the wounded and care for homeless newcomers to Madina. The Prophet stated that the best supplication is to pursue good health. Also, the Prophet said: "There is no disease that Allah has sent down except that He also has sent down its treatment" (Sahīh Bukhärī, Vol. 7; Hadith 5678). Muslims are encouraged, within the human agency and reason granted to them in Islam, to seek treatment through various approaches: medical, spiritual, DIYs, and personal as long as these treatments abide by what is lawful in Islam. There is a hadith from Prophet Muhammad that affirms that the Prophet encouraged seeking treatment. When asked by Bedouins about the permissibility of treating sickness, he said: "Treat sickness, for Allah has not created any disease except He has also created the cure, except for one disease." They said, "O Messenger of Allah, what is it?" He said: "Old age" (Jāmi 'At-Tirmidhi, Vol.4; Hadith 383).

Rang et al., explain that in the post-industrial and developed Western world, the biomedical disease model views disease as an imbalance of normal functioning of the body that can be described in structural or biochemical terms, identified using objective measurements, and can be improved using appropriate surgical or chemical interventions (95). This scientific approach results in evidence-based medicine where new information is examined and integrated into the existing health care practices. The impacts of evidence-based medicine on morbidity and mortality are well documented. According to a study conducted by the Australian Institute of Health and Welfare $(A I H W)$, the number men dying from infectious diseases decreased to 6 in 1980 from 283 per 100,000 people 
in Australia. During this period the average life expectancy increased by 23.6 years for men and 25.1 for women ("Mortality over the Twentieth Century in Australia", 2006).

Even though in the Middle Ages both the Muslim world and Western Europe received medical knowledge derived from Hellenistic and Greek sources, the extent of the material and the manner in which they were used differed significantly between the two societies. For instance, the Arabic authors accessed more of Galen's works, which contained significant philosophical and logical components. Galenism (Hippocrates's medical system refined by Galen) silenced most dissenting voices at that time by developing and further refining the all-encompassing system of humoral pathology to take into account new material and ideas. Arabic writers also had access to the corpus of Greek philosophy, especially the works of Aristotle. Consequently, the links between philosophy and medicine were strong among Arabic writers. This adds further explanation to the strong ties between mind, body, and spirit in Islamic medicine. However, these writers' philosophical alignment should not be allowed to obscure the contention that the Arabic medical works were certainly medical, scientific, and were appreciated in the Muslim world and later in modern Europe for their systematic and extensive accounts of diseases and treatment.

\section{Islamic Medical System}

\section{Historical Overview}

Although the Islamic medical system was syncretic and comprised various medical systems when it started to flourish, it is quite distinct from folk Arab medical beliefs and practices which used oils, folk experiences, and herbs to cure diseases. 
Islamic medicine relies on spiritual and physical (including medical and herbal as recommended by Qur'an and teachings of Prophet Muhammad) means to cure diseases and promote wellbeing. With the rise and spread of Islam in the $7^{\text {th }}$ century, the "rudiments of Islamic medicine" started to take shape (Saniotis, 3). The Qur'an and Prophet Muhammad's teachings underscored the importance of both public health and personal hygiene. The Prophet said as reported in Sahīh Bukhārī: "Five practices are of the fitrah (natural disposition): circumcision, shaving the pubic region, clipping the nails and cutting the moustaches short, and depilating the hair of the armpits." (Vol.7; Hadith 779). Also public health and cleanliness is highly encouraged in Islam. The Prophet said as reported in Sahịh Muslim: "Removing harmful things from the road is an act of (sadaqah) charity." (Book 12; Hadith 72).

Prophet Muhammad recommended correct dietary habits like commensality, exercises, and "prayers to promote spiritual and physical well-being" (Al-Jawziyya I. 397). From the Qu'ran and his teachings, Muslims developed a medical compendium that has been used widely in the Muslim world. Early Muslims understood medicine as fostered by Prophetic teachings and the Qur'an. Nevertheless, as Muslims were spreading to other parts of the world, especially North Africa and Asia, they encountered various cultures that were absorbed into and shaped their medical knowledge. In the field of medicine, the Arabs improved upon the healing arts of ancient Mesopotamia and Egypt. They adopted many of the principles of Ayurvedic medicine in India. Guided by Prophetic injunctions and Qur'anic principles to seek and promote knowledge, from 800 AD onwards, Muslims diligently accessed ancient world knowledge. During this era, 
Islamic civilization flourished because of its concerted investment in arts and sciences. Khan states that various non-Muslim and Muslim thinkers translated scientific works from Persian, Greek, Aramaic, Syriac, and Indian Languages and complemented some relying on their own experiments and perspectives (15-16).

Essential developments in the field of medicine between the $7^{\text {th }}$ and $11^{\text {th }}$ century occurred not in rural, sparsely populated and economically undeveloped areas but in the developed commercial economies, the prosperous cities, as well as in the intellectual environments of the Muslim world of the Iberian Peninsula and the Middle East. Islam's rapid growth that started in the first decade of the $7^{\text {th }}$ century, Ashy explains, was followed by integration of Greek science and philosophy into Islamic culture in the $8^{\text {th }}$ and $9^{\text {th }}$ centuries (244-47). According to Pormann and Smith, among the Greek literature decoded into Arabic were medical works mainly by Hippocrates and Galen. By the $9^{\text {th }}$ century, Arabic-speaking doctors had absorbed this material. Generally, the authors of medical treatises in Arabic adopted and sometimes added and modified the Greek physiological and philosophical systems (12-14). Where therapy and pathology were concerned, they had recourse to Greek materials often supplemented by their own observations and analysis. Medical education took shape during the Islamic civilization era. Training of physicians in basic sciences, providing and launching a clinical training curriculum in internal medicine and surgery, and licensing of physicians were established in this era. In addition, employing inspectors to inspect drugs and maintain quality control of drugs was instituted. 
The basis of Islamic medicine can be traced to Greek traditions, especially the Galenic and Hippocratic theories. Ebrahimnejad claims that Muslims innovated and synthesized these medical traditions into an exceedingly refined medical model that was experimental, logical, and evidence-based (260-63). Gutas contends that it is during the $8^{\text {th }}$ century when Muslims started translating texts mainly from the Greek (2). These works of translations and research took place mainly in Spain, Baghdad, and Gundishapur. The reasons for these translations include the new conditions that had developed in the Islamic society. New needs, hopes, goals, problems, responsibilities, and moral issues encouraged Muslims to study other cultures that had gone through similar experiences as a source of knowledge. Besides, Muslims felt that the economic, political, and military power they had acquired needed to be accompanied by intellectual maturity and scientific knowledge for this power to be applied appropriately. In addition, Muslims were in need of advanced philosophy and science to compete effectively with superpowers of the time and to develop the logical and scientific foundations of their faith. Muslims mainly translated books in the fields of science, medicine, astronomy, psychology, and mathematics but attempted always to modify some and add their own thoughts and experiments. Given the religious importance of moral virtues, Muslim physicians have put much emphasis on ethical principles in their practice. Most of Muslim physicians would allocate part of their books to the topic of medical ethics. For thousands of years, ethics have been recognized as an essential requirement in the making of a physician .One of the most extensive works dealing with this, Ethics of a Physician, was written in the 10th century AD by Al Ruhawī. There are many other Muslim scholars 
and physicians who wrote encyclopedic books about medicine and ethics like Avicenna, Al Rāzī, Al Tabarī, etc.

\section{Medical Theories in Islamic Medicine}

\section{Humoral Theory}

The basic concept of the Humoral theory depended heavily on the four fluids, or humors, that were believed to constitute the human body - black bile, yellow bile, blood, and phlegm. The four humors were thought to live in cycles influenced by the constellations and seasons. For example, a disease during the cold winter was said to be the result of a disparity in phlegm, which brought about the chest and respiratory problems. On the other hand, a disease during the hot summer was linked to yellow bile, which caused bad temper, liver disorder, and fever. The other two humors, blood and black bile, were related to spring and autumn, respectively. Consequently, to balance humor, the corresponding treatments were constructed on opposites. For instance, to address over-saturation of mucus, which was linked to the cold of winter, hot substances were used. Similarly, illnesses experienced during summer were treated with cold substances.

According to Rohmann, observation played an important role in providing support for the humoral theory. In the four-humor-theory, the idea that well-being is defined by temperament or complexion correlates with the qualities of the four elements and their connection with the four humors (179). For instance, individuals who had a high concentration of black bile, yellow bile, blood, and phlegm were believed to have personality characters that were melancholic, choleric, sanguine, and phlegmatic, 
respectively. Doctors using the four humor theory diagnosed the sick based on their observations. Moreover, these doctors observed the patients' physical characteristics, which correlated with the related natural state of the humor. For instance, individuals who were found to be hot following a touch were said to have yellow bile imbalance, the humor that was linked with summer. Clearly, the four humor theory relies upon the scientific principle of observation. This is a significant advancement compared to the proceeding health care theories and ideas that mainly relied on mystical powers and superstitions to explain the origin of a disease.

Nevertheless, some treatment methods contained in this theory revealed its weaknesses. One of them is bloodletting which, as Lindberg explains, acted as a common method of keeping the humor of the body. Before bloodletting was administered, the healer would observe a patient for several days (116). Even though the four humor theory followed a scientific method in the diagnosis stage, the results of bloodletting treatment, according to Javier, were unpredictable. Physicians were so respected to the extent that patients thought that physicians had extensive knowledge of all diseases, which in turn made them feel well, although bloodletting was miles away from being helpful. The challenges of such treatment overshadowed its paybacks. For example, in the $17^{\text {th }}$ century, Charles II, the then King of England was subjected to bloodletting to battle a seizure. Not surprisingly, this led to the King's death (73). Therefore, bloodletting leads to the loss of oxygen level in the body causing many health complications. Other treatments grounded on four states of humor theory were used without much success, including blood leeching, induced vomiting, and breathing in the scent of pig manure to 
combat nose bleeding. Put differently, the four-fold humoral theory used treatments that would be considered absurd in the modern biomedicine era.

Interestingly, the four-fold humoral theory remained unchallenged for centuries primarily because of lack of established scientific knowledge during that time. This theory was highly attractive as it marked a departure from an understanding of human disease that leaned toward superstitions and mystical powers. In retrospect, the treatments that were developed using humoral theory proved highly ineffective in understanding etiology, diagnosing, and treating disease. It was not until the $16^{\text {th }}$ century when the foundation for the modern Western medical system; an understanding of disease as caused by forces and chemicals external to the human body gained ground. The rejection of humoral theory was accompanied by the advances of the scientific revolution witnessed during the Renaissance. Eventually, developments in modern science ended the long reign of humoral theory. Undoubtedly, the humoral theory has been precluded in modern days. The notion of having body fluids that influence the whole welfare of an individual, influenced by both seasons and nature, appears highly absurd in the present medical system.

\section{Prophetic Medicine}

In simple terms, Prophetic medicine denotes the actions and sayings of the Prophet with respect to the treatment of disease, nutrition, and hygiene. There are a number of sayings in which the Prophet emphasized medicine and discouraged seeking health interventions through charms, relics, and amulets. Prophet Muhammad said as 
reported in Sunan Abu Dawud: "Verily, spells, amulets, and charms are acts of idolatry" (Vol.4; Hadith 3883)

Prophetic medicine differs from the modern Islamic medical system in the sense that the latter is a broader category that includes a number of medical practices rooted in the ancient civilizations that informed medieval Islamic medical sciences. Prophetic medical traditions urge humans to not stop at observing Prophet Muhammad's teachings, but encourages them to look for cures as well. Therefore, the literature of Prophetic medicine occupies an important role in the elucidation of Islamic identity as constituted by a set of relationships to nature, medicine, and technology. Many practicing Muslims follow the Prophetic recommendations and resort to them wherever they go. Thus, these teachings and commands form part of their Islamic identity. For many, being a devout Muslim also is tied to love for the Prophet Muhammad and following his path. Hadith collections include many rulings and examples that provide the faithful with the guidelines to maintaining a Muslim identity. It is important to note that Islam and Arab culture overlap extensively. So, Arab Christians, for example, engage in many of the practices of Prophetic medicine as it developed in an Arab cultural context.

On several occasions, Prophet Muhammad visited sick people, and after conversing with them about their sickness, he advised them to take medication prescribed by an experienced physician. On a specific occasion and as narrated in Saḥịh Bukhārī, Prophet Muhammad visited Sa 'd bin abī Waqqās who was suffering from a heart problem. Though Waqqās had felt great relief after Prophet Muhammad had placed a hand on his chest, he was encouraged by the Prophet to seek help from a physician 
(Vol.7; Hadith 563). Another example clarifying the significant role of the physician is narrated by Al-Jawziyya who gives an example from the Jewish tradition. He states that Prophet Abraham once asked God: "O my lord! Where does disease come from?" He said, "From Me." Abraham said, "Where does the cure come from?" He said, "From Me." Abraham said, "What is the role of the doctor then?" He said, "A man in whose hands I send and cause the cure" (32).

These and many other instances greatly influence the Muslims' attitude toward disease and reinforce the fact that seeking treatment is encouraged. In contrast during the pre-Islamic age (al jāhiliyya), Arabs depended on petitioning various divinities for treatment of illnesses and had faith in the abilities of charms, amulets, and talismans to bring good luck or avert bad fortune.

Good health is something for which Muslims are accountable to God. Prophet Muhammad stated in a hadith that the first thing that every person will have to account for during the Day of Judgment is his/her health. The Prophet stated that during the Judgment Day, no person will move from his/her position until he/she has explained how he/she used his/her life, knowledge, and how he/she earned and spent his/her money and the pursuits he/she used his health in. In this regard, it is the duty of every Muslim to defend his/her health and not to permit any change to use it for in ill pursuit. The Qur'an (2.211) states that an individual who tampers with God's grace after it has been bestowed on him/her will receive punishment from God. The Qur'an also states that God would not tamper with grace bestowed on an individual unless they alter what they themselves have (8.53). 
Prophet Muhammad opposed the use of incantations and charms as a form of treatment for diseases. He said: "Spells, amulets and love-charms are shirk (ascribing a partner or rival to God in Lordship and/or worship" (Sunan Abu Dawud Vol. 4; Hadith 3883). Nevertheless, on some occasions where physical medicine was not obtainable, he recommended, particularly for psychological problems, the recital of Qur'anic verses that have a particular meaning. He also considered the victims of some diseases like cholera and plagues as martyrs. This provided comfort for those who were suffering from an epidemic. Moreover, he said: "Treat your sick by giving șadaqah (charity)” (A1Mundharī, Vol.1: 520). Always, Prophet Muhammad warned doctors to take great care in handling the sick and required those not well-informed in the expertise of medicine not to try treating the sick as they may be held responsible for any complications that would arise. In medieval Islamic medicine virtues, as Farage states, were to be exhibited by both physician and patient; the physician had to follow a set of duties that included being learned, well-mannered, properly attired and moderate in behavior. The patient, on the other hand, was required to be truthful and obedient (28). The Prophet instructed Muslims to always take great care of their health, whether seriously ill or not. He comforted them and asked them not to believe that they were victims of anger or that diseases were manifestations of the fury of God.

\section{Western Biomedicine}

\section{Historical overview}

In many pre-modern societies, people viewed diseases as curses from spirits or gods. Consequently, medical practice was the work of a variety of practitioners from 
shamans to medicine men. Even though magic formed an integral part of the healing process, the art and cult of these early practitioners were never wholly limited to the supernatural. By using their experiences and natural instincts, they witnessed incipient science based on empirical laws. For instance, through the acquisition of coding of particular reliable practices, the art of bone setting, herb doctoring, midwifery, and surgery were advanced. Just as early humans learned through observations that particular grains and plants were good for human consumption, so did the shamans and healers observe the nature of particular diseases and then passed on their knowledge and experience to other generations.

Evidence has shown that the practitioners across the globe had an active interest, rather than a mere intuitive interest in curative arts, serving as surgeons and users of tools. For example, human skulls with holes have been collected in different parts of South America, Asia, and Europe. It is believed that these holes were made to gain access to the brain. Perhaps these surgeries were done to rid the brain of malicious demons that were believed to be the cause of extreme head pain and epilepsy. Cranial surgery was carried out on living human beings, and some actually survived. This is because of rounded edges of the bone surrounding the hole indicating that the bone grew again after the operation. Survivors of such surgeries achieved a special status in society such that after the death, their skulls were used as charms to ward off abrupt outbreaks. From these beginnings, medical practice has become an integral part of human cultures and societies.

Like early religions, Egyptian mythology emphasized the relationships between health and the supernatural. One of their best practitioners was Imhotep who practiced 
medical arts so well that the Egyptians idolized him as the 'god of healing'. As ancient Egypt's influence spread, the Greeks, even with their own healing god, Aesculapius, recognized Imhotep's work. By 1000 BC, medicine was already a respected profession. In current terms, Aesculapius temples served as sanatoriums that had very strong religious overtones. Patients were received in these temples and were first prepared psychologically, through sacrifice and prayer, to appreciate the past achievements of Aesculapius. During the night, medical practitioners would visit patients and administer medical advice to awake patients. These medical practitioners were also involved in interpreting dreams for those who had been asleep. Patients were convinced that they would be healed by following the prescribed drugs, diet, or bloodletting. If they remained ill, it would mean their faith was low.

One of the most celebrated healing temples was on the island of Cos, the home of Hippocrates (450-380BC) a youthful man who acquired knowledge of the curative arts from his physician father. Sigeristt claims that Hippocrates is credited with injecting the scientific spirit and method into medicine (273). Following his contributions, diagnostic observation and clinical treatment started replacing superstition. Instead of blaming spirits and gods for diseases, Hippocrates held that diseases were a natural process that developed in a progression of logical steps and symptoms were the body's reaction to diseases. He emphasized that the body has its own recovery means and that the role of the physician is to facilitate these natural forces. Hippocrates considered every patient an original case requiring study and documentation. His insightful ways of describing diseases remain models for doctors even today. Hippocrates trained several individuals 
who later moved to all corners of the Mediterranean to spread his philosophies through practicing science-based medicine.

Another physician who played a crucial role in the development of Western medicine was Galen (130-200AD), one of the greatest physicians of Roman era. Galen posited three definitions of health. First, health is something that exists positively, and is not just absence of disease; second, health exists only when the functions of the body are in accord with nature; and lastly, health exists when the constitution of the organs by which human body functions are in accord with nature (1xxix). Galen became the medical celebrity of Rome after curing an emperor who was suffering from imperial fever. Unlike Hippocrates, Galen was a remarkable physician. For him, diagnosing was a fine art and in addition to caring for his patients, he responded to requests for medical services from the far reaches of the Roman Empire. Galen was so industrious that he wrote hundreds of anatomical observation books, including selected case histories and prescribed drugs. However, his understanding of human anatomy was misleading as he objected to human dissection and obtained his human analogies only from animal studies. Nevertheless, he dominated the medical scene and was endorsed by the Catholic Church. His writings and medical views became both "the law" and "bible" for pundits and pontiffs of the ensuing Dark Age when medical research was stagnated.

According to Lock and Nguyen, the foundations of what came to be known as scientific medicine were gradually set in place at the beginning of the $15^{\text {th }}$ century when anatomical dissection practice became a medical practice (25). With the collapse of the Roman Empire (476 AD), the Church became the repository of knowledge, especially of 
all scholarship that had drifted through the centuries around the Mediterranean. Medical knowledge was literally scattered and dispersed among many orders of the Church. The Catholic Church's teachings and beliefs in divine mercy made an inquiry into causes of death undesirable and unnecessary. Church members considered curing patients using rational methods as immoral interference with God's will. Use of drugs was seen as a lack of faith by both patients and doctors, and therefore scientific medicine fell into disgrace. In this regard, for centuries, medical research was minimal.

It was not until the Renaissance in the $16^{\text {th }}$ century, states Engelhardt, that a remarkable progress in the science of medicine unfolded (8). Hippocrates had once indicated that sickness was not a curse by the spirits but a natural phenomenon. During this period, older perceptions of supernatural causes of disease re-appeared and were promulgated. Nonetheless, the Reformation and Renaissance in the $15^{\text {th }}$ and $16^{\text {th }}$ centuries loosened the Church's strong beliefs in the role of faith in diseases. During the Renaissance, the need to pursue the real secrets of nature was stimulated, including medical knowledge. The study of human anatomy was advanced and seeds for more advanced study were planted by artists such as Durer, Michelangelo, and Leonardo da Vinci. The Renaissance painters studied humans in pain and sickness, and came up with amazing insight into the functions of the heart, brain, lungs, and muscle structure. They also tried to study human beings to discover their physical and emotional qualities. During this era, physicians started approaching their patients in pursuit of medical knowledge. New medical schools arose in Bologna, Padua, Salerno, and Oxford. These medical training institutions embraced the Hippocratic philosophy that the sick were 
humans, illness was a natural process, and that commonsense interventions were appropriate in helping the body in conquering diseases.

The Renaissance marked the onset of the age of measurements. In 1596, Galileo visited Padua, Italy, and lectured on mathematics to a large group of medical students. His famous inventions and theories were demonstrated and expounded upon. Using his theories, some students were able to measure the quantity of blood moving in human arteries to explain the functioning of the heart. Galileo argued in support of the use of experiments and actual measurements to provide medical practitioners with an effective check instead of using reckless speculation. Individuals involved in medical research started using scientific measurement methods in their inquiries. Pulse rate and body temperature became important measures that, linked to symptoms, helped physicians in diagnosing particular diseases. Concurrently, the microscope was developed to amplify human vision. However, new scientific instruments had little impact on the average physician at that time, and they, as Gerry reports, continued using traditional methods such as bloodletting to disperse toxins (12-13).

\section{Western Biomedicine Theories}

\section{Etiology theory}

Disease etiology has been explained in different ways across the world. Historically, before the works of Galen and Hippocrates, it was supposed that diseases were caused by an act of God. Such a divine action was considered a punishment from God for human sin. In polytheistic cultures, the disease related to gods, witchcraft, curses, demons, and astrological influences. It was Hippocrates, often considered as the father of 
medicine, who first tried to provide a rational explanation of disease in the Western world. Later, Galen tried to correlate and explain the anatomy of human beings by performing anatomical dissections on animals, mainly because dissection on human beings was prohibited. During the Renaissance in Europe, science grew by leaps and bounds and rational explanations were introduced for a majority of phenomena. Modern etiology theories like Genetic Theory and Germ Theory, which explain the cause of diseases, were also introduced.

\section{Genetic theory}

Even though there are many likely causes of diseases in human beings, family history has been identified as one of the strongest risk factors for common diseases like cardiovascular diseases (CVD), cancers, autoimmune disorders, diabetes, and psychiatric diseases. A child inherits a set of genes from his or her parent as well as a wide array of socioeconomic and cultural experiences. Family history is therefore said to be a good predictor of a person's risk for diseases because close family members, according to Kardia et al., represent the particular environmental and genomic interactions that a person experiences (144-45). Inherited genetic characteristics within families contribute both indirectly and directly to the pathogenesis of the disease. Wacholder et al. examined what is theorized about the direct relationship between cancer cases and genes to understand the role of genes in health and illness. They found that inherited genes increase individual's susceptibility to cancerous diseases (2000).

Based on their genetic contributions, human diseases can be categorized into three main categories: multifactorial, chromosomal, and monogenic. Monogenic diseases arise 
from alteration of one gene. Chromosomal diseases are caused by alteration of a number of chromosomes. For example, in a human genome, some chromosomes may not be available, some extra copies of a chromosome may be present, or particular portions of chromosomes can be duplicated or deleted. Multifactorial diseases are caused by variations in many genes, and they may or may not be influenced by the environment. The majority of human diseases are in this category. These diseases are responsible for most of the challenges in the human health system. Also known as complex diseases, these conditions include cancer, cardiovascular, diabetes, psychiatric and birth defects. Even though they are the most common diseases, they have presented the biggest challenge to health researchers, and identifying the genes that cause these diseases has proven quite challenging. Beyond these three causes, a number of alternative scenarios may also cause diseases. Such scenarios are known as epigenetics.

\section{Germ theory}

Germ Theory, introduced by Louis Pasteur in 1878 posited that diseases were caused by germs infecting human organs. This disease model serves as the groundwork of modern Western medicine. Pasteur, a French chemist, focused on the process of fermentation, including the production of alcohol in beer and wine and the production of lactic acid in sour milk. The better portion of the scientists of the time believed that putrefaction and fermentation were the results of spontaneous generation. Pasteur was able to demonstrate that yeast increased in weight as well as the concentration of carbon and nitrogen during fermentation, and maintained that yeast is a living thing that causes 
fermentation in wine and beer. He went further and identified the organisms that produce lactic acid fermentation such as bacteria.

To oppose the spontaneous theory, Pasteur carried out ingenious studies to demonstrate that fermentation does not occur in the absence of contamination by air. His work greatly improved the production of wine and vinegar and in 1865, he was requested to investigate silkworm epidemic in South of France. He also conducted a study on the spread of cholera to France from Egypt. In studying these diseases, Pasteur used the same microscopic techniques that had proven effective in his fermentation studies. Thagard claims that Pasteur made the most important leap in the history of medicine by realizing that just as fermentation is caused by bacteria, diseases may also be caused by living organisms (223). From the silkworm epidemic he moved on to other diseases such rabies and anthrax using the same microscopic techniques. Nonetheless, some microbes like the virus were too tiny to be observed by the microscopes available to Pasteur.

After Pasteur, other chemists like Lister showed the significance of living organisms in medicine. In the second half of the $19^{\text {th }}$ century, pronounced advancements were made in ascertaining new types of bacteria and showing their role in causing diseases, including tuberculosis, diphtheria, and cholera. By the end of the 1870s, chemists were no longer speaking of "the" bacterium, but of various bacteria. Concepts concerning specific types of protozoa and bacteria were developed in place of general concepts of infusoria and animalcule. Taxonomy of bacteria played a significant role in the development of germ theory.

\section{Major Aspects of Western Biomedical Model}




\section{Reductionism theory, fragmentation, and narrow specialization}

Since the times of Descartes (1596-1650) and the Renaissance (1300-1600), Sweeney and Kernick claim that science, including medical science, has taken a distinct direction in its analytical evaluation of the natural world (132-34). The new approach is rooted in the view that complex problems can be addressed by sub-dividing them into smaller, simpler, and more traceable units. Because this approach involves reducing problems into units, it has been termed "reductionism" and has been the most dominant paradigm of science in the last two centuries. Reductionism has had immense influence on modern medical science. It has also affected the way doctors diagnose, treat and prevent diseases.

In recent times, there have been noteworthy developments in disease diagnosis and treatment. This has resulted from a better understanding of the complicated process and components included in cell biology. For instance, scientists' knowledge of cell propagation pathways, as Beresford contends, has become more detailed, resulting in the development of a growing number of originally targeted therapies (722). To achieve better comprehension, scientists are using the "reductionism philosophy" in order to break down a multifaceted process into its constituent parts to allow for better analysis. Descartes is one of the famous reductionist philosophers. He held that the world is akin to a mechanical machine, which can be understood by studying each of its components individually. Since then, reductionism has been developed to include at least three interrelated themes: epistemic, procedural, and ontological. In medical science, ontological reductionism is the notion that every system is composed of molecules and 
through their interactions, they establish a hierarchy of physical, biological, and chemical properties. Procedural reductionism is the view that biological systems are effectively explored at the lowest possible level while epistemic reductionism holds that knowledge of higher domain may be lowered down to basic levels.

The relevance of reductionism theory pertains to both medical practice and medical knowledge. It influences not only how physicians investigate and explain diseases, but also how they diagnose and treat them. For instance, if a medical researcher holds that the underlying cause of a mental disorder is dysfunction in brain mechanisms or processes, particularly at the molecular level, then that disorder is often investigated comprehensively at that level. In turn, doctors classify mental disorders in terms of brain mechanisms or processes at the molecular level like depletion in neurotransmitter serotonin level. Accordingly, a mental disorder is treated pharmacologically by prescribing drugs to elevate the low levels of the neurotransmitter in the depressed brain to normal levels within the non-depressed brain.

Ahn et al. critique the limits of reductionism in medicine and argue that when the human body is perceived as a collection of various organs, the natural inclination of Western biomedicine is to isolate the single factor responsible for a certain disease. Just like a mechanic who repairs a broken vehicle by identifying the defective part, doctors typically treat the sick by identifying that isolatable abnormality (208). This practice is deeply rooted on the assumption that every disease has a single cause. Reductionism is becoming increasingly important in treating diseases such as urinary tract infection, aortic dissection and acute appendicitis, which are driven primarily by a pathological responsive 
to a particular intervention. Arguably, these conditions would be diagnosed poorly under a holistic approach, where comprehensive data acquisitions and lengthy analysis are required.

The reductionist method has been effective in explaining the chemical basis of various living processes. Regenmortel argues that the reductionist approach, though successful during the early days of molecular biology, ignores the role of psychological and social factors in the causation of disease (1017-18). Cohen and Tracy conducted a literature review that provided biologically and psychologically plausible explanations of how psychological factors can influence immunity and mediate diseases. This literature review provided substantial evidence that psyche factors such as negative affect, stress, lack of social support, denial and clinical depression, though ignored by reductionism theory, can influence both humoral and cellular indicators of immune function and status. Cohen and Tracy found a convincing relationship between negative effects and stress as well as the onset and progression of less serious infectious diseases such as herpes, colds and influenza (1996).

Biomedicine's theory of disease causation does not address or provide answers to existential questions about our place in this universe, the aim of our lives, etc. which is something many patients when inflicted with disease seek and consider. Moreover, the aim of biomedicine is curing and not healing. Today, patients search for healing and curing. Erickson differentiates between these two and states that healing is the restoration of physical, mental, emotional, social, and spiritual health. However, curing is removal and correction of organic pathology (192). 


\section{Health Care Capitalism}

In the Western world, and most specifically the US, there is endless debate about the issue of ever-increasing health care costs. In almost all capitalist economies, diagnosis and treatment of diseases is essentially a profit-driven business run by insurance companies promoting new technologies, cost-saving measures, and drugs to maximize profits. Since the 1980s, neo-liberal capitalism has converted patients into sources of revenue by the medical system. Capitalist economies are insensitive to the modern health care system which is increasingly inaccessible to many poor and middle-class people. Those who are lucky enough to have health insurance are paying increasingly more and receiving fewer benefits in a bid to maximize profit and minimize expenditures. In the US, Noah asserts, there is an increasingly complex tension between hospitals and insurers over who pays hospital bills (2007). The end result is that the US pays about twice as much per capita for health care as the United Kingdom (UK), France, and Canada, yet the US has slightly lower life expectancy than these countries and significantly higher infant mortality. These problems are associated with the growing competition among the US health institutions in their striving for more profit.

Over-reliance on technology

Any new medical technology or drug that actually 'cures' a disease has an effect on the profit of the entire medical system. Even though new technologies have increased the cost of health care, they have succeeded in many cases in improving the quality of 
life. Modern technologies such as better monitoring systems, minimally-invasive surgeries and more comfortable scanning equipment have enabled patients to spend less time in the recuperation process. Modern technologies have also made robotic surgeries possible, implying that doctors do not even need to be in the operating room when surgery is being performed. Doctors are currently relying on technology in most of their practices. Today, surgeons can operate out of their "home base" and patients may have the procedure done in clinics and hospitals close to their homes, and in effect eliminating the stress and hassle of health-related travel.

Although machines have the ability to do much of what doctors do, they should not replace doctors. Nonetheless, doctors should embrace them. Computers are now being used in making diagnosis and treatment better than the average clinician is while putting into consideration many factors and making fewer errors. The role of a physician is multifaceted. It is not just used for clinical knowledge or data. It includes making judgments, communicating with the patient and recognizing patterns. Most importantly, the role of a doctor is to use clinical knowledge to suit the patient's needs within the prevailing regulatory and ethical framework. Robots or computers or algorithms may be able to do some of these roles, but not all. These days, people come from very diverse backgrounds. Therefore, machines, no matter how good they are, are far away from being able to handle human complexity and cultural difference. Diagnosis is more than a systematic reliance on numbers and equations. Even when pain is discussed, it is mainly on a range from one to ten. Qualitative questions are replaced by quantitative questions and yes/no ones with an ensuring loss of complexity and uniqueness. 
In addition, biomedicine pays little attention to the body's innate ability for selfhealing and is related to the knowledge and power that doctors prefer to claim as their own. This ability, as Erickson states, is downplayed in favor of the interventions of pharmaceuticals, surgery, and biotechnological innovations. This natural tendency to selfheal, Erickson affirms, is augmented by many ethno-medicines and is mediated by the mind-body connection (193). Assumption of scientific neutrality and rationality

Western biomedicine is founded on the assumption that scientific methods, claims, and results are objective. Put differently, scientific claims, methods and results are not influenced by value judgements, particular perspectives, personal interests, or cultural community, to mention but a few relevant factors. As an evidence-based science, in Western bio-medicine, objectivity is considered as the ideal for scientific research. Guyatt et al. defined evidence-based medicine as a medical practice that de-emphasizes unsystematic clinic experience and pathophysiological rationale as grounds for medical decisions and emphasizes examination of evidence from clinical research. The scientific approach has replaced subjective, idiosyncratic, error-prone traditional judgments through systematization of inquiry to promote accuracy (2420-22). However, this approach has belittled and subsequently marginalized the subjective world of the patient with its social, personal, and spiritual tracks. Biomedical physicians, proclaims Erickson, treat a decontextualized and often dehumanized individual physical body, sometimes even a part of a body (188). Biomedicine stops at the scientific explanation of illness 
leaving questions of why and how humans bear the misfortunes of illness to other realms like religion and psychiatry.

\section{Mind-body dualism}

Before the emergence of Western biomedicine, quasi-religious views of illness and health were dominant and disease was associated with penance, sin, and immoral spirits and behaviors. During this time, the body and soul were seen as one sacred entity that was beyond the power of human intervention. Nonetheless, the view of the human body as a machine marked a noteworthy turning point away from spiritual notions towards a secular outlook of the human body. Scientific innovations - especially through autopsies that associated the unhealthy body organs with signs detected before death and Pasteur's germ theory - finally introduced a belief in the difference between mind and the body. In the circles of philosophy, this came to be referred to as mind-body dualism, also known as Cartesian Dualism, named after Rene Descartes.

According to Fernando, the proposal made by Descartes in the $17^{\text {th }}$ century that mind and body belong to two separate and independent realms set the stage for Western thinking about the mind (30). Descartes stated that even though the mind and body interact with each other, they are distinct entities. Thus, the brain is seen as part of the physical body while the mind is believed to exist in the spiritual world and was seemingly evidence of a God-given soul. Such separation provided a philosophical validation of secular intervention on the physical body in form of medical therapies. Descartes argued that the mind can be studied to understand introspection of the body using natural science methods. Due to the fact that the body was seen as a mere vessel for 
the immortal spirit or soul, medicine could easily focus on the body while religious convictions could concentrate on the soul. The assumption of mind-body dualism became the basis for Western biomedicine where the disease was situated in the physical body, and thus the mental state, or mind of an individual, was considered insignificant. Also, focusing narrowly on disease saves time and effort by reducing the patient to the affected organ.

Dualism theory is one model that has been associated with the poor integration of psychological and social factors in Western biomedicine system. Adversaries of this model view it as a decisive philosophical issue, which radically separates the realm of body and realm of a mind in both practice and theory. One of the things driving popular interest in alternative medical systems in the West is the ability of other ethno-medicines to address the domains that remain outside the biomedical purview. Erickson argues that Westerners today are increasingly seeking a reintegration of mind and body; thus, aiming to restore balance and harmony in their lives (192).

Health equals absence of disease or definition of diseases as deviation from 'normal' biological functioning of the body

WHO has provided a holistic definition of health. According to "Constitution of WHO Principles", health is a state of social, mental and physical well-being, not merely the non-existence of disease (2005). This much-cited definition shows that there is a wide range of biological, psychological, and social factors that influence human health. Furthermore, health needs to be conceptualized as not simply the absence of disease, but rather in the positive sense of well-being. Although this description has been criticized 
for its vague notion and utopia of complete well-being, it is important because it highlights the necessity of a broader approach to health than the one by the Western biomedical model. Spector underscored this definition by arguing that health is the balance between a person's wellbeing - physical, spiritual and mental - and in the outside world - metaphysical, communal, and natural (76). Foucault argues that man can be treated as independent systems of discourse, but he did not give up his earlier position that social institutions influence this practice (13).

The Western biomedicine model defines health as the absence of disease and disease as a deviation from the normal functioning of the body. To physicians in Western countries, the major basic signs of a disease include suffering, pain and discomfort. Generally, a disease in the Western world accounts for human suffering by inflicting discomfort and pain, sometimes intolerable, thus requiring medical intervention. This argument has been criticized because there are a number of natural and cultural procedures that cause discomfort and pain but are not diseases, such as menstruation, circumcisions, stress, depression, teething and childbirth. Pain is an experience, a narrative, a cultural realm that cannot be easily quantified and thus understood exclusively in numbers and equations.

The central objective of Western physicians, claims Taylor, is the alleviation of human suffering associated with injury and illness (556-57). The extensive recognition of the Western biomedicine model's shortcomings, from those outside and within the medical profession, has resulted in the development of a variety of multifactorial models such as the web of causation model, bio-psychosocial model and ecological model. While 
this new model represents a substantial advancement on the Western biomedical model in recognizing the multiple determining factors of health, to a greater extent, they remain dedicated on health interventions directed to an individual, especially through behavioral and lifestyle changes and health education. Baum et al. argue that what is needed is an explicitly social model of health capable of providing effective health interventions at individual and community levels (429-30). Under a number of influences, health service professionals are renegotiating approaches to health, placing more emphasis on "disease prevention and health promotion" (3). This reorientation obviously requires a stronger focus on the impacts of social, environmental, and economic factors on health, and creation of inter-sectoral links to achieve these goals. Also medical schools have started ten years ago to integrate prevention education into the medical school curriculum. Departments of family medicine--including departments of family and community medicine, departments of family and preventive medicine, and departments of family practice at US medical schools regularly participate in teaching prevention principles to students, using a variety of formats and methods.

There are no universally accepted definitions of health and disease. However, the holistic definition provided by WHO has been central to literature related to the meaning of disease. The WHO definition presents three major components of health - physical, social and mental. The biological or physiological component of the definition implies soundness of the physical body. Often, disease involves malfunction of a body organ or intrusion of harmful organisms like parasites. The social constituent includes the spiritual and behavioral aspects of human health. In defining health, Larson holds that WHO 
understood the role of social interactions and behavior in influencing human health (124). The mental constituent includes the emotional, psychological, and mental status of a human being. Emotional fixation, apathy and maladjusted personality are part of the manifestation of a disease.

\section{Patient-centered care}

Over the last three decades, patient-centered care in Western countries has been a notable development in an effort to promote health and human wellness. The allembracing philosophy of patient-centered care is described by collaboration between the health-care provider and the patient in developing a treatment plan that addresses all the interests of the patient and all practices recommended by the doctor. For this collaboration to be achieved, doctors must listen and empathize with the patient's experience. Patients, as Kleinman affirms, differ in the way they experience, think about, and respond to diseases; they have different experiences with illness (8). Therefore, doctors must respect patient's opinions and thoughts and consider them in making recommendations. Under patient-centered care, illnesses are viewed from a biopsychosocial perspective. This implies, according to Gorske and Smith, that reductionism is given less emphasis and more focus is given to multiple factors (psychological, biological, environmental, and social), which play a role in the development of a disease (11). The patient is considered as a unique individual and therefore, has a unique understanding of an illness and what it means in their lives.

Patient-centered care has helped in promoting the egalitarian relationship between patients and doctors. The historical view of doctors as "all knowing" has been replaced 
with a collaborative model of "patient-doctor cooperation and collaboration" (Saha et al., 1284). This has made doctors to respect patients independently and to view them as active decision-makers in their own medical care. The key ingredients of patient-centered care are the abilities of providers to see the patient as an exceptional person, build effective rapport, maintain unconditional positive regard, discover patients' values, beliefs and meaning of the disease, and find shared ground in making treatment plants. Patient-centered care also includes a set of skills and knowledge that a health care provider should possess to be able to accomplish his or her tasks. These skills include understanding the functions and stages of medical interview and ability to promote patients' physical and psychological comfort.

Despite the benefits associated with patient-centered care, nothing much has been realized in reality. Livingston, Alicia and Brink examined the existence of patientcentered care in forensic mental hospitals (2012). They found that the forensic mental health service is predominantly driven by physician-led treatments and that they include biological reductionism. For this reason, patient-centered care has not been prioritized in forensic mental health institutions. Kleinman argues that even though many comparative and ethnographic studies start with a holistic definition of health, most psychiatric and medical researchers still isolate social reality in their practices. Social reality includes interactions existing outside an individual and between individuals. It is important to study the relationship between health and cultural settings that shape health care systems (34-35). There are increasingly many proponents for patient centeredness in health care like Fadiman, Kleinman, Leninger, and Spector. This shift in health care started in the 
1970s and was mainly fueled by the Women's Health Movement which was propelled by women's demand for knowledge about their bodies and greater control over their health care. This feminist movement permanently changed the provision of health care in the US. The movement took feminist tenets about empowerment and challenging patriarchal structures in a new direction to give women increasing control over their bodies, and especially their reproductive systems. Instead of being passive clients of a medical system dominated by men, women challenged doctors' carefully guarded monopoly on medical knowledge. Since the 1990s, the movement has been carried forward and expanded through the concept of reproductive justice based on a broad human rights perspective and is still active in the Western world, thanks to many scholars, medical anthropologists, nurses, doctors, social workers, feminists, and social justice activists. One of the anthropologists who attempted to fill a gap in the anthropology of US society about the understanding of reproduction and its roles in women's lives is Emily Martin in her book The Woman in the Body: A Cultural Analysis of Reproduction (2001). The book with its field work study is not only a cultural analysis of the perception and experience of various reproduction-related issues in women's bodies. It is rather a sociopolitical analysis and an appeal for liberation from the prejudices of biomedicine, sexism, racism, and class oppression.

\section{Major Aspects of Islamic Medical System}

\section{Health as a bounty - test of patience or purification of soul}

Pamela Erickson indicates that ethno-medical beliefs about the causes of illness have provided alternative theories of sickness, health, and treatment approaches in the 
non-Western world (188). In the Islamic context, disease does not always connote a negative or bad event. However, many Muslims believe that good health is a gift from God. In this regard, a human being must be grateful to God to get the gift of good health. This gratitude should be in form of doing a good thing and worshiping God. People often tend to take God's gifts for granted and therefore, fail to be grateful. They only understand the importance of the gifts when they are taken away from them. A typical person may fail to appreciate or understand the importance of good health when he or she is healthy. After falling ill, the value of healthy body is appreciated and is understood but most often, for a short time span. Everything is forgotten once the disease is over. Therefore, disease is perceived in Islam as an opportunity to remember God's blessings and regard them as valuable.

For many devout Muslims, diseases are perceived as a test of patience. These Muslims believe that human destiny (qadar), is strong. Although in some cases qadar can result in fatalism, and in other cases, it is believed, as examined by Nabolsi and Carson, to suggest positive acceptance of God's will as well as hope for God's healing ability (2011). Illness, state Padela et al., is also seen as an opportunity to reconstruct humans' connection with God or lack of faith acquired through consistent prayer and a sense of self-responsibility (847-48). Therefore, it is not weird to see many practicing Muslims when afflicted with pain or illness to be welcoming and happy to their guest. Enduring pain is one way of attaining reward from God. Practicing Muslim patients bear illness faithfully to prove for God their belief in qadar and their contentment with their fate. Prophet Muhammad said in a hadith: "Any fatigue, or disease, or sorrow, or sadness, 
or pain, or distress that befall a Muslim, even if it is only the prick he receives from a thorn, Allah expiates some of his sins for that" (Saḥịh Bukhārī Vol.7; Hadith 544).

Spiritual leaders, Imams, (the imam leads Islamic prayer and services but may also take on a larger role in providing community support and spiritual advice), are often considered as indirect agents of God's will and key facilitators of the healing process as reported by Abu Ras and Abu Bader (2008). Imams are also believed to play a role when it comes to shaping community and family responses and attitudes to illness. Abu-Ras and Abu-Bader interrogated 22 Imams and 102 believers from 22 mosques in New York and found that imams play a significant role in promoting mental health. In a different study, Ali, Milstein \& Marzuk found that 95 percent of 62 Imams interviewed spend much of their time counseling their followers (204).

Turning to religiosity through faith, recitation of Qur'an verses, supplication, prayer, thankfulness to God and people, and exercise of patience, all play important role in enabling many Muslims to cope with role-conflict and life problems as examined in a study conducted by Achour et al. (2015). Therefore, the quality of life and body health may be enhanced through these practices. Strong imān (faith) and trust in God play a major role in the healing process. Regardless of which religion, faith can change the very perception of disease symptoms. For example pain is, to a certain degree, subjective. So is how we respond to it. A believing person who trusts in God may feel less pain from an injury than a non-believer with the same injury. Reading a religious text such as the Qur'an daily and trying to understand its meaning motivates people to better cope with both illness and psychological problems. In fact, recitation of the Qur'an brings about 
better feelings enhancing the ability to make a quality decision. Devout Muslims think that God listens and responds to prayers. Therefore, Muslims are taught to turn to God for help to better resolve and manage difficulties. Repenting and asking for forgiveness from God while trusting in him are both important for a balanced and healthy life.

\section{Four health components}

In Islam, health is understood to have four components: physical health, spiritual health, mental or psychological health and social health. Spiritual health includes upholding the right relations with God-the-Creator. God in turn orders relationships with other people and the environment. Health in a mental sense is keeping physiological function in the optimum situation. Being aware of risky behaviors and conscious not to indulge oneself in vicious paths which distract oneself from proper functioning. Psychological health constitutes being aware of and at peace with oneself and the social environment around. In a social sense, health means harmonious working in the social milieu, including take-and give-relations. These various components of health are interconnected or inter-related and are closely inter-reliant such that a challenge in one may easily result in disequilibrium of the others.

\section{Holistic outlook}

In the Muslim tradition, health is perceived in a holistic sense. The components of good health are physical health, spiritual health, mental or psychological, and social health. If a particular part of the body is unwell, then the entire body is sick. To them, if one member of the family is sick, then the whole family is sick as all the members are affected psychologically and emotionally. Any disease outbreak in the community has 
some negative implications for all members of the affected community. The holistic view also means that psychological, mental, emotional, physical, and spiritual health are considered together. An individual who is emotionally sick will sooner or later become physically ill. The various components of health are inter-related and closely interdependent such that a problem in one can easily lead to disequilibrium in others. If any part of the body is sick or not feeling well, the whole body is sick.

Unlike Western societies, many Muslims view health or 'afiyah as something holistic. Holistic health focuses broadly on all the factors needed for health, including exercises, nutrition, hygiene, attitude, emotion and relationships. Holistic medicine is a form of healing that considers the whole person -- body, mind, spirit, and emotions -- in the quest for optimal health and wellness. According to the holistic medicine philosophy, one can achieve optimal health -- the primary goal of holistic medicine practice -- by gaining proper balance in life. The approach used in most of the Western world concentrates more on the alleviation of symptoms. The alleviation of symptoms is likely to ignore the root causes of the symptoms and even uses medicines that actually reduce symptoms but compromise the overall health. However, recently there have been growing demands from patients across the US for implementing holistic health care. Growing interest in holistic healing is contributing to personalization in care delivery. Personalized care, asserts Erickson, is revolutionizing the patient care process across the US. Westerns seem to be seeking nowadays a reintegration of mind and body and to want their health care system to address relationships to the social, natural, and supernatural 
worlds. She believes that perhaps they are seeking restoration of harmony and balance in all four domains of their lives (188-90).

Holistic health means taking all aspects of health into account. In general this is mental, emotional, spiritual, energetic health and physical wellness. By being healthy in all of these aspects you can create better overall wellness and move towards homeostasis (which is considered to be total health). Examples of the holistic approach to health are:

- Physical Wellness - the foundation of health.

- Holistic Medicine - herbal remedies, holistic pain management, detox practices.

- Holistic Nutrition - dietary practices or habits, supplements, cooking styles.

- Mindfulness Meditation - deep breathing, visualization, object focus.

- Energy Healing - massage, reiki, acupuncture, qigong.

- Holistic Homemaking - feng-shui (a Chinese geomantic practice in which a structure or site is chosen or configured so as to harmonize with the spiritual forces that inhabit it), eliminating indoor pollution, creating tranquility.

- Global Citizenry - community involvement, finding your purpose, reducing environmental impact, compassion for others.

A holistic doctor may use all forms of health care, from conventional medication to alternative therapies, to treat a patient. For example, when a person suffering from migraine headaches pays a visit to a holistic doctor, instead of walking out solely with medications, the doctor will likely take a look at all the potential factors that may be causing the person's headaches, such as other health problems, diet and sleep habits, stress and personal problems, and preferred spiritual practices. The treatment plan may 
involve drugs to relieve symptoms, but also lifestyle modifications to help prevent the headaches from recurring. According to "Holistic Medicine: What It Is, Treatments, Philosophy, and More", holistic medicine is also based on the belief that unconditional love and support is the most powerful healer and a person is ultimately responsible for his or her own health and well-being. Other principles of holistic medicine include the following:

- All people have innate healing powers.

- The patient is a person, not a disease.

- Healing takes a team approach involving the patient and doctor, and addresses all aspects of a person's life using a variety of health care practices.

- Treatment involves fixing the cause of the condition, not just alleviating the symptoms (2017).

Islam is guided by three principles which occupy a central position in Islamic theology: tawhìd (oneness), wasatiyyah (moderation), and shumuliyyah (comprehensiveness). Tawhīd is the most essential component of Islam as it stresses the one-ness of God. Tawhīd motivates looking at the patient, the disease, and the environment as one system that is in equilibrium. Thus, all factors related to these three elements are considered while making decisions. The second concept, wasatiyyah motivates the need for moderation and not doing anything in excess. This explains that healing approaches in Islam are sought from various sources. Invasive procedures, for example, are encouraged if used in moderation to avoid putting the body to risk. The third concept, shumuliyyah (comprehensiveness in the perception of microcosm and 
macrocosm) extends the first one by requiring an overall comprehensive view of the disease and treatment situation. This explains the perspectives of many Muslim that there is unity, harmony, and inter-connections among different forms of life and the physical world. In Islamic thought, the human being is conceptualized as an integrated entity. Therefore, his/her health not only consists of each single dimension, but also the full health together with the health of society gets meaning in a balanced and coordinated set. God has definite purposes from creation and that human life must fulfill those purposes. God defines this purpose in the Qur'an: "I have created the jinn and humankind only for My worship.” $(51.56)^{10}$

\section{Health is relative and subjective}

Conceptualizations of what constitutes health are subjective and relative. They are influenced by age, gender, norms, state, place, and environment. For example, due to stress and trauma, Fullilove claims that displaced people or refugees are likely to suffer from various mental disorders (1516). A physical state that may be considered healthy in a young one may not be so in an elderly person. The norms and conventions of what constitutes good health change from culture to culture and even in one place may vary from generation to generation. The subjective feeling of good health varies by gender. Generally, women are more worried about diseases than men are. Those who strongly believe in God may feel subjectively healthier compared to those who lack these attributes.

\footnotetext{
${ }^{10}$ Jinn are supernatural creatures found in Islamic and Arabic writings, particularly the Quran. The Quran says that the jinn were created from a "smokeless and scorching fire," separately from humans or angels. However, they can appear in human or animal form to interact with people.
} 


\section{Close relationship between physicians and patients}

The doctor-patient relationship is closer in the Muslim-majority states than in modern Western world due to traces of Galeno-Islamic medicine and its emphasis on the role of the hakim (physician). Many doctors practicing in the Muslim majority states inherited this ethical role of the physician and believe that they must fulfill this role. Also Muslims' medical ethics highly recommend that the physician be responsible for alleviating suffering, assisting the patient to withstand the agony of illness and to find the right balance in his/her life. As mentioned previously, the physician, according to Galeno-Islamic medicine, is the one who cures not only physical pain but also spiritual pain. He feels the pain and his touch is valuable whether in diagnosing, treating, or in creating empathy and trust with the patient. In this regard, ethical guidelines in Islam are obtained from a collection of rights, duties, and principles that govern the practice of medicine and the role of the physician. Today these guidelines fall under the name of Islamic bioethics. Moreover, many Muslim practitioners in the Muslim majority areas abide by and respect what is permissible in Islamic bioethical laws regarding treatments, interventions, and nutrition. Saving a life is considered one of the highest imperatives. The Qur'an states: “And whoever saves one (life) - it is as if he had saved mankind entirely" (5.32). Al-Rāzī (865-925 CE) and Al-Ruḥawī, $9^{\text {th }}$ c-prominent Muslim physicians, involved themselves with medical guidelines and ethics. The two wrote medical books over a thousand years ago. In his book, Akhlà' al-țabìb, al Ruhawī wrote about the doctors' responsibilities to their patients, some of which are to treat sick people kindly, not to be aggressive or rude and to be compassionate, soft-spoken, and behave 
modestly (qtd. in Barakat, 130-33). Physicians are supposed to inspire their patients, even those who have lost hope of recovery. Chamsi Pasha and Albar add that another duty of physicians highlighted by Al-Rāzī is treating all patients equally irrespective of their social status or wealth. The aim of a doctor should not be the payment made after treatment but to heal. Doctors need to be as keen on treating the needy and poor as they are in treating the wealthy (122).

In the Galeno-Islamic medical tradition, the pulse was a keystone of the medical art since it revealed the condition of health, disease, and the states in between. As such, the pulse was a fundamental diagnostic, prognostic, and therapeutic aid to the physician. To the trained physician's discriminating touch, the pulse sounded imbalances in both body and soul. Therefore, the doctor in early Islamic medicine till present, is called hakim. A hakim, according to Farage, is one that possesses wisdom and is far-sighted and can cure not only ailments of the body, but also disorders of the soul (25). This clearly explains why medicine and philosophy at that early time were wedded. The pulse is a cornerstone for building trust with the patient.

In Western biomedicine, informed consent is seen as a cornerstone of the doctorpatient relationship, and it has been acknowledged as a legal obligation to the medical profession. Medical practitioners are required to obtain informed consent from patients themselves or their legal guardians in cases involving minors or mentally deficient patients, before undertaking any surgical or medical procedure. Physicians must provide a clear explanation of the planned procedure, potential risk, intended benefits, and any 
likely complications. Seeking informed consent is done in observance of the individual rights of a patient.

\section{Patient's autonomy and privacy}

Islamic law respects the privacy of individuals: "He has commanded you to worship none except him. That is the right religion, yet most people do not know" (Quran 12.40). Therefore, the necessity of this basic and obvious principle is that people have no sovereignty over each other's lives, possessions and personal affairs except the case that for such sovereignty enough sensible reasons based on Islamic religious law are offered. To observe the autonomy of a patient, the doctor should have deep knowledge related to the cultural behavior and values of his or her patient. Among many Muslim patients, depending on level of religiosity and cultural background, absolute autonomy is very rare, and every person has a feeling of his or her responsibility toward God, which is greatly influenced by their relatives and the community. Muslims value kin relations especially that of the parent-children and the husband-wife. In many cultural contexts among Muslims, the nuclear family is regarded as a unified decision-making unit and all family members are expected to have a voice in discussing any member's health issues. This is a big jump to laying out some of the issues about which medical practitioners dealing with Muslim patients should be aware of.

Doctors treating devout Muslims should be aware of religious considerations with respect to fasting and Ramadan. They should know that during this holy month, many Muslims prefer to take medications after breaking their fast or before starting it at dawn. So, Western-trained physicians, if possible, should customize the medication accordingly. 
It is not mandatory for Muslims to fast if sick or have to abide by certain medications. However, if a Muslim patient is able to fast while sick and taking medications, physicians should respect that and understand the religious background of their patients. Fadiman in her seminal work on the Hmong and the health care system in the US, demonstrated how cultural barriers between health care teams and patients affect the success of a treatment plan (2000). Many scholars have proposed changes in the health care system that address and respond to cultural differences among health care providers and patients. A

pluralistic medical system that approves and responds to various cultural preferences and perspectives has been advocated by many scholars and health care professionals. Ethnic similarity between minority members of a society and their physicians is, according to Shaw, the most regularly quoted aspect of culturally suitable health care in public health policy literature (524).

\section{Religion and gender sensitivity}

Muslim culture is generally poorly understood in the Western biomedical system. Issues about modesty such as gazing and touching people of opposite genders are very important for devout Muslim patients. For instance, many practicing Muslims often do not shake hands with members of the opposite sex. Instead, greetings are conveyed by placing the hand over the heart. Thus gender can play a critical role in shaping the doctorpatient relationship when the patient is a devout Muslim. For a Muslim woman, for instance, it can be very stressful to expose her body to a male physician or to discuss sensitive issues. Accordingly, as Yosef states, some Muslim women fail to disclose their health concerns and issues to male practitioners (286). Inhorn and Gamal assessed how 
Islamic religious culture influences medical practice and how immigrant Muslims experience and view medical care in the US (936-37). Because of their experiences, many Muslim immigrants want to be treated by health care providers who are Muslims. Even though Islam does not require Muslim patients to seek medical attention from a Muslim, many Muslims prefer to be attended by fellow Muslim doctors, based on the supposition of shared religious orientation and cultural background. Sensitivities of Islamic beliefs have key implications for the effective delivery of medical care. For instance, a Muslim doctor is projected to understand the treatment and dietary restriction of Muslim patients like the prohibition of substances made with alcohol or pork. According to "Rules Regarding Looking, Touching and Examining" in medical issues, if there is no availability of female clinicians or health care providers who are reputable and qualified, Muslim women are allowed to seek male clinicians but preferably with male company from their families and that she uncovers only the diseased part of her body.

\section{Critiques of the Western Biomedical System}

Even though the Western biomedical model represents a major improvement in the understanding of the causes of disease and has led to the introduction of effective medical interventions, it has come under some criticisms from scholars within the medical field and from a wide range of behavioral, anthropological, and social disciplines like psychology and sociology. For instance, the idea of particular etiology applies to a limited range of infectious illnesses. A majority of diseases are an indirect consequence of a collection of circumstances but not a direct result of singular determinant factors. Moreover, not all individuals exposed to a contagious disease actually contract it. For 
instance, a group of people can come into contact with another one suffering from a contagious disease like flu, but only a few will contract it This implies that, contrary to the Western biomedical view, disease causation is complex and probably includes multiple factors like physical condition, nutrition, immunities, and stress which influence an individual's susceptibility and vulnerability to a certain disease.

The understanding and treatment of pain is a prime example of the criticisms that have been launched against the Western biomedical model. In the Western biomedical system, pain is understood as an important symptom that signifies a fundamental pathology. Western medical ethics require that pain be alleviated or avoided as much as possible. In this approach, pain is viewed as an adverse sensation that may be avoided or alleviated. This led to overuse of opioids and fueled the current crisis of addiction. This orientation neglects the significance of psychological factors in illness and health. Nonetheless, investigators have found it important to widen the definition of pain to go beyond these bio-medical confines. Melzack \& Wall proposed the gate control theory of pain, which holds that pain is not a mere sensory process under which the nervous system responds to a harmful substance or contact directly. Instead, the gate-control theory holds that outlying pain signals are moderated as they pass through the spinal cord to the brain stem, using a multifaceted inhibitory feedback system that can modify the perception of pain (972-75).

Melzack \& Wall's definition contains a psychological dimension, and the likelihood that pain cannot always indicate tissue damage. In fact, it has reinforced the biopsychosocial model of pain introduced in the 1980s as a response to the inability of 
the Western biomedicine model to address chronic, stubborn pain and combat painrelated disabilities. Certain earlier biomedical success in acute pain management had provided some assurance in the contention that pain can be addressed entirely through organic methods. However, chronic pain became an obstacle. Duncan holds that it is now incorrect to relate any disability related to chronic pain only to pathological and bodily impairments (512-13). In its place, the patient's behavioral and psychological responses to pain should be considered as an integral part of the problem. Moreover, any theory of chronic pain must contain the cultural, familial, and socio-political context of the patient. There have been various attempts to quantify pain as a physiological phenomenon, but none have proved effective enough to replace self-reporting. Pain cannot be measured with numbers alone because it is something that defies numbers and is related to deep human experiences, feelings, and interactions.

Psychosomatic or holistic medicine has been advocated as a corrective mechanism to the limitations of the Western biomedical system. One of most recent holistic version is the "biopsychosocial approach" that gives equal consideration in treatment and diagnosis to social, psychological, and biological levels in a natural organization. This approach is based on the integration of psychosocial information with medications. The present-day use of the term "psychosomatic" includes two conceptions: the role of psychological factors in causing illnesses and the holistic view of the human being. Whatever acceptance these two conceptions have gained in professional and lay circles, psychosomatic medicine has had very little impact in Western biomedicine. Psychosomatic diagnoses work by creating a reality of what it intends to describe. In 
cases that lack empirical evidence, psychosomatic explanation forces a link between the body as object and mind as a subject. When doctors make psychosomatic analyses, socially objectionable parts of the self (emotions) are split off and identified as causal agents for the patient's illness. In this manner, both the patient and the physician work together in addressing the problem.

The Western biomedicine model is based on a mind-body dualism that aims at repairing the "broken fragments" of the machine-like human body. Because illness is considered as something that may be accurately observed and treated, it may result in the objectification of patients as cases, bodies, or diseased instead of treating unique individuals who hold particular desires. This criticism often underscores the claim of doctors' poor communication and interpersonal skills. Medical scientism may also arise, and this involves the reverence of scientific approaches of observation and measurement as superior to understanding and treating diseases. These may result in dismissal of patients' feelings, thoughts, and subjective experience as they are considered unscientific.

A further reproach of Western biomedicine is its reductionism. Development of medical science has resulted in a growing focus on smaller and smaller segments of human biology as the cure and cause of illness - from physical organs to internal organs to cells to genetic materials. Ahn et al. argue that by reducing disease focus to molecular, biological, and genes levels, Western biomedicine has downplayed or ignored the psychological and social aspects of the disease (208). This has made the experience of disease to be treated as if it took place in a social vacuum. Most importantly, it has marginalized the importance of social support networks and ignored the influences of 
social factors like poverty, poor work environment, and discrimination in influencing a person's mental and physical health. Seabrook argued that the social support provided by kinship relations and neighborhood conviviality are important in a patient's recovery process (270).

Another criticism related to reductionism is the increasing number of medical professionals such as heart specialists (cardiologists) and eye specialists (ophthalmologists), grounded on the assumption that every part of the body can be disengaged from other parts. Such an attitude has resulted in excessive spending on medical technology, drugs, and surgical procedures. It has also fueled interventionist and curative prejudice in medical care at the expense of equally workable non-medical and prevention alternatives. This trend of reductionism is highly problematic when it comes to Muslim patients who come from Muslim-majority states where the patient is allowed to address all pains to his/her physician regardless of his/her specialty. It is perceived that these numerous pains in different body parts are often related to mental, psychological, or social factors.

Even though reductionism theory produces a comprehensive understanding of disease in mechanistic or molecular terms, many patients and clinicians are dissatisfied with it. Both doctors and patients hold that the theory excludes essential information related to the nature of the disease. Instead of simply treating diseases, information related to the nature of the diseases is important, especially in the treatment of chronic cases. Often, patients feel as if doctors have reduced them to their diseases or to their own affected body parts. Patients prefer an approach to medical knowledge and treatment that 
involves their disease experience. Instead of striving to restore the patient to his or her pre-illness state, doctors in Western biomedicine should aim at assisting the patient in defining what the disease means for their life.

Western biomedicine also includes racial component. Hoberman asserts that racial characteristics have been assigned to various diseases (sickle-cell anemia, cystic fibrosis, etc.), organs, personalities, and age groups. It is against this backdrop that the Western biomedical system is facing significant hurdles in trying to address cultural competence in its ranks. Nonetheless, its failures have more to do with the disproportionately small number of physicians from minority communities. Hoberman calls for recruitment of medical students from minority ethnic communities and training physicians to give patients from minority communities access to routine preventative health care (154-157).

The last criticism of the Western biomedical model is that it often results in victim-blaming by tracing the cause and cure of an illness solely on an individual. Instead of asking why diseases occurred and trying to remove the conditions that resulted in a disease, Western medical researchers spend much of their time trying to understand the natural mechanisms through which illnesses function so they can prevent them. This makes the victim's body the focus of a treatment process. In effect, illness and health become primarily a victim's duties. The excessive preoccupation with handling the victim has the likelihood of legitimizing a victim-blaming tactic to illness. This either would be by advancing the thinking that poor health is an outcome of poor genetics or a result of poor lifestyle or bad behavior. By overlooking the social context of illness and health and consequently placing the main responsibility within an individual, there is 
very little appreciation of the role social responsibility plays when it comes to creating a healthy working environment and healthy living. Also, a patient is reduced to his/her affected body organ and his/her body is a territory of war between the disease and the medical intervention.

\section{Critiques of the Islamic Medical System}

Adib believes that it is challenging to define clearly the exact composition of modern Islamic medicine (697-98). Nonetheless, many beliefs, perceptions, and activities associated with Middle-Age-Islamic medicine have been carried out and financed by health organizations, particularly in Gulf countries and in some Middle Eastern and Asian countries. To assess the overall ability of the Islamic medical system as an alternative to the modern Western biomedical model, it is important to note that the Islamic medical system accepts the validity of the Western biomedicine model. Almost all Muslimmajority countries rely on the biomedical system. Today this system is hegemonic globally due to many factors like travel, trade, war, imperialism, conquest, colonialism, and globalism. In fact, Muslims in the Middle East and the Gulf region prefer to be eclectic and choose among various systems including biomedicine, Islamic, folk, Ayurvedic, etc. Moreover, a number of Islamic medical meetings and publications seem to concentrate entirely on demonstrating the consistency of modern practices and concepts with Islamic holy texts. It is doubtful that many Muslims resist using Western medical facilities when diagnosed with serious diseases, and those using Islamic health centers in developing Islamic countries may be doing so because of convenience rather than conviction. Currently, there is no purely Islamic-medicine-training institution in the 
Arab and Muslim-majority world. However, there are many health care facilities which offer many of the treatments and recommendations from classical Islamic medicine like cupping, holistic care, spiritual and faith healing, and alternative medicine etc. beside biomedical services. Also, as mentioned previously, many Muslim patients as well as physicians seek a close relationship between doctor and patient beside their perception of pain, touch, balance, and harmony in the realm of health and illness.

Facilities set aside for health services are run by self-taught medical practitioners and herbalists with little governmental oversight, regulation, or control. Found nearly in all Islamic societies, these practitioners assume to base their practices on holy texts. The intervention of these practitioners is often sought when the sick or their family members suspect an evil spirit to be the cause of a disease. No available data shows historical patterns of change in the predominance of faith-healing practices in the Islamic world. A 1999 study by Al-Awadi, Al-Hashel, \& Al-Hajeri among 376 civil servants in Kuwait found that 56 percent of the patients seek medical attention from faith healers. Ninety percent of those interviewed held that they would encourage other Muslims to use faith healers to promote their health, and 55 percent indicated that evil spirits contribute to making people ill. Of those interviewed, 65 percent maintained that some diseases can only be cured through faith-healing practices.

The negative side of the Islamic medical system as practiced today becomes clear when it results in delaying or denying required care. However, delays in seeking care does not articulate with Islamic teachings. Delays are more related to folk practices and beliefs (not formally synonymous with practices of classical Islamic medicine) such as 
causation of diseases by evil spirits or when biomedical care is blocked due to financial or systematic issues. Many practices and beliefs assumed to be 'Islamic' today are in reality traditional and folk, having no Islamic-text base. Many Muslims mix these folk practices with Islamic teachings while no recommendations have been made in Islam for these folk practices. In the Kuwaiti study, 36 percent of the respondents indicated they used faith-based healing without any other medical care. In addition to reading the Qur'an, faith-based healers ask patients to take blessed water like Zamzam water, eat blessed honey, or they massage the painful area with blessed oil. ${ }^{11}$ Tapes of a particular healing verse can be prescribed and played continuously until the disease vanishes. One could argue these ritualized behaviors can result in psychological and physical improvements. Nevertheless, the potential for harm is high in some healing practices. For instance, water 'blessed' by immersing hand-written or printed fragments of the Qur'an in it may result in chemical intoxication. Moreover and according to Philips, in some cases, powerful evil spirits believed to be causing disease in an individual may have to be exorcized through physical violence. Such violence may include slight slapping on the face and hand, and serious beating with sticks and sandals. Electrical shocks are also applied to patients to cure ailments (5-8).

Under the Western biomedicine model, disease is a deviation from the normal functioning of the body or biological norms, caused by some identifiable chemical or physical events. On the other hand, devout Muslims perceive disease as a test of patience

${ }^{11}$ Zamzam is the name of a famous well in al-Masjid al-Haraam [the Sacred Mosque in Makkah. It is the well from which Allah quenched the thirst of Isma'eel the son of Ibraaheem when he was an infant. 
or a purification of their souls. Although the Islamic medical model has received widespread criticisms, it includes some potentially positive components such as patientcenteredness, holistic care, and cultural competencies, which according to Saha et al., are deemed key approaches to promoting efficient health care delivery and which recently have been promoted extensively (1284-85).

Many Muslims continue to actively engage in folk and religious healing practices. Therefore, as Alrawi et al. believe, medical practitioners who take care of Muslim patients should be aware of the possible influences of these practices on their health behaviors (495-96). Walton et al. argue that Muslims have special attitudes, beliefs, and perceptions that can have a direct impact on health care practice within a pluralistic medical system and integrative medical approach that can have unique sensitivities to Islamic cultures (38-39). In such an environment, it becomes imperative to strive for a more pluralistic understanding of health, wellness and health care.

\section{Need for Medical Pluralism}

\section{Background}

The term medial pluralism was introduced by Leslie (1976) in the context of medical revivalism in South Asian societies (191). Medical pluralism has been defined as "the use of more than one medical systems or the use of both complementary and alternative medicine (CAM) and conventional medical system (CMS)" (qtd. in Ruhil, 309). Today, this concept has been extended to more stratified societies in the Western world. Medical pluralism also refers to several medical traditions coexisting in relative insulation from each other in a defined region. The concept has now become popular in 
applied health research not only because of increasing popularity of alternative and complementary medicine but also because a public health care funding crisis is putting pressure on governments to make policy changes.

In the US, the practice of medicine started in a rich pluralistic environment. Before the $19^{\text {th }}$ century, the medical system in use involved a collection of coexisting options that were not permanently or rigidly defined. A wide spectrum of medical practitioners from diverse cultural background held a shared perception of being legitimate practitioners. By 1800, there were about 200 graduates from medical schools supplemented by about 300 immigrant doctors with European diplomas. By 1830, the number of medical doctors had increased to 6,800 , serving mainly the upper socioeconomic classes. Ethnic practitioners like slave doctors and Native American healers ministered mostly to populations in rural areas. Gradually medical professionals sought to extend their authority over non- bio-medically trained doctors while the latter considered themselves as improvised substitutes for medical professionals.

In the $19^{\text {th }}$ century, medical pluralism in the US was a "war zone." The first phase of organized opposition to medical orthodoxy was led by the Grahamites (healthy food), Thomsonians (botanical healing), and homeopaths (microdilution medicine). This medical conflict included legislative strategizing, rhetoric maneuvers, and nonfraternizing clauses. In 1847, the American Medical Association (AMA) was introduced to establish a boundary between irregulars and what was coming to be an orthodoxy. Until recently, the Western medical community has mainly sought to suppress and ignore unconventional medical practices. Nonetheless, medical pluralism may probably succeed 
in the US because of the changes driven by social and feminist movements and activists to the Western biomedical community as well as demographic factors as the US population is increasingly becoming diverse.

Some players in the medicinal field advocate a peaceful and mutually advantageous reconfiguration. Although hurdles remain and the future is unpredictable, many practitioners hope that advances in medical pluralism will help patients from different backgrounds to be served. At all points in US history, a number of medical options have been available to citizens. The contemporary increased awareness of alternative medicine serves as a good ground for medical pluralism and a dramatic shift from antagonism to the postmodern acknowledgment of cultural diversity. This implies that medical pluralism is likely to succeed in the US. Many principles of Islamic medicine may serve as sources of biomedical ethics that can, as Sachedina believes, be integrated into the Western biomedicine model in order to come up with more comprehensive medical research and practice (13).

The growing need for medical pluralism in the US can be related to an increased cultural awareness in Western biomedicine as well as demographic changes in the US. However, the major institutions such as medical schools, the AMA, the National Institute of Health, and the pharmaceutical industry, do not have the capacity, ability, or perhaps even the will, to create a pluralistic health care agenda in the face of the ever-growing and solidifying consumer-oriented health care system. Another contributing factor to the growing need for medical pluralism is the societal acknowledgment of religious, ethnic and cultural diversity. The continuing dissolving of a single modernist medical myth has 
increased awareness of medical pluralism. The traditional war of dominant culture versus heretical rebellion in religion and politics as well as health care has started to transform into a postmodern recognition of multiple narratives.

Substantial portions of the US medical system started to seek reconciliation with alternative medicine in the last decade of the $20^{\text {th }}$ century. Major medical training centers, managed care organizations, hospital providers, insurance carriers, and individual doctors are increasingly receptive to various medical cultures, something that would have been unthinkable several decades ago. AMA introduced a coordinated theme on alternative medicine for a particular issue of each of its nine journals in 1998. This marked, claim Fontanarosa and Lundberg, a major shift from its position that there is no alternative medicine; that there is only scientifically-proved and evidence-based medicine (1619). This made pharmaceutical companies complement their pharmaceutical lines with cultural practices, including herbal products. Although some members of the biomedical community yearn for the continuation of traditional dominance of Western biomedicine, there is a widespread acknowledgment, assert Ernst and Kaptchuk, of the need for new relationship and new dialogue between modern biomedicine and what was at one time seen as alternative medicine (412).

Medical pluralism has succeeded in a number of countries. For instance, China introduced a unique medical pluralism policy where Western Biomedicine and Traditional Chinese Medicine (TCM) are both used widely in the health care system, to realize, as Hua et al. contend, "positive health outcomes" for the sick (127). However, the fusion of Western and traditional medical principles can seem contradictory because the 
two are fundamentally different. Under TCM, good health is viewed holistically, including physical activities, psychology and diet while Western biomedicine focuses on intervention, concentrating on biological causes of disease and considering health as merely the absence of disease. Despite these conspicuous differences, China continues to enjoy immense advantages arising from the integration of these systems. This integration has helped in improving health outcomes in chronic disease, increased cost-effectiveness of health care, and helped in meeting the growing demand for a culturally-sensitive medical system.

Medical pluralism has also succeeded in India. The Indian government has invested heavily in the traditional medicine systems known as Ayurveda, Yoga, Unani, Siddha, and Homeopathy (AYUSH). AYUSH are largely codified systems that have become professionalized and institutionalized over time. Through AYUSH, the Indian government has been able to further the key assumption on which medical pluralism is premised upon - that the effectiveness of a health care system requires not just the supply of medical care but also acceptance, trust and use of services by patients. Due to the prevalence of use of folk medicine especially in rural areas, people in India are benefiting from the use of their traditional medical system and having access to modern biomedical services. To enjoy the optimum benefits of medical pluralism, the cultural needs of patients need to be respected. Patients make pluralistic health care choices - moving freely between their folk or religious resources and professional physicians based in what they believe in and what they can actually access. Efforts need to be made in order to deconstruct the view that the Islamic medical system and Western biomedicine model are 
opposing health care systems. Trained medical practitioners should appreciate, understand, and integrate into their practice positive Muslims' healing beliefs and practices, especially the holistic definition of health and patient-centeredness. Islamic principles that serve as sources of Muslim biomedical ethics can be integrated into Western biomedicine to come up with universal medical research and practice.

\section{Recommendation and Conclusion}

In the end, it is important to highlight the role of culture in shaping our attitudes, values, beliefs, and behaviors, especially about health, disease, and medicine. Rather than a clash between biomedicine and Islamic medicine, there should be positive collaboration that leads to medical pluralism and integrative medical system. Both Islamic medical system and Western biomedicine model pose challenges to patients. Physicians tend to represent these two systems dualistically - as in competition with each other and as mutually exclusive systems. On the other hand, patients make pluralistic health care choices - moving freely between faith-based healers and professional physicians bases in what they believe in and what they can access. The US health care system should integrate other medical systems with their perspectives, beliefs, and practices with Western biomedicine through creation of awareness about the importance of medical pluralism. Ultimately, Western doctors should learn more about Islamic faith in organized settings such as medical schools. They also should be motivated to accept new philosophies and perspectives of health care. Such a medical pluralistic approach can be particularly essential when serving Muslim populations because they are likely to use the pluralistic approach to meet their diverse health needs. 


\section{CHAPTER THREE}

\section{THE SYRIAN REFUGEES}

\section{The Syrian Refugee Crisis}

The Syrian conflict, which began in 2011, has resulted in the largest refugee crisis since World War II, with millions of Syrian refugees fleeing to neighboring countries including Lebanon, Jordan, and Turkey. Syrian refugees have also fled to Europe, with many crossing the Mediterranean Sea in order to reach European Union-member nations, mainly Greece, then traveling north to countries such as Germany and Sweden. According to CDC's report on Syria (2017), about 77,000 Syrian refugees have been taken by UNHCR as refugees in the United States and Canada as of January 2018. Syria's pre-war population of 22 million people has been reduced to approximately 17 million, with an estimate of half the population labelled as refugees and internally displaced persons or IDPs (six million having fled the country, and more than six and a half million displaced within Syria). "Syria's Civil War Explained from the Beginning" states that as the Syrian conflict enters its seventh year, more than 465,000 Syrians have been killed in the fighting, more than a million injured and over 12 million Syrians, about half the country's prewar population, have been displaced from their homes whether internally or as refugees (2018).

Overview of the Syrian Civil War 
In 2011, what became known as the Arab Spring revolts toppled Tunisian President Zine ${ }^{3}$ 'ābidīne Ben A 'li and Egyptian President Ḥusnī Mubārak. Sparked in March of the same year in the town of Dar'a by a group of 13-year-old boys who wrote on the side of their school "The Government must go". One of the boys, 13-yearold Hamza ${ }^{3}$ Khatīb, died after having been brutally tortured. Unrest in Syria began when residents in the small Syrian town of Dar'a, took to the streets to protest the torture of the young boys who had penned anti-government graffiti on their school building. President Assad responded with heavy-handed force, and demonstrations quickly spread across the country. Up to this point in March 2011, President Bashār Al Assad and the Ba 'th Party had been ruling over the Syrian people with an iron fist. After the initial protest in March 2011, President Al Assad started to crackdown on the demonstrations across the country. In April 2011, the regime began to send tanks and military forces into cities where they opened fire on civilians. The Syrian government, led by President Al Assad, responded to the continuing protests by killing hundreds of demonstrators and imprisoning many more. In July 2011, a group of high-level defectors from the military announced the formation of the Free Syrian Army (FSA), a rebel group aiming to overthrow the government, and Syria began the slide into civil war. In August 2011, the Syrian National Council (SNC) was formed to fight the Syrian government. Their goal was to end President Al Assad's rule and establish a modern democratic state. Unfortunately the opposition was, as MacFarquhar states, a fractious collection of political groups, longtime exiles, grass-roots organizers and armed militants, divided along ideological, ethnic or sectarian lines (2012). A movement began as an uprising for 
democracy, has since disintegrated into a pot of competing rebel groups, terrorist elements, international powers, and religious factions--all with millions of Syrians killed and more millions displaced.

Sectarian divisions in Syria play a pivotal role in the conflict. The Assad family, and much of the nation's elite, especially the military, are members of the Alawite sect, a minority in a mostly Sunni country. Alawites constitute about 12 percent of the 23 million Syrians. Sunni Muslims, the opposition's backbone, make up about 75 percent of the population. What started as an attempt by the Assad regime to shoot Syria's largest uprising into submission has devolved into a regionalized civil war that has partitioned the country into three general areas in which US-designated terrorist organizations are dominant. In Syria's more diverse west, the Alawite and minority-dominated Al Assad regime, and a mosaic of Shi'a militias trained and funded by the Iranian Revolutionary Guard Corp (IRGC), hold sway. In the center, Sunni moderate, Islamist, and jihadist groups, such as ISIS and ${ }^{3}$ Qā ida affiliated with Jabhat Al Nusrah, share control and in the northeast, the Kurdish-based People's Protection Units (YPG) are centered. As the Syrian crisis enters its seventh year, it is abundantly clear who has and who has not assisted the vulnerable Syrian population and taken charge in hosting the Syrian refugees. The Arab world Response to the Syrian Crisis

Due to geographical borders and a history of economic cooperation, Syria's neighboring countries' economies were heavily impacted by the ongoing Syrian war and the large influx of refugees. Turkey, Lebanon, and Jordan have been the most responsive Arab countries to the Syrian crisis taking in more than five million Syrian refugees. On 
the other hand, the nearby petro-rich Gulf countries, which include Saudi Arabia, Kuwait, Bahrain, Oman, and Qatar have done little to mitigate the Syrian refugee crisis, justifying this inaction by stating that they did not sign the 1951 UN Refugee Convention. The United Arab Emirates has done slightly better than its regional allies by taking in 200,000 Syrian nationals by 2015 . In contrast to the stark indifference shown by the wealthy Arab Gulf countries, a few Western countries in Europe showed more substantial support for Syrian refugees.

\section{Syrian Refugee Crisis and the West}

Western countries have not begun to respond seriously to the Syrian refugee crisis until the summer of 2015 when newscasts began showing the faces of many doomed and hopeless Syrian refugees flooding into Europe on foot or on packed boats. German Chancellor Angela Merkel called on her fellow citizens and European allies to welcome the fleeing Syrian refugees. In 2016, Germany took nearly 300,000 Syrian refugee. In the US, former American President Barack Obama promised to allow 10,000 Syrian refugees into the United States in fiscal year 2016. However, these humanitarian declarations were followed by numerous terrorist attacks in Brussels, Nice, Berlin, San Bernadino, and many non-Western countries as well, igniting a new wave of Islamophobia. Right-wing political parties began winning electoral victories in parts of Germany and other European countries, where calls for a Muslim ban were triggered in part by the deadly ISIS-inspired terrorist attacks in Berlin, Nice, and Brussels. In 2016, the United Nations International Children's Emergency Fund (UNICEF)'s report “Uprooted”, stated that the 
rise of xenophobia and discrimination towards refugees was one of the key conditions to be confronted for the successful resettlement of refugees to continue in Europe (1).

Calls for a Muslim ban were growing in the United States as well. In his campaign for presidency, Donald Trump called for a ban on Muslims entering the country, even though no single terrorist attack was documented as an act committed by a Muslim refugee. Along with the anti-Muslim, anti-refugee public sentiment, more than thirty US governors took measures to prevent Syrian refugees from entering their home states. One of those was the Republican Governor Rick Snyder of Michigan- the state with the largest number of Arab residents.

Even before Trump assumed the presidency, the US response to the Syrian refugee crisis was apathetic. According to Zong et al., only 26,000 Syrians have been identified and referred by UN agencies for resettlement in the US by November 2013 representing a diminutive fraction; $0.5 \%$ of the total number of Syrians who had fled their homeland by that time. A year later, only 132 Syrian refugees had actually been accepted into the US i.e., a mere $0.2 \%$ of the 70,000 refugees who arrived legally in the United States that same year and far fewer than the 292,540 refugees offered asylum in the EU (2017). According to the Refugee Processing Center (RPC)'s “Admissions and Arrivals", the total number of Syrians who had entered the United States by the end of 2015 was only 2,174 . This number is almost insignificant as anthropologist Jeffrey H. Cohen in “Syrian Refugees Next Door?” writes, “The possibility that a Syrian family might become your neighbor is nearly zero. Syrian refugees represent less than 0.0007 percent of the nation's population" (2016). The RPC report about Syrian refugees' arrivals states 
that during 2016 fiscal year, the total number of Syrian refugees resettled in the US was 12,486 although the Obama administration had set a goal of resettling 10,000 Syrian refugees during this fiscal year. While a formal target for Syrians was not set for FY 2017, it was anticipated the US would receive more than 12,500 . With the administration ending less than four months into the fiscal year and with President-elect Donald Trump having pledged to suspend Syrian refugee admissions, the FY 2017 resettlement pledges were not met. Only 6,557 Syrian refugee were admitted to the US in FY 2017. According to the Department of State's figures of refugee arrivals to the states by nationality, there are 35 Syrian refugees reported from October 1, 2017 through January 31, 2018.

According to an Oxfam International Report "Syria Refugee Crisis: is Your Country Doing Its Fair Share?", less than three percent of the Syrian refugee population (five million) have actually arrived in receiving countries through resettlement programs with the US only meeting $10 \%$ of its fair share of refugees based on the size of its economy and its ability to deploy significantly more personnel to embassies in the affected region for the vetting process (2016). The US admissions cap of 10,000 per fiscal year "pales in comparison to the numbers accepted by other countries" (Goyette, 2016). Canada, for example, admitted 40,081 Syrian refugee between November 2015 and the end of January 2017 (Immigration, Refugees and Citizenship Canada Offices, 2017).

With a population equivalent to only three percent of the US population, Goyette states that Sweden took in more than 100,000 Syrians over the first five years of the war (2016). Andy Baker, Oxfam's lead on the Syrian crisis team, denoted that there is a 
growing anti-refugee xenophobic backlash of which Syrian refugees are the victims ("No Escape for Syrians Seeking Safety Six Years After First Protests", 2017). Xenophobia is widespread in the United States and has a long history encompassing anti-Catholic, anticommunism, and anti-Semitism among others. Public anxiety towards immigrants and refugees on one hand, and refugees' fear of the Western world with its history of colonialism and missionary efforts on the other hand, both serve to boost feelings of mistrust on both sides. Xenophobic feelings towards Syrian refugees can be traced back to three main reasons.

There are three main concerns that color the public and private debate regarding immigrants and refugees entering the US: culture, economy, and threat. Each generates an anxiety that feeds xenophobia. The first concern is the social change that might arise from these newcomers. The fact that large number of people seen as significantly different in culture, religion, language, and practices creates fears that their presence will change the country's values, ways of life, and cultural identity. The second fear, state Papademetriou et al., is that immigrants and refugees create additional economic burden and competition for limited resources and opportunities (2016). However, Syrian refugees are less likely to fit into this category since high percentage of these refugees have elementary or middle school education with limited or no command of the English language and no financial or family resources. The third main concern and the one that is most politically polarizing nowadays is the fact that immigrants and refugees are linked to national security concerns. Ruthven argues that news media attention to the militancy of some extremists and their acts of terror leads many to understanding Islam as a 
religion that condones violence and terror (3). This failure to differentiate between subgroups of Arabs and Muslims and to consider that the majority of Muslims can hold Islamic beliefs and practice its cultural rituals and traditions without adhering to the political ideology of a few extremist's factions play a major role in shaping the public opinion and in the opposition to accepting Syrian refugees in the United States. In fact, Muslims represent a very diverse group of individuals with a rich and heterogeneous intellectual and cultural history. Some Muslims abide by certain cultural practices and religious laws in their thought, lifestyles, and dress codes. On the other hand, there are others who do not adhere to these laws but are still Muslims. Add to these some Muslims who are extremists and who do not represent Islam nor its teachings. So, we cannot label all Muslims under one category and assume that the category 'Muslim' comprises all these subgroups. Syria, as a Middle Eastern country is demographically heterogeneous, home to a number of religious and ethnic groups. Before going into Syrian demographics, I will shed the light on the US refugees admission process.

\section{Refugees' Admission Process to the US}

When UNHCR — or, occasionally, a US Embassy or a specially trained nongovernmental organization - refers a refugee applicant to the United States for resettlement, the case is first received and processed by a Resettlement Support Center (RSC). The US Department of State's Bureau of Population, Refugees and Migration (PRM) funds and manages nine RSCs around the world, operated by international and nongovernmental organizations and one US interests section. Under PRM's guidance, the RSCs prepare eligible refugee applications for US resettlement consideration. Some 
refugees can start the application process with the RSC without a referral from UNHCR or other entity. This includes close relatives of asylees and refugees already in the United States and refugees who belong to specific groups set forth in statute or identified by the Department of State as being eligible for direct access to the program. The RSCs collect biographic and other information from the applicants to prepare for the adjudication interview and for security screening. Enhanced security screening is a joint responsibility of the Department of State and the Department of Homeland Security and includes the participation of multiple US government security agencies. Officers from the Department of Homeland Security’s US Citizenship and Immigration Services (USCIS) review all the information that the RSC has collected and also conduct an in-person interview with each refugee applicant before deciding whether to approve him or her for resettlement in the United States. All USCIS-approved refugees undergo a health screening to identify medical needs and to ensure that those with a contagious disease, such as tuberculosis, do not enter the United States. Finally, the RSC requests a "sponsorship assurance" from a US-based resettlement agency that is experienced in providing assistance to newly arrived refugees. Most refugees undergo a brief US cultural orientation course prior to departure for the United States. Those refugees who are approved by USCIS receive assistance upon arrival in the United States through the Department of State's Reception and Placement Program - a cooperative public-private program made up of a number of participants. The support of millions of Americans is fundamental to the program's success. Though Congress mandated the program, it is local communities that have ensured the success of the resettlement program by welcoming and helping refugees from 
around the world. Below is a chart explaining the process

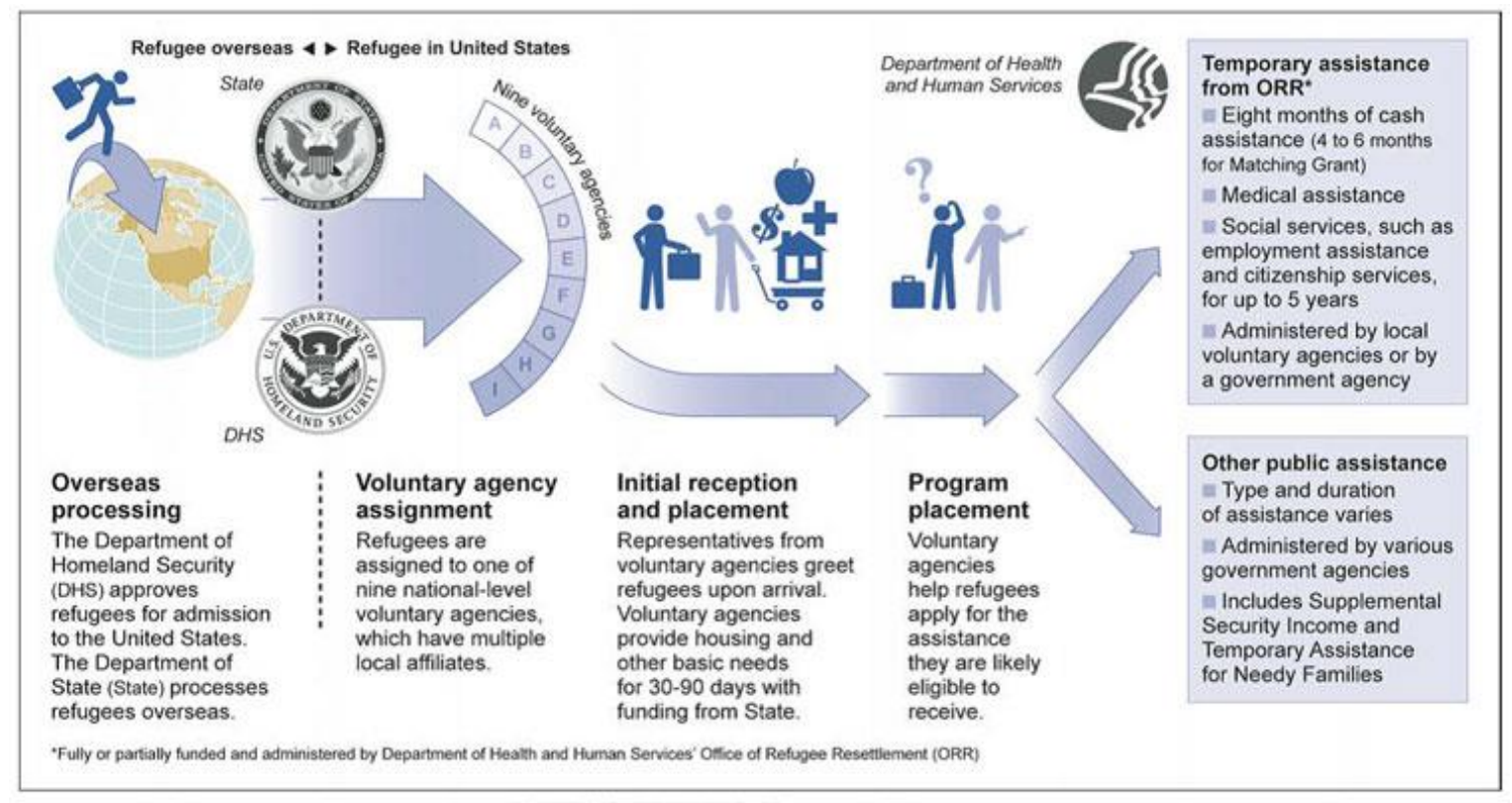

Source: GAO: National Atlas (globe).

\section{Syria's Demographics and Ethnic Groups}

Syria is a lower middle income country with a population of 22.3 million.

Approximately 90\% of Syrians are of Arab descent with the remaining nine percent of

Kurdish decent and one percent Armenian, Circassian, and Turkoman decent. Syria is a

largely Islamic country. According to the latest data from CDC in 2016, 87 percent of the

country's population is Muslim. Broken down, around 74 percent are Sunni and around

13 percent are Shia. There are approximately two million Alawite in Syria today, and

representatives of this group dominate Syrian politics and military. This political

fragmentation was the outcome of French colonialism after WWI and its focus on the

distinctiveness of Syria's two regionally compact minority groups, the Alawites and the

Drūze. Their autonomy mainly had been fostered by the French in an attempt to break 
Syrian unity. Syria's current President, Bashār Al Assad, is an Alawite. The other two major religious groups in Syria are Christian (around nine percent of the population) and Druze (three percent). Arabic is the official language of Syria and is spoken by approximately 90 percent of Syrians. Circassian, Kurdish, Armenian, Aramaic, and Syriac are also spoken. French and English are understood particularly among highly educated groups in urban areas. I will now examine Syria's health care system in order to have background information about Syrian refugees' health care access and services during and before war.

\section{Syria's Health System and Health Traditions}

Syria's public health program is administered by the Ministry of Health and is augmented by programs arranged by the Ministry of Social Affairs and the Ministry of Education. The Ministry of Social Affairs provides vaccinations, medicine, and maternity care at rural community development centers throughout the nation. The Ministry of Education administers a preventive medicine and dentistry program for schoolchildren. The health system is based on primary health care and is delivered at three levels: village, district and province via government clinics and health centers. Syria provides virtually free medical care to its citizens and imposes a ceiling on charges by private hospitals. Government employees and their dependents are also fully or partly reimbursed for private health care and medication costs. Since government salaries for doctors are quite low, they are allowed to set up private practices while also working in government health centers. However, the overall efficiency and effectiveness of the public health system are constrained by many factors. 
Galdo claims that the overall efficiency and effectiveness of the Syrian public health system are constrained by rapid turnover of skilled staff; insufficient coordination between different departments within the Ministry of Health; inadequate managerial skills; low level of qualified nurses and paramedical staff; and poor distribution of human resources (5). Consequently, some Syrians prefer to pay for higher-quality private services rather than using free public services, and 85 percent of health expenditures come from households which highlights the key role of the private sector in providing services. Due to the increasing use of vaccinations and various preventive measures, health conditions in Syria have generally improved since the 1980s. Although the infant mortality rate has decreased significantly, Galdo asserts that some health problems persist for children, among these are: hunger, poverty, overcrowding, poor nutrition and lack of knowledge about disease prevention or treatment, especially in the rural areas (5). In preconflict Syria, the government emphasized health care, but in a country with a high rate of population growth, funding could not keep up with demand or maintain quality equally. As is often the case, access to health care was uneven between rural and urban areas. Although approximately 95 percent of the population is within half an hour of a primary health care center and pharmacist. Doctors who have finished medical school and who do not intend to specialize - are required to practice in rural areas for at least two years. Infrastructures and medical treatment provided in rural areas remain inadequate. For example, in Damascus in 2009, there was one doctor per 339 people, while in rural ${ }^{3}$ Hasakah governorate, the ratio was one doctor per 1906 people according to the WHO. 
Not surprisingly before 2011, mental health care was in short supply with only two public psychiatric hospitals and 70 psychiatrists serving a population of 22 million.

Despite inequity in access to health care facilities, health indicators improved considerably in the Syrian Arab Republic over the past three decades. According to data from the Syrian Ministry of Health, life expectancy at birth increased from 56 years in 1970 to 73.1 years in 2009; infant mortality dropped from 132 per 1000 live births in 1970 to 17.9 per 1000 in 2009 ; under-five mortality dropped significantly from 164 to 21.4 per 1000 live births; and maternal mortality fell from 482 per 100000 live births in 1970 to 52 in 2009 (2015). The Syrian Arab Republic was in epidemiological transition from communicable to non- communicable diseases with the latest data showing that $77 \%$ of mortalities were caused by non-communicable diseases. ${ }^{12}$ According to WHO's "Global Health Observatory (GHO) Data: Syrian Arab Republic", total government expenditure on health as a percentage of Gross Domestic Product was 2.9 in 2009 (2018). Despite such low public investment, the Syrian Ministry of Health states that access to health services increased dramatically since the 1980 s, with rural populations achieving better equity than before (2015). Thus, Syria achieved substantial improvements in population health over the past decades. Contributory factors include access to maternal and child health services through comprehensive primary health care, health promotion and education supported by a network of Women's Committees, better nutrition through

\footnotetext{
${ }^{12}$ Epidemiological transition is used to describe a development phase which is marked by a sudden and abrupt increase in population growth rates of living organisms. This increase might be brought on by medical innovation in therapy and treatment of sickness or disease. World Health Organization, "Non-communicable Diseases (NCD) Country Profiles", 2014.
} 
food subsidies and an acknowledgment of the need to address the social determinants of health, largely unknown to the region. Some of the achievements of the health system, according to Galdo, may be summarized as the following:

- Comprehensive vaccination coverage

- Improved levels of literacy (particularly among women)

- Plans to address a rising incidence of non-communicable diseases (NCDs) through partnership with local communities

- A re-organization of services in 1998 to increase the local level control as part of the process of decentralization

- Steps towards systematization of data and trends through the Health Metrics Network and the Syrian National Health Accounts (7-9). The following two tables highlight a declining infant mortality rate (IMR) and a greatly improved maternal mortality rate (MMR). Obtained from Syrian Ministry of Health (2015), the tables show significant declines in IMR from 132 per 100000 live births in 1970 to 17.9 in 2009; and in MMR from a high of 482 per 100000 live births in 1970 to 52 in 2009 . The decrease is a notable achievement, given the relatively low per capita income and public expenditure on health services. 
Table 1: IMR /Table 2: MMR
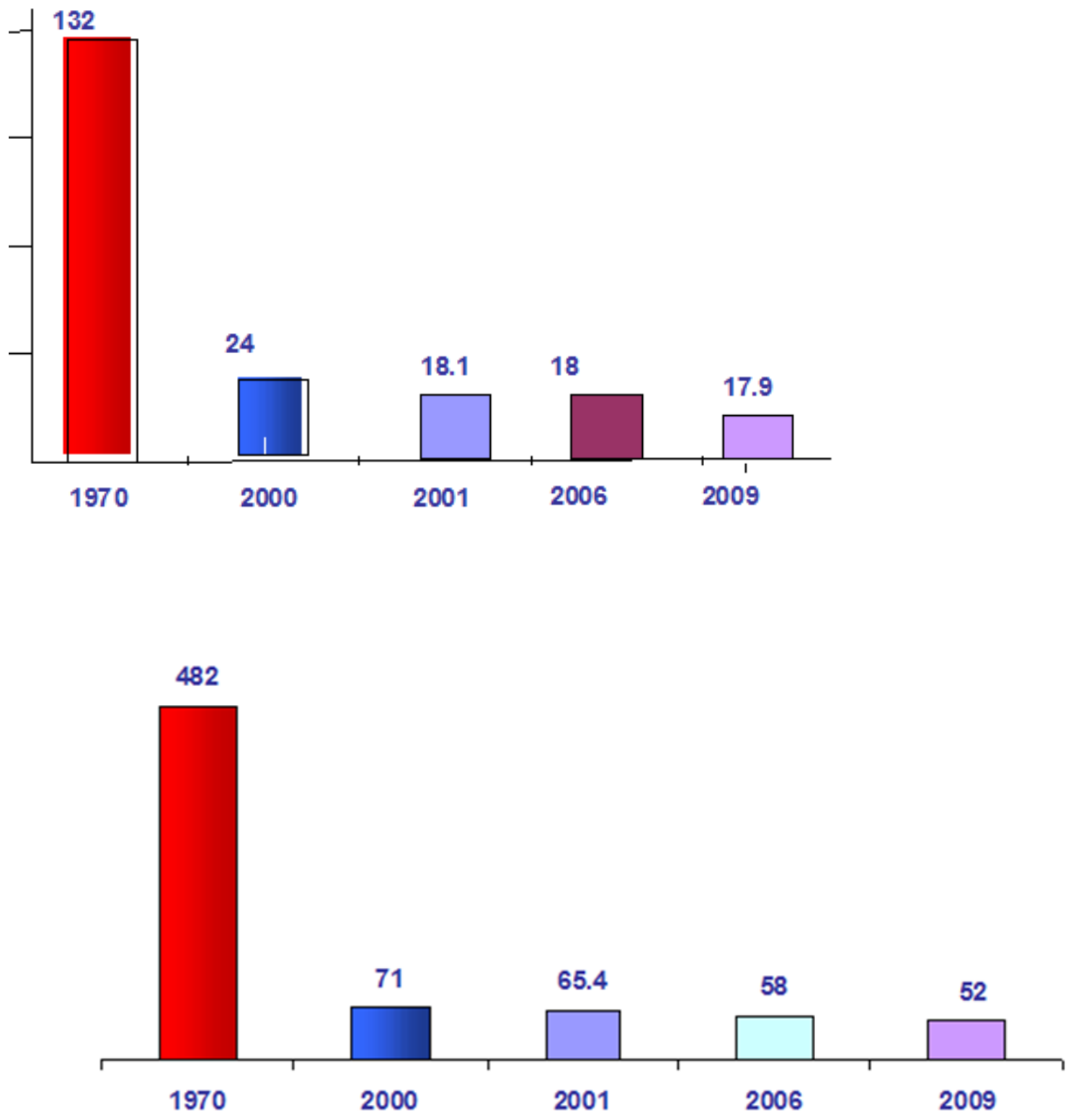

This suggests that the health sector was largely self-sufficient with little reliance on international cooperation with WHO and until a bi-lateral agreement with the European Union (EU) in 2003 took place. In 1997, community-based developmental programs were developed in affiliation with WHO and UNICEF, and in collaboration 
with the Ministries of Education and Municipalities. Also some vaccination programs were activated with the help of WHO. These above health outcomes, states Galdo, were achieved through an integrated approach to health services including primary, secondary and tertiary care and one where institutional deliveries constituted $>90$ percent of all deliveries (10-11).

Despite the apparent improved capacity of the health system, a number of challenges prevailed which needed to be addressed to reduce inequities in access to health care and to improve the quality of care; these include, according to Kherallah et al., addressing validity of the data, overall inequity, lack of transparency, inadequate utilization of capacity, inadequate coordination between providers of health services, uneven distribution of human resources, high turnover of skilled staff and leadership, inadequate number of qualified nurses and allied health professionals. More recently there has been an uncontrolled and largely unregulated expansion of private providers marking a neo-liberal economic turn. This turn resulted in uneven distribution of health and medical services among geographical regions which left some rural regions with the only option of public health care facilities and services. These public health care services, though free, were not always compatible with quality and equality standards.

Standardized care and quality assurance and accreditation are major issues that needed to be addressed (51-53). These pre-war conditions indicate a significant erosion of the health care system.

The current seven-year conflict has shattered the country's health care system leaving many Syrians with little or no access to basic medical care, including childhood 
immunizations. In addition, the protracted political and socioeconomic crisis Syria is experiencing has resulted in a severe deterioration of living conditions which have eroded health in general. Vital infrastructure has been destroyed or comprised resulting in the lack of energy resources, shelter areas, deterioration of water and sanitation services, food insecurity, and serious overcrowding in some areas as people flee armed conflicts. By 2013, roughly half of the country's health care facilities had been damaged, and a substantial number of Syria's health care professionals had fled or been killed or injured. According to "2014 Syrian Arab Republic Humanitarian Assistance Response Plan (SHARP)", as drug production fell, treatment for both chronic and critical illnesses became scarce. Many chronically ill patients have been compelled to interrupt their treatment. Patients with life-threatening injuries have been given higher priority and referred to conflict-free zones. Elective surgeries and non-urgent medical conditions and interventions have been delayed or interrupted suggesting that a growing number of patients, mainly with chronic conditions, are facing terrible situations while awaiting treatment. By targeting medical facilities and frequently blocking humanitarian medical aid, the Syrian government has prevented its citizens living in areas under the control of opposition forces from receiving health care. Moreover, with the imposition of sanctions, the quality of health care has been drastically affected. ${ }^{13}$ A deterioration in the functionality of medical equipment and tools due to the lack of spare parts and

${ }^{13}$ In 2012, the Arab League, European Union, United States and Turkey have all imposed economic sanctions on Syrian individuals and companies. Economic sanctions affected access to health care, to medicines and to basic essentials. The EU banned crude oil imports from Syria and the US imposed sanctions on Syria's energy sector. The Arab League and Turkey freezed Syrian government assets and suspended all financial dealings with Syria's central bank. 
maintenance, as well as shortages of drugs and medical supplies, has also had serious consequences for health care.

As the situation has escalated over the course of war years, and with the increased numbers of cities and towns targeted by air strikes and artillery bombardment, the Syrian medical community has reacted creatively with initiatives to establish and organize makeshift medical facilities. Since hospitals and clinics have been damaged or destroyed, more "underground" and secretive approaches have been taken for establishing healthcare facilities and maintaining them. Often these places were built underground to keep them safe from heavy weaponry attacks. Although Syrians initially named these facilities "field hospitals," the majority were by far too basic and lacked necessary medical equipment, imaging utilities, medications, and specialist medical expertise to be able to adequately respond to mass casualty events.

The siege by the forces of Al Assad's regime around many civilian areas further complicated the situation. In addition to banning food and fuel, medications and medical supplies were strictly prohibited. The blockade has rendered wide areas and hundreds of thousands of people devoid of basic medical care like vaccinations for children and medications for chronic diseases. As a result, this has raised fears of epidemics of infectious diseases, including leishmaniasis, hepatitis A, cholera, and tuberculosis. Some of these fears came true when a recent alarming report of several suspected cases of polio emerged and were later confirmed, although polio had been eradicated in Syria since 1999. Field hospital personnel, state Al Ahdab et al., were also at risk of many of these 
infectious diseases, particularly typhoid fever and brucellosis along with malnutrition (52).

Medical personnel were also at greater risk during attacks, as in the case of the chemical weapon attack on Eastern Ghouțah in August 2012. In this attack, most of the medical staff who responded to the incident were severely affected and some actually died. Civilian volunteers have helped operate and run the field hospitals alongside the remaining few of Syrian doctors. In fact, most of those who offered nursing and other services at remaining hospitals were university students who came from nonmedical backgrounds such as economics, law, literature, electronics, and engineering. Medical and pharmacy students often took a leading role in managing care of the injured. These unqualified personnel were faced with very complicated injuries and conditions that required very advanced surgical expertise. A number of consequences resulted from having personnel from non-medical backgrounds to manage these makeshift hospitals. Among these, particularly concerning are the mortality and morbidity associated with preventable complications. These conditions rendered field hospitals non risk-free sites and not obviously a long term solution for the dramatic deterioration of health services. WHO assessments to evaluate the status of health care services during conflict came up with many concerns. According to "WHO Response to the Syrian Crisis", fully functional health facilities are over-subscribed, overcrowded and understaffed with the human resource situation being a critical gap. The average number of physicians in functional hospitals / 10,000 population range from one in Dar'a to 18 in Damascus (2015). 
In Syria, public hospitals are owned either by the Ministry of Higher Education (MoHE) (university/teaching hospitals) or the MoH. According to WHO's "Health Resources Availability Monitoring System (HeRAMS) Annual Report 2015 for Syrian Arab Republic", 31 percent $(2,952)$ of medical doctors (specialists and resident doctors) worked in MoHE hospitals, while 69 percent $(6,503)$ worked in MoH hospitals. The MoHE hospitals are located in four governorates (Damascus, Rural Damascus, Aleppo and Latakia), serving the whole country. By the end of December 2015, of the 113 assessed public hospitals (MoH and MoHE), 43 percent (49) were fully functioning, 31 percent (35) were reported to be partially functioning, while 26 percent (29) were reported to be non-functioning. The report gave cause for alarm concerning developments in the availability of medical personnel in Syria. It showed that the number of medical doctors in public hospitals decreased by 11percent from 10,586 in January to 9,455 in December 2015. In the same period, the number of nurses decreased by 9 percent from 16,450 to 14,892 . The number of midwives in public hospitals decreased by 13 percent in 2015 from 1,516 to 1,319. An increase in the maternal mortality rate from 49 deaths per 100,000 live births in 2010 to 68 deaths per 100,000 live births in 2015 may be an indicator of how the crisis is affecting public health but is not an indicator of the quality of health care provision as such. The report also demonstrated geographical differences between Syrian regions in the density of university trained health personnel (WHO, 2015). This report acknowledges that due to security reasons and lack of quality registries it found it difficult to assess the impact of the present crisis on the quality of the health care services. Given the dire situation described above of an overburdened health 
facilities, difficulties in public transportation, lack of staff, equipment, and medicine, absence of safety, and inflation of the Syrian pound causing the price of imported and locally-manufactured drugs to rocket, many Syrians opted for herbal and folk medicine.

As Syria's war and economic crisis grinds on, Syrians are returning to traditional medicinal preparations to save on medical costs. Several of the major Syrian pharmaceutical companies are located in battle zones; many of the factories have been completely destroyed, and those that still stand have been forced to suspend operations due to failing finances and the logistical nightmare of distributing drugs. Before the war, Syrians relied on locally-manufactured drugs produced in Aleppo, Syria's economic capital, and in Rīf Dimashq governorate; but some factories such as 'amrit, Asia and Barakāt sit idle as a result of the clashes. As a result, Adra claims, the cost of medicine made in Syria has increased by 25-50 percent. The price of imported drugs has increased in line with the value of the US dollar to the Syrian pound: before the war the US dollar was worth 50 Syrian pounds compared to 190 Syrian pounds today. Little imported medicine was available, making up only 10 percent of the drugs in pharmacies. Adra adds that once the war started, Syrians began to search the Internet for herbal medicines for specific diseases to avoid seeing the doctor to save on check-up fees and buying drugs and medications. However, even before the uprising many Syrians has recourse to herbs to treat various illnesses because they trusted herbal treatments more than chemical medications since they believed they had fewer side effects. It was not uncommon for doctors to prescribe herbs rather than modern medicine especially in rural areas in Syria (2014). 
The famous Al-Buzuriyyah souq, a traditional market specializing in herbal remedies in the Old City of Damascus, was for decades a destination for dervishes and the poor who sought cheap treatments for their ailments. ${ }^{14}$ Due to the cost and difficulty involved in collecting the herbs in the countryside, the herb market has also undergone changes after shop owners raised their prices. However, they are still cheaper than the chemical drugs sold in pharmacies. One of the herb vendors, as quoted in Adra, says that Syria's environment supports a rich variety of herbs, including nearly 3,700 different kinds growing in the desert, coastal mountains and valleys. They include wormwood, capers, thyme, ammi visnaga, oregano, rosemary, hawthorn, sage, mint, stone parsley, zallouh root, chamomile and hyssop. Adra writes of a private-sector employee in Damascus searching the stalls for weight loss herbs. She states that herbal remedies, which they find on the Internet or satellite TV channels, save them a visit to the doctor's clinic or fees that range between 1,000-2,000 Syrian pounds (5-10 US dollars) compared to 500-1000 pounds before the uprising (2014). People working in the field of herbal treatments are either independent researchers or laypersons who engaged in self-study about herbal medicine using books and online websites, or herbalists who inherited the profession of their fathers or grandfathers. A third type or group has recently surfaced as well especially during the Syrian crisis. Those belonging to this group seek fast financial profit, and they can target their victims pretending that their knowledge in herbal medicine is well established. These people do not have any license, knowledge, or

\footnotetext{
${ }^{14}$ Dervish is a member of a Muslim (specifically Sufi) religious order who has taken vows of poverty and austerity. Dervishes first appeared in the 12th century; they were noted for their wild or ecstatic rituals.
} 
experience to manufacture any of the herbal products; however, they claim to have miracle treatments in their herbal concoctions. Syrians rely on both biomedical and folk treatments and this reliance varies according to many factors. These factors include: medical literacy, urban-rural demographics, age, cost, urgency, class, beliefs, and time. Many people especially those higher middle class residing in urban areas endorse biomedicine solely. People in rural areas tend to be more expansive in their approach to health issues; thus, use both. In all cases, herbs, folk medicine, and Prophetic medicine are still in use by many Syrians whether still living inside or outside of Syria.

In a study conducted by Alachkar and colleagues about the use of Traditional Arabic Medicine (TAM) or folk medicine in Aleppo governorate in the north of Syria, it was found that many plant species were used for the treatment of various diseases. Researchers carried out ethnobotanical and ethno-pharmacological research on the plants traditionally used to cure various diseases in northern Syria. They selected the most common 100 species used in the treatment of more than 25 diseases. Among these plants, 53 are used for treating gastrointestinal disorders, 38 for respiratory system diseases, including asthma, bronchitis, and cough, 34 for skin diseases, 21 for diabetes, 17 for kidney and urinary disorders, 16 for cardiac disorders, 14 for infertility and sexual impotency, 13 for treating liver diseases, 13 for several types of cancer, 9 for enhancing breast milk excretion, 8 for weight loss, 5 for reducing cholesterol, and three for weight gain (2011). Not only are herbs and folk medicine part of Syrians' medical behavior, whether during conflict or pre-conflict, there are also some treatments adopted from Prophetic medicine or from the Qur'an. These treatments include the use of honey, 
ginger, black seed, olive oil, dates, etc. There is no available data or surveys about the use of Prophetic medicine or the Qur'an in dealing with diseases or pain; however, data from the interviews I conducted with the Syrian refugees in Louisville highlighted the usage of these treatments and their impact even before war. This data is fully analyzed in the next chapter. Having discussed the status of health care services and the health situation in Syria before and during war, I turn to the refugees' arrivals, living conditions, and access to health services by country of asylum.

\section{Overview of Syrian Refugees' Health in Hosting Countries}

According to the UNHCR's inter-agency information sharing portal for the Syria regional refugee response which was last updated on 24 October, 2018, there are $5,628,303$ registered Syrian refugees. The number of unregistered refugees will likely increase, as refugee camps have become overcrowded as the number of Syrian refugees grows. The table below shows the registered refugees' regional distribution.

\section{Country of}

Asylum
$\%$ of the Total

Source Data date Population of

Refugees

\begin{tabular}{lccc}
\hline$\underline{\text { Turkey }}$ & Government of & 18 Oct 2018 & $63.7 \%$ \\
& Turkey, UNHCR & & \\
\hline$\underline{\text { Lebanon }}$ & UNHCR & 30 Sep 2018 & $16.9 \%$ \\
\hline$\underline{\text { Jordan }}$ & UNHCR & 24 Oct 2018 & $11.9 \%$ \\
\hline
\end{tabular}


$\underline{\text { Iraq }}$

Egypt

Other

$\underline{\text { North }}$

UNHCR
$4.4 \%$

30 Sep 2018

30 Sep 2018

$2.3 \%$

$\underline{\text { Africa) }}$

According to UNHCR “Syria Refugee Regional Response", there are 395,982 registered refugees residing in camps, and 5,229,470 registered refugees in three areas: total urban, peri-urban and rural. Each country of asylum has its own restrictions and benefits that govern access to health services. In Iraq, there are certain specific services offered to select registered refugee populations. In Jordan, only Syrian refugees registered with UNHCR can access the public health system. In Lebanon, UNHCR registration is required for Syrian refugees to access primary health care services. Registration of new arrivals was halted in May 2015 per the request of the Lebanese government. In Turkey, registered Syrian refugees living in satellite cities (non-camps), are enrolled in the Turkish General Health Insurance Program and are able to access free health services. In camps, NGOs provide clean water, sanitation, and a variety health services. Lastly, in Egypt, Syrians are granted access to the public health system but are required to pay the same fees as Egyptians. In all cases, local services are overburdened and often inaccessible due to cost (2018). Data from CDC's "Syrian Refugee Health 
Profile" provides an overview of health care access and health concerns among Syrian refugees including immunization, primary health care, reproductive health, and mental health.

Prior to the Syrian civil war, Syria was classified as a lower-middle income nation, with a fairly stable middle class that had a relatively high socioeconomic status. As a result, the health conditions observed in this population include chronic conditions less often associated with newly arrived refugees (e.g., hypertension, diabetes, and cancer). In addition, acute illnesses and infectious diseases reflect the challenges associated with displacement, crowding, and poor sanitation.

Access to health care varies greatly depending on country of asylum and whether a refugee lives in a refugee camp or in an urban or informal settlement. UNCHR reported that the majority (72.1 percent) of primary health care visits in Za'tarī camp (Jordan) were due to communicable diseases. Non-communicable diseases (21.8 percent), injuries (4.8 percent), and mental illness (1.3 percent) were also noted as reasons for seeking primary care. Similarly, the majority of primary health care visits in Iraq and Lebanon were due to communicable diseases. Notably, primary health care visits attributed to noncommunicable diseases accounted for just 7.4 percent and 8.3 percent of all primary health care visits in Iraq and Lebanon respectively.

\section{Immunizations}

Some Syrians may have received vaccinations prior to displacement. In partnership with WHO and UNICEF, the Syrian Ministry of Health has undertaken monthly polio immunization rounds since December 2013. Refugees have received some 
immunizations from NGOs operating in refugee settlements or camps. For example, Médecins Sans Frontières (MSF) also known in English as Doctors Without Borders is assisting refugees through basic health care including immunization, treatment of chronic diseases, antenatal care, and mental health care, as well as distributing relief items (2016).

\section{Reproductive Health}

A recent study by Reese Masterson et al. assessing the health status of women presenting to six regional primary health care clinics in Lebanon found that 65.5 percent $(\mathrm{N}=452)$ of women between 18 and 45 years of age were not using any form of birth control. Within this group, the mean age at first pregnancy was 19 years. Additionally, 16.4 percent were pregnant during the current conflict. It is noteworthy that 51.6 percent of all women surveyed reported dysmenorrhea or severe pelvic pain, 27.4 percent were diagnosed with anemia, 12.2 percent with hypertension, and 3.1 percent with diabetes (2014). Birth control and family planning services are available in the Za tarī Refugee Camp, one of the largest refugee camps. However, studies, such that of Doocy et al., indicate that only 1 in 3 women of reproductive age are aware of birth control options in the camp. A survey of Syrian households in Jordan found that most women (82.2\%) received antenatal care, with an average of 6.2 visits during pregnancy. Furthermore, 82.2 percent delivered their infants in a hospital, with 51.8 percent of births taking place in public hospitals and 30.4 percent in private hospitals (2016).

Decisions regarding contraception and family planning are often made by the man and woman together. The study suggests that when offering birth control education, the 
health care providers should consider providing contraception counseling to individual women and, with their consent, including male partners in these discussions.

\section{Mental Health}

Historically, mental illness has been stigmatized in the Syrian community. Syrians may be reluctant to acknowledge mental health issues as they may be viewed as personal flaws and might bring shame upon family and friends. As a result, individuals are often reluctant to seek professional psychological or psychiatric care. However, with the recent increase in psychological trauma related to war and displacement, some Syrian refugees have become more open and accepting of mental health conditions and treatment.

The availability of mental health services for refugees in the Middle East is limited. The quality of services, state Weissbecker and Leichner, is often poor, largely due to overstretched capacity and a shortage of trained mental health providers (2015). However, mental health providers in the Middle East have seen an increase in the number of Syrians with severe mental health disorders. The largest psychiatric hospital in Lebanon, state Hassan et al., has observed an increase in admissions of Syrians with severe psychopathology and suicidality since the conflict began (33). Additionally, the International Medical Corps (IMC), according to CDC's “Syrian Refugee Health Profile", has treated more than 6,000 Syrians, 700 (11.7 percent) of which had psychotic disorders in outpatient facilities (2016).

These were some health statistics and facts about Syrian refugees in the Middle East. Syrian refugees have resettled in several European countries, United States, and Canada. Early in the chapter, I examined the Syrian refugees' arrival in the United States 
since the beginning of the Syrian war. Now I explore the process of their medical screening and the health benefits they receive in the United States.

\section{US-Bound Refugees' Medical Screenings}

According to data from the CDC's report, "Syrian Refugees' Health Profile" 2016, Syrian refugees who have been identified for resettlement to the US receive a required medical examination. Depending on the country of processing, refugees may receive additional pre-departure and pre-embarkation checks. The full required medical examination occurs three to six months prior to departure; the pre-departure medical screening and pre-embarkation checks, if conducted, occur close to or immediately before departure for the US.

\section{Visa Medical Examination}

A visa medical examination is mandatory for all refugees coming to the US and must be performed according to the CDC's Technical Instructions. The purpose of this medical examination is to identify applicants with inadmissible health-related conditions. These include, but are not limited to, mental health disorders with harmful behavior, substance abuse, and specific sexually transmitted infections (untreated). Active tuberculosis (TB) (untreated or incompletely treated) is an inadmissible condition of significant concern due to its infectious potential and public health implications. The required medical examinations for refugees processed in Jordan, Iraq, and Egypt are conducted by physicians from the International Organization for Migration (IOM). In other countries, including Lebanon, Turkey, and Austria, examinations are performed by a local panel of physicians appointed by the US Embassy. The CDC provides the 
technical oversight and training for all panel physicians who regardless of affiliation, are required to follow the same technical instructions developed by the CDC. Information collected during the refugee visa medical examination is reported to CDC's Electronic Disease Notification System (EDN) and is sent to the health departments of states where the refugees will be resettled.

\section{Pre-Departure Medical Screening (PDMS)}

Depending on the country of processing, pre-departure medical screening is conducted approximately 2 weeks before departure for the United States for refugees previously diagnosed with a Class B1 TB, pulmonary condition (abnormal chest X-ray with negative sputum TB smears and cultures, or pulmonary TB diagnosed by panel physician and fully treated by directly -observed therapy). The screening includes a medical history and repeat physical exam. This screening primarily focuses on tuberculosis signs and symptoms, and includes a chest X-ray, and sputum collection for sputum TB smears (if required). Depending on the country of processing, refugees with other chronic or complex medical conditions may receive a cursory medical screening prior to departure in order to assess a refugee's fitness for travel. However, this exam is not routinely conducted by panel physicians and is not required.

\section{Pre-Embarkation Checks (PEC)}

Depending on the country of processing, IOM physicians perform a preembarkation check within 24-48 hours of the refugee's departure for the United States to assess fitness for travel and to administer presumptive therapy for intestinal parasites. 
The CDC is working with the IOM and independent panel physicians in the Middle East to expand PDMS/PEC throughout the region.

\section{Vaccination Program for US-bound Refugees}

In addition to vaccines received through national immunization programs and/or administered by NGOs, Syrian refugees may receive select vaccines as part of the Vaccination Program for US-bound Refugees. Whether or not a Syrian refugee receives vaccines prior to departure depends on the country of processing, vaccine availability, and other factors. Refugees in Iraq and Jordan may receive bivalent oral polio (bOPV), MMR, and pentavalent (DTP-Hepatitis B-Hib) vaccines, depending on age. Hepatitis B surface antigen testing will be conducted for refugees receiving hepatitis B vaccine once testing kits are available.

All vaccines administered through the Vaccination Program for US-bound Refugees, as well as records of historical/prior vaccines provided by NGOs and national programs, will be documented on the DS-3025 (Vaccination Documentation Worksheet) form. US providers are strongly encouraged to review each refugee's records to determine which vaccines were administered overseas. US providers should refer to each refugee's PDMS form to determine which interventions, including vaccinations and presumptive therapy for intestinal parasites, were administered overseas.

\section{Post-Arrival Medical Screening}

The CDC recommends that refugees receive a post-arrival medical screening (domestic medical screening) within 30 days after arrival in the US. The US Department of Health and Human Services Office of Refugee Resettlement (ORR) reimburses 
providers for screenings conducted during the first 90 days after the refugee's arrival. The purpose of these more comprehensive examinations is to assess for health conditions and to introduce newly arrived refugees to the American health care system. The CDC provides guidelines and recommendations for this medical screening, while state refugee health programs oversee its implementation. The screening is conducted by state refugee health programs or private physicians designated by these programs. Most state refugee health programs then collect data from this screening. Each state receiving Syrian refugees implements its own screenings and medical examinations within the CDC guidelines. Demographic information about Syrian refugees resettled in Kentucky can be retrieved from Kentucky Office for Refugees (January 2018).

\section{Syrian Refugees in Kentucky: Demographics and Health Profile}

\section{Demographics}

Between May 2014 and September 2017, 494 Syrian refugees have been resettled in Kentucky (there have not been any Syrian arrivals since September 2017). Of these, 383 were resettled in Louisville and 111 in Lexington. Additionally, resettlement agencies have served 33 Syrian secondary migrants (someone who was initially resettled in another state but moved to Kentucky and requested services), 23 secondary refugee in Lexington and 10 in Louisville. Average age at arrival in the US is 19.5 years. Here is a break down: 
0-5 years

6-17 years

18-60 years

Above 60
111

178

235

3

Highest education level of those 18 and above at arrival:

No Formal Education 16

Primary School $\quad 76$

Secondary School $\quad 92$

Some College 5

College Graduate $\quad 12$

No Data Available $\quad 37$

Screenings

Refugees arriving in the United States are eligible to receive a domestic Refugee Health Assessment (RHA). While no national requirements exist for the RHA, the Centers for Disease Control and Prevention (CDC) and the Office of Refugee Resettlement (ORR) provide guidelines for data elements that can be collected. This surveillance and epidemiology report, entitled "State of Refugee Health in Kentucky", is composed using data embedded in the Arriving Refugee Informatics Surveillance and Epidemiology (ARIVE). The purpose of the RHA is to follow up with any condition identified in the overseas medical evaluation, identify individuals with communicable diseases of public health importance, identify health conditions that could affect the 
resettlement process including employment, and serve as an introduction to the US health care system including establishing a primary care location. In Kentucky, RHAs are conducted at six clinics - three in Louisville (Family Health Centers-Americana, Home of the Innocents [pediatrics only], and the University of Louisville 550 Clinic), one in Lexington (Bluegrass Community Health Care Center), one in Bowling Green (ZipClinic) and one in Owensboro (Green River District Health Department). Refugee health assessments include a review of overseas medical information, a complete medical and socio-ethnographic history, a physical exam, and laboratory screenings. Refugees should receive a health screening within the first 90 days of arrival in the US. RHA clinics utilize in-person interpreters and phone interpreters to communicate with refugees in a variety of languages.

Refugees receive a comprehensive medical screening as part of the Refugee Health Assessment. The RHA includes screening for parasites, body mass index, urinalysis, eosinophilia, total cholesterol, high density lipoprotein, varicella titer, tuberculosis, complete metabolic panel, vision, hearing, mental health, hepatitis B, and dental, as well as other health indicators. Laboratory tests are reviewed with the refugee and the physician can make diagnoses and refer for follow up treatment. According to data and statistics from the University of Louisville Global Health Center (MedCenter One) formerly Vaccine and International Health and Travel Center 550 Clinic, the top diagnosis for refugees from Syria are dental abnormalities, overweight, obesity, and total cholesterol. For many other health conditions, Syrians tested negative, normal, or low on eosinophilia, high density lipoprotein, varicella titers, tuberculosis, parasites, metabolic 
panel, vision, blood lead level, and surviving or witnessing torture. Syrians screened positive on the mental health screening. The Refugee Health Screener-15 (RHS-15) is a quantitative screening instrument developed to detect emotional distress in newly arrived refugees. An RHS-15 is completed by refugees 14 years and older during the RHA visit. According to University of Louisville "Kentucky Refugee Health Assessment Report", fifty-seven percent of refugees from Syria had a positive RHS-15. Refugees with a positive RHS-15 may be referred to the mental health coordinator (41).

\section{Benefits}

Refugee resettlement agencies in Louisville assist Syrian refugees enroll in health insurance plans. University of Louisville (UofL) 550 Clinic and Family Health CentersAmericana start their medical screenings and tests in order to refer them to primary care providers as the first step in navigating the US health care system. Funding for primary care at UofL 550 Clinic ceased as of January 2018 and funding only for initial screenings continued. So, Syrian refugees have to choose from a list of primary care physicians given to them by the 550 Clinic and find the best match. Syrian refugees receive health insurance (Passport Health Plan) which is the nonprofit that administers Medicaid benefits in the Louisville area. Once they start working this insurance is switched for their employment insurance if their income exceeds certain limits.

There are two main resettlement agencies in Louisville: Kentucky Refugee Ministries and Catholic Charities. Kentucky Refugee Ministries, Inc. (KRM), a non-profit organization, is dedicated to providing resettlement services to refugees through faith- 
and agency-based co-sponsorship in order to promote self-sufficiency and successful integration into our community.

KRM's Louisville and Lexington offices operate as local affiliates of two national resettlement agencies, Episcopal Migration Ministries and Church World Service. KRM was founded in 1990 by Donna Craig and began welcoming refugees to Louisville, Kentucky. KRM is committed to offering access to community resources and opportunities and to promoting awareness of diversity for the benefit of the whole community. It provides cultural orientations, social networking, language classes, health benefits, and assistance with the school system, employment, and the health care system. Physical health services include:

- Initial orientation and support to navigate the US medical system

- Scheduling refugee health screenings with trained local clinics

- Coordinating follow-up referrals with community providers

- Educating refugee clients so they can maintain health care follow-up on their own Special medical caseworkers collaborate with local agencies and providers such as Kynect, Medicaid, Managed Care Organizations such as Passport Health Plan, and various clinics such as Family Health Centers, University of Louisville Vaccine and International Health and Travel Center (the 550 Clinic), and Home of the Innocents Open Arms Clinic, among others. For mental health and wellness, services include:

- Referral/coordination of community mental health services

- Culturally-specific community support and education groups

- Case management with clients who have more significant mental health issues 
- Coordinate bi-monthly mental health provider workgroup within the Louisville Metro area

- Providing professional trainings on cultural competency and working with interpreters to community agencies

- Increase access to more holistic activities for improved wellness, such as yoga, hiking, on-site support groups, sewing, and more Catholic Charities of Louisville, the other resettlement agency, is the socialservice arm of the Archdiocese of Louisville. They provide help and create hope for the poor and vulnerable through a wide range of programs assisting clients of all races, backgrounds and beliefs. Their service area includes 24 counties throughout Central Kentucky. Established in 1939, Catholic Charities of Louisville is one of over 160 Catholic Charities USA social service agencies. Catholic Charities of Louisville's mission is to provide help and create hope for the poor, vulnerable and those on the edge of society including refugees.

In conclusion, in order for US health care providers to deal with Syrian refugees' health, they need to have an overview of this population's health beliefs and status and conditions in their country of origin. Syrian refugees' former health experiences, in addition to their health beliefs, tend to accompany them even when they start new lives in countries of resettlement. These experiences and beliefs are part of their identity and mentality. 


\section{CHAPTER FOUR}

\section{RESULTS}

As mentioned in chapter 1 , the methodology used in this study is abductive analysis which begins with a theory or model in mind and through observations and constant comparison between data and observations ends up with new findings in conversation with the model adopted. After analyzing my data, my findings were in accordance with Rachel Spector's Health Tradition Model/Framework; but they also provided new insights and theoretical abstractions about refugees' resettlement and the

calls for pluralistic health care system. In this chapter these new insights are highlighted and exploratory findings stemming from Spector's theory are addressed and discussed.

\section{Rachel Spector's Health Tradition Model/Framework}

Spector's model as mentioned earlier was intended originally as relating to cultural competence and transcultural nursing models. However, I will be adopting this framework to promote medical pluralism which is a much broader project than cultural competence. Spector's model provides a valid foundation for practicing medical pluralism within a multi- ethnic country as the US.

Spector claims that the catastrophic events of September 11, 2001; the wars in Afghanistan and Iraq; and the Americans' preoccupation with terrorist threats have pierced the consciousness of all Americans in general and health care providers in particular. She argues that now more than ever, providers must become informed about 
and sensitive to the culturally diverse subjective meanings of health/HEALTH, illness/ ILLNESS, caring, and healing practices. Spector asserts that cultural diversity and pluralism are a core part of the social and economic engines that drive the country, and their impact at this time has significant implications for health care delivery and policymaking throughout the United States (4-5). Spector contends that the compelling need for culturally and linguistically competent health care services for diverse populations has attracted increased attention from health care providers. So, what is cultural and linguistic competence as seen by Spector?

Spector states that one's personal cultural background, heritage, and language have a considerable impact on both how patients access and respond to health care services and how the providers practice within the system. Cultural and linguistic competence suggests an ability by health care providers and health care organizations to understand and respond effectively to the cultural and linguistic needs brought to the health care experience. This leads not only to improved health care outcomes, but also efficiency and patient increased satisfaction. This is a phenomenon that recognizes the diversity that exists among the patients, physicians, nurses, and caregivers. Many of the people in the workforce are new immigrants and from ethno-cultural backgrounds that are different from that of the dominant culture. Cultural needs and perspectives regarding HEALTH and ILLNESS are also vital when striving to be 'culturally and linguistically competent' (5).

Health and illness, with respect to Spector, can be interpreted and explained in terms of personal experience and expectations. We can define our own health or illness, 
she states, and determine what these mean to us in our daily lives. We learn from our own cultural and ethnic backgrounds how to be healthy, how to recognize or diagnose illness, and how to act when ill. Therefore according to Spector, the meanings we attach to the notions of health and illness are related to the basic, cultural-bound values by which we define a given experience and perception (5).

\section{Heritage Consistency and Health Beliefs}

Spector's framework relies on the concept of heritage consistency developed by Estes and Zitzow (1980) to describe the degree to which one's lifestyle reflects his or her respective culture. Spector believes that one's heritage has a great impact on his/her health beliefs and practices. There is a relationship between people with strong identities - either with their heritage or the level at which they are acculturated into the American culture - and their health beliefs and practices. Hand in hand with the concept of ethnocultural heritage is that of a person's ethno-cultural history, the journey a person has experienced predicated on the sociocultural events that have touched his or her life directly or indirectly. The values indicating heritage consistency exist on a continuum, and a person can possess value characteristics of both a consistent heritage (traditional) and an inconsistent heritage (acculturated). The concept of heritage consistency includes a determination of one's cultural, ethnic, and religious background. The heritage assessment tool is a set of questions used to elicit a person's ethnic, cultural, and religious background (9-13). By performing this assessment, how deeply a person identifies with his/her own traditional heritage can be determined. Therefore, this tool is quite useful in setting the stage for assessing and understanding a person's traditional HEALTH and 
ILLNESS beliefs and practices and in helping determine the community resources that will be appropriate to target for support when necessary (Spector, Appendix E). Spector states that usually the dominant society expects that all immigrants are in the process of acculturation and assimilation (discussed later in this chapter), and that the worldview of health care practitioners is shared by patients too. Spector stresses the fact that because we live in a pluralistic society, many variations of health beliefs and practices exist (20). The debate today still rages among those who believe that America is a melting pot where all groups' (native, newcomers, and immigrants) values and norms blend resulting in hybrid identities, those who claim that all groups of immigrants must be assimilated to an American norm, and those who dispute theories of assimilation and believe that the various groups retain their own cultural identities and practices within the American whole resulting in cultural pluralism.

Therefore, the concept of heritage consistency is one way of exploring what aspects of heritage people are maintaining and of determining the scope of a person's traditional cultural heritage. Once explored, health care practitioners can understand the various health beliefs and concepts immigrants and refugees bring with them. In case of Syrian refugees, the degree to which these refugees identify with their religious and folk heritage is high due to the short period of time they have spent in the US, the problems they are facing with the health care system, and the positive impact of using these practices upon resettlement in the US. Acculturation, especially if understood as one way process, usually starts two to three years after resettlement. Indeed at the time of 
interviews, most of the Syrian refugees had been in the US for less than two years. These issues will be discussed in the data analysis.

\section{Health Traditions Model}

Spector perceives health and illness in her model as holistic; therefore she refers to them as HEALTH and ILLNESS. HEALTH is defined as the balance of the person, both within one's being - physical, mental, and spiritual - and in the outside world natural, communal, and metaphysical. On the other hand, ILLNESS is the imbalance of one's being — physical, mental, and spiritual - and in the outside world - natural, communal, and the metaphysical (76). The Health Traditions Model uses the concept of holistic HEALTH and explores what people do from a traditional perspective to maintain HEALTH, protect HEALTH or prevent ILLNESS, and restore HEALTH. HEALTH in this traditional context has nine interrelated facets, represented by

1. Traditional methods of maintaining HEALTH: physical, mental, and spiritual

2. Traditional methods of protecting HEALTH: physical, mental, and spiritual

3. Traditional methods of restoring HEALTH: physical, mental, and spiritual The traditional methods of HEALTH maintenance, protection, and restoration require the knowledge and understanding of HEALTH-related resources from within a person's ethno-religious and cultural heritage. These methods may be used instead of or along with modern methods of health care. They, Spector argues, are not alternative methods of health care because they are methods that are an integral part of a person's ethno-cultural and religious heritage (76-77). Tradition (which I replaced with the term 'folk') is the essential element in this model. Given that the US has been a melting pot, it 
has frequently weakened or discarded the traditions of immigrants during the process of assimilation, especially where HEALTH beliefs and practices are concerned. For many people, modern medicine or biomedicine has not provided a compelling replacement. These facts and ideas are going to be highlighted in the data analysis part in this chapter where lots of Spector's views and concepts will be explored and new findings will emerge. Before moving into data analysis and discussing my findings, I will highlight the literature on the concepts of acculturation and adaptation. Spector's Health Tradition Model lies is contrary to the melting pot theory.

\section{Acculturation and Adaptation}

The classical definition of acculturation was presented by Redfield, Linton, and Herskovits: "acculturation comprehends those phenomena which result when groups of individuals having different cultures come into continuous first-hand contact with subsequent changes in the original culture patterns of either or both groups" (149). Although acculturation is a neutral term in principle (that is, change may take place in either or both groups), in practice acculturation tends to induce more change in one of the groups than in the other. While cultural pluralism is the option favored by most immigrants, Gordon asserts that it has never really existed in the US. In his view, the acculturation process has led to outcomes best reflected in the Anglo conformity thesis: basic values, norms, and symbols taught to immigrants and fully absorbed by their children correspond to those of the dominant culture (159). Adaptation refers to changes that take place in individuals or groups in response to environmental demands. These adaptations can occur immediately, or they can be extended over the longer term. 
According to Berry and Ataca, short-term changes during acculturation are sometimes negative and often disruptive in character. However, for most acculturating individuals, after a period of time, some long-term positive adaptation to the new cultural context usually takes place (607). Rumbaut distinguishes between group and individual assimilation. He states that at the group level, assimilation may involve the absorption of one or more minority groups into the mainstream, or the merging of minority groupse.g., second-generation West Indians "becoming black Americans". At the individual level, assimilation denotes the cumulative changes that make individuals of one ethnic group more acculturated, integrated, and identified with the members of another (82).

Berry claims that there are four acculturation strategies adopted by ethnic minorities to handle stress arising from contact with a new culture. These strategies carry different names, depending on which group (the dominant or non-dominant) is being considered. From the point of view of non-dominant groups, when individuals do not wish to maintain their cultural identity and seek daily interaction with other cultures, the Assimilation strategy is defined. In contrast, when individuals place a value on holding on to their original culture and at the same time wish to avoid interaction with others then the Separation alternative is defined. When there is an interest in both maintaining one's original culture while in daily interactions with other groups Integration is the option; here there is some degree of cultural integrity maintained, while at the same time seeking to participate as an integral part of the larger social network. Finally, when there is little possibility or interest in cultural maintenance (often for reasons of enforced cultural loss) and little interest in having relations with others (often for reasons of exclusion or 
discrimination) then Marginalization is defined. Acculturation strategies have been shown to have substantial relationships with positive adaptation: integration is usually the most successful; marginalization is the least; assimilation and separation strategies are intermediate.

According to Berry, the type of acculturation strategy a person adopts is contingent upon two main principles: a) cultural maintenance (extent to which a person values his/her culture and is willing to maintain it) and b) contact and participation (extent to which a person values the host culture and decides to come into contact with it). Berry also states that a set of moderating variables occurring prior to and during acculturation shapes the adopted strategy. The prior acculturation variables cover age, gender, education, socioeconomic status, expectations, cultural distance (language, religion, and cultural values), and personality characteristics. The other set is during acculturation which is composed of the phase of acculturation (length of time), acculturative strategies (attitudes, beliefs), coping resources, social support, and social attitudes (prejudice, discrimination, etc.). The four acculturation strategies which Berry calls cultural adaptation carry with them different levels of stress dependent upon coping methods and the moderating variables mentioned above. He claims that to respond to acculturative stress, individuals use a variety of coping methods from adaptive to nonadaptive strategies (703-705). I examine the stress that Syrian refugees suffer as they try to enter the acculturation process, here with the US health care system, and the coping strategies they employ to reduce this stress. 


\section{Primary Research Questions and Coding Process}

The primary research questions were designed to provide the freedom and flexibility to explore Rachel Spector's Health Tradition Model and to delve into diverse emotional reactions Syrian refugees go through in their resettlement process and their experience with the US health care system. For these goals, the central research questions were as follows:

1. How do Syrian refugees perceive Health and Illness?

2. Do Syrian refugees feel depressed when they become sick in US and why?

3. What do Syrian refugees feel when using Arab Islamic and folk treatments in the US?

4. What are the major problems Syrian refugees go through when navigating the US health care system?

Syrian refugees' Health Tradition Model was fully explored by relying on

Spector's model and by constant comparative method during data collection, analysis, coding, and memo-ing. Interesting results were obtained regarding Syrian refugees' experience with US health care system and the emotions they undergo throughout this experience. Open coding was used during line-by-line reading of transcripts to identify "in-vivo" codes derived from the words of the participants. A total of 111 codes were identified throughout data analysis. As interpretation progressed with axial coding and constant comparison, conceptual relationships among the codes were further derived from the data. Emerging patterns were recognized and provisional categories were identified as similarities and differences among the codes were considered. Theoretical sampling facilitated further refinement and development of multiple categories. As a 
result, six distinct categories were identified from the data including thirty sub-categories. Eventually, a core category emerged that ultimately unified the findings or surprising facts I came up with and which served as the theoretical scheme of Syrian refugees' resort to folk and Arab/Islamic health practices during their resettlement experience. A point of data saturation was reached upon analysis of the twenty first interview. A total of thirty interviews were conducted, with a total participant $\mathrm{N}$ of 30 refugees and 6 additional interviews with health care staff members in charge of Syrian refugees' health care. Perspectives of health care staff were explored to yield rich and relevant information in order to broaden the expanse of the theoretical abstraction discovered through analysis of the refugees' interviews. In the following two parts, I explore Spector's Health Traditional Model through my data analysis and then present new findings derived from my data analysis. Then, I demonstrate how my data fills a gap in Spector's model, and can therefore, propel the practical realization of medical pluralism.

\section{Data Analysis and Results}

\section{HEALTH as Holistic}

Spector in her model uses the term HEALTH signifying that it is not restricted to physical wellness. It is holistic term comprising the balance of the person, both within one's being - physical, mental, and spiritual - and in the outside world - natural, communal, and metaphysical. This view of health was recurrent in almost all the interviews I conducted. When Syrian refugees were asked about what health means to them, their answers correlated with what Spector uses in her model. A person is comprised of the: 
1. Physical entity: anatomical organs, genetic inheritance, body chemistry, age, gender, nutrition, etc.;

2. Mental entity: cognitive processes such as thoughts, memories, and knowledge. This includes emotional processes as feelings, defenses, and self-esteem; and

3. Spiritual entity: includes both positive and negative learned spiritual practices and teachings, dreams, symbols, stories, protecting and metaphysical forces.

These three entities, according to Spector, are in constant flux and change over time and are affected by the socio-demographic context of every person which includes his/her family, culture, work, community, history, and environment (78-79). There is often great overlap between mental and spiritual entities. These three entities' interrelationship in addition to their being not mutually exclusive were echoed in almost all my interviews.

When asking him about the meaning of health, Salah, a 47- year-old male and former restaurant owner from Aleppo defines it as, "Health is everything, and it is our capital. It is divided into two equally important parts: mental and physical. If I am worried about my son or my wife, my health is not good. However, we are immunized with our faith and religion”. Fadel, another 58-year-old male who suffers from partial loss of vision gives greater value to the mental entity in HEALTH: "Health is related more to the mental well-being. When I am mentally good and not worried about my living, I am healthy and my body is strong". Five male subjects out of the thirty subjects interviewed assigned greater value for mental entity of HEALTH. This is normal since these men come from a culture which allots most living and housing expenses to men. Religious beliefs can strengthen the physical and mental health. Muslim religious beliefs 
have an impact on the mental health of individuals, families, and communities, and are considered a central component of their identity (151-53). With its spiritual teachings, holy words and books, symbols, and practices, religion plays major role in ameliorating the mental status of practicing Muslims and sometimes the physical. ILLNESS is another concept in health beliefs which Spector defines as the imbalance of one's being physical, mental, and spiritual - and in the outside world - natural, communal, and meta-physical.

It is reported that the Prophet Muhammad said: "A Muslim does not encounter fatigue, tiredness, concern, sorrow, injury, or grief, or even a thorn which pricks him without Allah expiating his errors for him by that" (Sahīh Bukhārī Vol.7; Hadith 544). Therefore, illness is an opportunity for purification of the soul from sins and it is a sort of mercy from God to His servants. However, seeking treatment for illness does not conflict with seeking help and support from God. Also, illness is viewed in Islam as an examination of faith and patience. When encountering illness or hardships of any type a Muslim would be urged to see it as a sign of love from God. The prophet said, "If God loves someone, He will test him" (Saḥịh Bukhārī Vol.7; Hadith 548). This love is evident in the following: recognizing your need for God, erasing your sin and enjoying big rewards for being patient about your illness. Allah said in the Qur'an: "Verily, We shall put you to test with some fear, and hunger, and with some loss of wealth, lives, and offspring. And (O Muhammad) convey good tidings to those who are patient, who say, when inflicted by hardship, 'Verily we are of God and verily to Him shall we return;' upon them is the blessings of Allah and His mercy" (2.155). Twenty eight participants 
out of thirty interviewed in this study view illness as a test of faith and patience. All the participants' experiences of illness are shaped by enduring it and trying to invoke religion to explain the unexplainable. 83 percent of the participants consider illness as comprising the physical and mental entities of a human. Daily life worries and problems inflict illness as do other somatic defects. Salah a 47-year-old male when asked what illness means to him, says: "Illness is everything related to adversity. It is an exam and we should be faithful and patient". Mirvat, a 40-year-old female, while sipping her coffee, adds: "Illness is a test and remembrance from Allah to us and a reminder of His blessings". Fadel, a 58-year-old partially blind male and overwhelmingly distressed says: "Illness is loneliness and being far from country and family. Among your relatives and family there are no feelings of illness. In all cases, it is a test and we should be patient and thankful". Thus, Syrian refugees' view of illness conforms to the religious teachings of Islam that assigns a positive value for illness.

Islam attributes illness causes to a sort of imbalance in the relationship between an individual and his/her self (smoking, drinking, overeating, etc.), the individual and others (harming others, humiliating, mistreating, killing, etc.), and the individual and his/her Creator (not obeying Allah). Islamic texts purport that whatever inflicts a human is destined from God; however, a human has his/her own share in causing harm to his/her self. According to the Qur'an, there are two types of diseases that afflict the heart: one is doubt and error, and the second is lust and desire: "In their hearts is a disease of doubt and hypocrisy and Allah has increased their disease" (2.10). Therefore, illness or disease in Islam is not only a sort of physical pain or abnormality in the functioning of the body, 
rather it can afflict the heart (soul) or the body. In this sense, disease here is an outcome of a person's mal behavior and lack of faith. Thus, this view of Illness as holistic and as a mutual relationship between a human (physical, mental, and spiritual) and his surrounding: natural, communal, and meta-physical as viewed by Spector echoes the view of Illness in Islam.

\section{Health Maintenance and Restoration}

Two major questions Spector explored in her model or framework were:

1. What traditional methods are used to maintain HEALTH - physical, mental, and spiritual?

2. What traditional methods are used to restore HEALTH - physical, mental, and spiritual?

These two questions were re-worded in my interviews as:

1. What do you do to maintain your health?

2. If you became sick or notice change in your health what do you do?

3. Whom do you resort to when sick?

4. Do you follow any religious or folk eating/drinking habits when sick? According to Spector's Health Tradition Model, the 'traditional' ways of maintaining HEALTH are the active, everyday ways people go about living and attempting to stay well or HEALTHY — that is, ordinary functioning within their family, community, and society. These include such actions as wearing proper clothing, special objects, preparing special foods, certain methods of food preparation, traditional diets, food taboos and restrictions, and hygienic habits (86). One's ethno-religious heritage 
plays a strong role in the determination of how foods are cooked, what combinations they may be eaten in, and what foods may be eaten. For example, in Chinese culture, service of expensive and rare foods usually shows the respect to the guests. A formal dinner includes 4-6 cold dishes, 8-10 hot dishes, served with soup and fruits. A usual family dinner serves close friends. Moreover, in the Spring Festival in China, people eat dumplings to express the relationship between themselves and God. Mental HEALTH in the 'traditional' sense is maintained by concentrating and using the mind - reading, crafts, books, music, art, hobbies, and other habits that help in the maintenance of mental well-being. Spiritual HEALTH is maintained in the home with family closeness - prayer and religious celebrations. Kindred occasions are also family and community events. Spector states that the strong identification with, and connection to the "home" community are a significant part of traditional life and the life cycle, as well as factors that contribute to HEALTH and well-being (79-80). This holistic way of looking at HEALTH as a connection of body/mind/spirit is congruent with many Muslims' view of their HEALTH. All the above ways of maintaining HEALTH are touched upon in the answers I obtained from the Syrian refugees regarding their ways to preserve HEALTH.

Nutrition is prophylactic and is one way of preserving HEALTH for Syrian refugees. For example, cooking at home, eating halal food (no pork, no alcohol, meats slaughtered according to Islamic way), and avoiding preservatives and added colors in food are preventive measures. Syrian refugees prefer to bring halal meat from Middle Eastern groceries across Louisville. They expressed their disinterestedness in eating outside their homes (at restaurants or from fast food places). When asked what you do to 
preserve your health, Salah a 47-year-old male from Aleppo and a former restaurant owner says: "We eat quality and halal food with no preservatives or chemicals, and we don't eat before bedtime. But my kids are suffering from free time here which is causing them obesity". Nadia a 32-year-old female says as she holds her baby: "I do my task and leave it to Allah. I avoid too much sugar and too much salt”. Dalal a 29-year-old female decidedly says: "To preserve our health, we avoid harmful foods, we eat only halal, no sodas, and no artificial colors in food, we eat at home from our own traditional cooking, and we walk too".

Religion too is prophylactic. It is a main tool in maintaining HEALTH; for Syrian refugees it meant following the Prophetic teachings and recommendations (Sunnah) regarding eating and what foods are better to eat. Many Syrian refugees follow the Prophet's recommendation to eat in moderation; "The son of Adam never fills a vessel worse than his stomach. The son of Adam only needs a few bites that would sustain him, but if he insists one third should be reserved for his food, another third for his drink and the last third for his breathing" (Sunan Ibn Mājah Vol.4; Hadith 3349). The Qur'an also warns against extravagance in consuming food: "And eat and drink but waste not by extravagance" (7.31). Samira a 45-year-old female from rural Aleppo asserts: "I try to eat in moderate quantities, and I eat dates in odd number, as Prophet Muhammad taught us. I walk as much as I can”. Many Muslims invoke religion and Qur'anic verses before eating/drinking. Farida a 51-year-old female from Damascus affirms: "to preserve my health, I follow Prophetic recommendations because they give me strength and health. I 
say Allah's name before and during eating to have blessed food. We eat moderately according to Sunnah; everything in Sunnah if you apply it, you will be healthy".

In addition to the above ways of preserving HEALTH adopted by many Syrian refugees, there are also special foods that the Qur'an recommends Muslims to eat and others which Prophet Muhammad encourages Muslims to consume. First, is olive oil which was mentioned in the Qur'an: “And a tree (olive) that springs forth from Mount Sinai, that grows oil, and (it is a) relish for the eaters." (23.20). Olive oil is also recommended by the Prophet: "Eat olive oil and use it as an ointment, because it is produced by a blessed tree" (Sunan Ibn Mājah Vol.4; Hadith 3320). Another important food in Islam is the black seed. Prophet Muhammad said: "Use the Black Seed, because it contains a cure for every type of ailment, except for death." (Sunan Ibn Mājah Vol.4; Hadith 3447) Ginger too is beneficial as well as rewarding. The Qur'an describes the food those in Paradise will enjoy: "And they will be given to drink there a cup (of wine) mixed with Zanjabil (ginger)." (76.17) In addition to these foods, there are dates which are mentioned several times in the Qur'an and Prophet Muhammad recommended eating them: "Whoever eats seven ajwah (special kind of dates) dates in the morning, will not be harmed by any poison or witchcraft that day" (Sahīh Bukhārī Vol.7; Hadith 5768). Palm trees appear many times in the Qur'an and is referred to as the food of the dwellers of Paradise. Honey is another highly recommended food and its powerful healing attributes have long been used to promote health and healing. Both the Qur'an and Hadiths (Prophetic traditions) refer to honey as a healer of disease. In the Qur'an we read, "And thy Lord taught the bee to build its cells in hills, on trees and in people's 
habitations... there issues from within their bodies a drink of varying colors, wherein is healing for humankind. Verily in this is a sign for those who give thought." (16.69) The Prophet said: "Honey is a remedy for every illness and the Qur'an is a remedy for all illness of the mind, therefore I recommend to you both remedies, the Quran and honey." (Sunan Ibn Mājah Vol.4; Hadith 3578) There are other special food recommended in Islam, but these are the major ones which are used by many Muslims across the world. Many rely on these foods as ways to maintain or preserve HEALTH and others rely on them as healing foods. Alongside these religiously-inspired foods, folk formulations inherited from older generations have become part of Syrian ethno-cultural heritage. Thus, when Syrians are sick they combine three sources: folk/Arab, Islamic, and biomedical or modern.

When asked about what you use to preserve your HEALTH, Nader, a 49-year-old male suffering from heart disease says: "I eat healthy food cooked at home, follow my doctor's instructions, take my medications on time, and most importantly I follow the teachings of the Qur'an and Sunnah. I eat dates, figs, olive oil, black seed, ginger, herbal teas, honey. Also I avoid coffee for high blood pressure". Fatima, a 44-year-old female from urban Ḥoms with back pain states: "I preserve my HEALTH by controlling my weight, doing a bit of sports for back pain, drinking herbal teas which is more important and comforting than taking anti-biotics, I am bored with medications. I eat dates, honey, and olive oil. All Prophetic teachings are precaution." In addition to the above practices adopted by Syrian refugees to preserve HEALTH, there is also another important route that many Muslims take to maintain their and their children's HEALTH: Ruqyah (divine 
remedy). Ruqyah in Islam is the recitation of the Qur'an, a means of seeking refuge in God. It is sometimes attended by supplications asking for protection from God.

Recitation can be done to cure evil eye, possessions of Jinn, envy and magic. ${ }^{15}$ The secret behind this is that one puts full trust, reliance, and dependence on God as a source of healing. "The Prophet has allowed using Islamic prayer formulas (Ruqyah), against fever, the evil eye, and sores." (Sunan Abu Dawud Vol.4; Hadith 3888) Thus, seeking Rukya as a protective option for HEALTH is part of the Sunnah; therefore, many Muslims rely on it as precaution and sometimes treatment. In other words, the text itself has healing and protective qualities. Allah says: "And We send down of the Qur'an that which is a healing and a mercy for the believers, but it does not increase the wrongdoers except in loss.” (17.82)

Mayada a 31-year-old female from rural Dar'a in replying to what she does to protect her health says: “To preserve my HEALTH, I use Rukyah and Qur'an to dispel the evil eye and envy. We eat clean food; no cans, only halal meat and sausages, dates, fresh milk, herbs, sage, thyme, cumin, and lemon." Mirvat a 40-year-olf female from Aleppo asserts: "I preserve my HEALTH by avoiding what Allah forbids, not worry a lot, use herbs, and Rukya from the Qur'an”. These are the major prophylactic steps that Syrian refugees in this study had recourse to. Sixteen out of thirty subjects interviewed stated that Prophetic teachings and Qur'an are included in their HEALTH maintenance

\footnotetext{
${ }^{15}$ In Islam, jinn are created from a smokeless and scorching fire and are a different kind of spirit creature that can do evil or do good. They have a free will just as humans do but can also oppress and possess human beings, animals, and objects.
} 
kit. Now, I turn to the healing approaches that Syrian refugees seek in curing their

\section{ILLNESS.}

Spector claims in her HEALTH Tradition Model that HEALTH restoration in the physical sense can be accomplished by using countless traditional remedies, such as herbal teas, liniments, particular foods and food combinations, massage, and other activities. In the mental domain, the restoration of HEALTH in the mental domain may be accomplished by the use of various techniques, such as performing exorcism, calling on traditional healers, using teas or massage, and seeking family and community support. Lastly, the restoration of HEALTH in the spiritual sense can be accomplished by healing rituals, religious healing rituals, or the use of symbols and prayer, meditation, special prayers, and exorcism (87). These ways again are echoed in the Syrian refugees' practices for treating diseases and restoring HEALTH.

When asked about what they do when they feel pain almost all refugees states that they try to treat themselves at home by a range of practices from folk ways of healing with herbs, soups, herbal teas, etc. to taking over the counter pain medications like Tylenol. Twenty six out of thirty participants said that they endure their pain and rely on folk and religion-inspired treatments as a first step. Twenty two participants said that they seek biomedical intervention only when the pain continues for a long time and as a last option. Only one participant said that he goes to the doctor first. Five participants claimed that they rely on spirituality only as a way to treat themselves at home. In his reply to my question about what he does when feeling pain, Nabil a 46-yer-old male from urban Damascus explains: "the hospital is the last option. We cure ourselves and if we reach a 
blocked path in treatment, we go to the doctor. When I feel sick here I am depressed and afraid because I have to go into this system. We, the Arabs have lots of natural cures and experience. I have a blood pressure machine at home". Mirvat a 40-year-old female from Aleppo states: "I try to treat myself according to our customs and our ancestors' experience. We use herbs and olive oil and if we did not feel better, we go to the doctor". Another female, a 46-year-old Samira affirms: "if the disease is serious and unbearable, I take an appointment, but here they give me an appointment after one month, so I try to try my folk treatments and formulas from ginger, honey, and chamomile till the time of the appointment. If disease is normal and does not disable us, we treat ourselves from what we know". Yasmin a 33-year-old female from urban Aleppo says: "When I feel there is a change in my health, I cure myself first trying homemade teas like cumin and mint tea and relax. If disease persists, I try medications I keep at my home and if pain persists, I go to the doctor. Also prayers and supplications make me feel better, you know in Syria we have folk medicine along with modern medicine".

Another question related to the previous one was whom do they resort to when sick. Most participants answered that they resort to God first then to their families. With the word God or Allah they meant prayers, supplications, Ruqyah, and the Qur'an. Two participants answered that they seek the doctor first and three participants that they resorted to God exclusively. The two participants who answered that they seek the doctor first were young in their age; between 20 and 25 years old. A 20 -year-old female from urban Homs, Farah, states: “if I am mentally exhausted, I seek Allah’s help through prayers and Qur'an but if physically ill, I depend on Allah, go to the doctor and take 
medications". Having only two participants out of thirty stating that they go to the doctor first is not enough to indicate that maybe younger generations are less prone to relying on spiritual and folk cures first when sick. This needs further research and study but it was eye opening as I was transcribing my interviews. Another 32-year-old female from Dar'a, Rana, explains: "when I am sick, I resort to Allah first. He sent us the disease and He cures us, then I resort to my husband and sister overseas". Eighteen out of thirty subjects interviewed answered that when sick, they resort to God and spiritual cures first and then their family support. Four participants claimed that they seek God's help then the doctor.

The last question related to the issue of treatment was "What special foods do you eat when sick?" The answer to this question was more open-ended because each participant had special foods to rely on when sick. It was informative to know about these various foods used as folk treatments. Many foods and formulas were mentioned like: ginger, mint, chamomile, rosemary, and cumin for stomach ache and flu, dates and black seed mixed with honey for energy and almost any disease, yoghurt and garlic for high blood pressure, sage and thyme for throat infection, vinegar pads for fever, olive oil massage for pain anywhere, potato for diarrhea, no beans in case of intestinal pain, rose water for bloating, and many others. Kamal a 33-year-old male from Dar'a affirms: "We use citrus fruits when we have flu; we use sage and potato for stomach aches; and we use mint, chamomile, and pomegranate for diarrhea. We also prepare yoghurt and garlic for vomiting. We have lots of herbs in Dar'a”. Fayez a 53-year-old male from urban Damascus says: "there are lots of special foods which cure me, like lentil soup, herbs, water, dates, and honey everyday". Recommending the usage of herbal drinks, Mirvat a 
40-year-old female from rural Aleppo states: "we have lots of special foods, thank God, that cure and improve your health. We drink hot fluids like herbal and vegetable drinks, we have ginger which is a whole pharmacy. We have dates, honey, Prophetic medicine, and raisins which we use whether we are sick or not." Nader a 49-year-old male from urban Homs says: "When I have high blood pressure I avoid salty and fatty foods. I eat fruits. Figs and olives are mentioned in the Qur'an as a cure for many diseases. I eat dates with milk, black seed, and olive oil." These were the main ways of maintaining HEALTH and curing ILLNESS for Syrian refugees. In what follows I examine the discomfort that Syrian refugees have experienced with the US health care system and how this discomfort is relieved partly by resorting to folk and spiritual treatments.

In my interviews, many problems refugees experienced with US health care emerged; some of them were expected as normal outcomes of the resettlement experience (new culture, system, language, society, and laws) and the status of refugees when they arrive in the host country. Almost all the Syrian refugees interviewed do not know English and they come from lower middle class background. Most of them used to work manual jobs or they were self-employed as construction workers, farmers, and traders. The most recurrent problem Syrian refugees reported was the delay in getting appointments. For example, if one is sick and his/her sickness was serious and continuous, he/she would call her/his doctor and take an appointment. The appointment was given after three to four weeks. By that time, the sickness would have subsided. Twenty six out of thirty participants mentioned this problem. When asked about the Syrian health care system, twenty eight out of thirty said that in Syria, you get an 
appointment on the same day or a day or two after. They also reported that the doctor is accessible at any time; you can have your doctor's number and call him/her at any time. On the same street you may have ten doctors of the same specialty which gives the patient more options and saves him/her time in transportation. Salah a 47-year-old male from Aleppo says:

I had a problem here in my bladder which persisted for more than a week, so I called to get an appointment. They gave me a late one. So I had to cure myself. To do so I bought a belt. When the appointment came, they told me your solution is in the belt. By the time our appointment day is due, we would have felt better and cured ourselves. The biggest problem for me and my family is going to a doctor here and entering the routine network from questions to papers to insurance. We, here as refugees, the biggest catastrophe is becoming sick. In Syria, if you have to wait for maximum time, you wait half an hour in a doctor's clinic. You go to the doctor whenever you want. Here you go from doctor to doctor and in the ER you wait for five to six hours to be seen by somebody and at the end they prescribe for you Ibuprofen which in Syria is not much recommended because of the harm it brings to the body. The difficulty in reaching the doctor here drives us to cure ourselves. Here there are good people but the routine is not comfortable. The Capitalist system causes materialism in everything even time. Even if there is an urgent condition, there is a routine to be followed.

A 52-year-old male from Aleppo, Yasser, says: "The problems in health care here are the treatment and diagnosis. Here the people are very kind. In Syria if you have cold 
or flu you can go to the pharmacist and get your medication and prescription fast. Here you have to go to the ER if you want fast treatment and to wait for five hours".

The second recurring problem was receiving wrong diagnosis and wrong treatment. Many Syrian refugees in their home country were diagnosed with certain health problems and here were diagnosed with something totally different. It is worth noting here that when I was almost approaching the end of my interviews, a Syrian primary care doctor, Dr. Fouad, started his work in Louisville. Almost all the Syrian refugees who were interviewed after that time were seen by him. It was apparent from the interviews conducted after Dr. Fouad started seeing Syrian refugees that they felt comfortable with him, and had no problems in translation or doctor's availability since they had his private number; therefore, they called or texted him at any time. For example, Jamal a 47-year-old male said: "Now I am seen by Dr. Fouad. Before that I was diagnosed here with cancer and the doctor here referred me to an urologist. The urologist gave me appointment for colonoscopy after two months. During that period, I felt depressed and deluded. The result of the colonoscopy had nothing negative. Now I am seen by Dr. Fouad and he did not diagnose me with such health problem”.

The third major problem Syrian refugees have faced was the heavy reliance on machines and technology to diagnose and examine. Related to this problem was the quantifying of pain (describing pain from 0 to 10) and the new medical system here that they were not used to in Syria. This included the process and way of examination and diagnosis, the time the doctor spends with the patient, and the lack of comfort from the doctor. Twenty two out of thirty subjects interviewed said that in Syria the doctor 
comforts the patient with his/her words, he/she spends enough time with the patient listening and questioning. The system in Syria is different according to the Syrian refugees. There the doctor is responsible for examining (usually physical examination on bed), taking vital signs, asking questions and getting enough information about the patient, diagnosing, and even comforting the patient. Here in the US, things are quite different. The patient when entering the clinic, he/she goes into certain routine: has to fill out some papers with lots of yes/no questions, is checked by the nurse who asks questions and takes the vital signs and puts them into the computer. Then the patient waits for the doctor to come for five to ten minutes to give his/her conclusions based on the numbers and answers he/she gets from the computer. The doctor asks about the pain from 0 to 10 and where that pain is. He/she then gives the primary diagnosis before referring them to more imaging, blood tests, or other procedures. No one of the participants mentioned being examined physically by the specialty doctor. Thus, the sense of touch is absent from their encounters with US biomedical system. Seven of the participants indicated that in Syria, the public sector is good but there is lots of "wāsța (you have to know or be protected by somebody who is powerful to be admitted quickly). The private health sector is not free and not all people can afford the private hospital. Therefore, most of the Syrian refugees preferred to go to doctors' clinics and sometimes pharmacists.

Answers elicited from two related questions: "what problems are you having with health care here? And "what is the thing you wish for in health care here?" reveal clearly articulated problems and solutions. Nabil a 46-year-old male from Damascus says: "The problems here are time and translation. I wish the doctor here would feel my pain, touch 
it, and ask about my pain instead of asking about the number of pain. Translators here abridge my complaints." A 47-year-old male from Aleppo, Salah, admits: "The problems here are time, no comfort from doctor, and reliance on devices and numbers. There is no trust that the doctor understands my pain. Access to doctor is hard here. Also there is no value for pain; pain is in numbers only." Mirvat a 40-year-old female from Aleppo explains:

There are positive and negative things here. The positive thing is the good treatment for people. The negative things are: language, I am not able to communicate what I feel. There is no trust in translators. The system here makes you feel afraid if you get sick. Here is a new system of treatment we are not used to. For example, the medication here is prescribed at the end, and here they offer very slow treatment while in Syria they directly give you treatment. Also the health care staff is very frank; they don't hide anything, and they shock you with their words and diagnosis. I wish for a direct examination by doctor, where he/she examines the pain area and not quantify pain.

Farah a 20-year-old female from Ḥoms answers when asked about her wish: "I wish here the doctors give you more time. Here they are always in a hurry and they don't follow up with your pain. They ask you indirectly through the papers, but not directly. They can't know my pain through papers and numbers from 0 to 10; therefore, I am curing myself most of the times." A 45-year-old female from rural Aleppo, Samira, describes her experience with US health care: 
Here they rely on technology and machines in medicine. The doctor does not examine you. There is a long time for diagnosis and you go from one doctor to another. Time is spent in routine things like papers, insurance, and you become tired. Every physician here is for a part of the body and diagnoses the part or speaks about the pain he/she is specialized in. Here there is no spiritual comfort from the doctor, they speak everything frankly with no respect to our feelings. In Syria, even if they only doubt it is cancer, they tell the parents or the partner. I wish here the doctors feel the pain and comfort you in their words. The way of examination is new too.

In addition to the above listed problems the Syrian refugees were having upon navigating the US health care system was translation.

Nineteen out of thirty participants in this study reported their dissatisfaction with the translation services either because of lack of these services sometimes, being forced to speak to translators on phone, not being able to communicate pain to translators, lack of trust in translators, or translators insisting on refugees to recap and be fast. These situations in hand create an atmosphere of discomfort and renders the experience with the health care system an unsuccessful or unproductive one. Yasmin a 33-year-old female from urban Aleppo reports: "my translator always asks me to summarize." When asked about what you wish for a 33-year-old male from Dar'a, Kamal, replies: "language, I wish doctor could understand me. The translator summarizes and not communicate everything to doctor. They rely here on numbers and tests while in Syria the doctor examines on bed and knows my pain". It was really surprising when I was transcribing 
and collecting my data and found that the translation service which is one of the basic resources refugees are in need when they resettle is not satisfactory. Instead of comforting these refugees and making things easier upon resettlement, translation services were not unfortunately doing their job. I think this is one of the major reasons Syrian refugees were switching to Dr. Fouad. It seems from the data collected that more than 90 percent of the refugees interviewed were satisfied with the Syrian health care. Complaints were only about having to pay money in private hospitals and use 'wāsta' in public ones. They had no problems with accessibility of doctors, language, pain, way of diagnosis or treatment, time, and appointments. Salam, a 48-year-old female from urban Homs asserts: Health care in Syria is excellent, no waiting, no appointments given late, and the doctor is available whenever you need him/her. There is physical exam always, the doctor comforts you with his/her words and calms you down". Therefore, the main problems Syrian refugees encountered with US health care can be outlined as: time, quantification, access, frank talk, specialization, and lack of warm interaction.

These problems and the discomfort they caused for refugees can be juxtaposed to the comfort and happiness they experienced upon using religious and folk health traditions. Thirteen out of thirty refugees interviewed expressed their fear and sort of depression when sick due to the need to call the doctor and take appointments. This is eye opening for the necessity of providing a healthy encounter with the US health care system where feelings of fear and discomfort are lessened.

Twenty five out of thirty Syrian refugees interviewed reported their comfort and happiness when using folk medicine and religious recommendations in HEALTH and 
ILLNESS. Various opinions circulated about the reason behind that comfort. Some said they felt as if they were in Syria or they reminded them of the golden days in Syria and their (country, family, parents, old habits, etc.). Others expressed their healing effects which resulted in happiness and comfort. Three refugees said that they comforted them because they saved them the time to go to doctors here. Three Syrian refugees said they felt nothing upon using these religious and folk health traditions. Two participants said they rarely use them. These two were younger in age than all other participants (less than thirty years). When asked about feelings when using religious and folk health traditions Rawan a 47-year-old female from rural Aleppo affirms: "prayers, Sunnah recommendations, and herbs make me happy and comfortable. They bring back nice memories and days. Once I was here walking to my neighbor's apartment nearby and found some chamomile leaves so I picked them and was extremely happy." A 31-yearold female from Dar'a, Mayada asserts: "these folk and religious traditions comfort me for sure, all are good and beneficial. If we follow all of them and the Qur'an we don't get sick. They remind me of Syria and my family." Yasser a 52-year-old male from Aleppo explains: "folk and religious traditions comfort me, they remind me of the old days in Syria. I used to be a baker back there, and here I am trying to do ma rūk (a Syrian dessert) just to revive the old habits and days." So, from these answers, we can understand the sense of comfort and psychological resilience that these Islamic and folk health traditions are generating in Syrian refugees amid the stressors and problems they are facing with the health care system upon resettlement. 
The encounter with the health care system is a vital part of the resettlement process. Sixteen out of thirty participants interviewed reported that they chose to resettle due to health issues in their families and for the purpose of treating disabilities or chronic conditions. After analyzing all interviews and collecting the data, I conclude that it is recommended for the US health care system to be aware of the folk and religious HEALTH traditions of Syrian refugees. These traditions are vital for two reasons. First, to obtain a pluralistic health care system which can accommodate various medical perspectives and could create a zone of trust for patients. Second, the Syrians' ethnocultural and religious health system provides them with many ways of diagnosis, treatment, and prophylactics. These folk and religious HEALTH traditions comfort refugees, lessen feelings of stress and fear, and contribute to their resilience when navigating the health care system in US. So, my hypothesis would be partly in conversation with Spector's HEALTH tradition model adding to it the effect of these traditions on refugees and modifying the model to aim not solely for cultural competence but also for medical pluralism.

It is quite apparent that folk and religious health traditions provide psychological and spiritual comfort, a sense of community and continuity, social and cultural capital to adjust to a new environment, and could be a source of income. Furthermore, they can act as a medium to maintain various levels of identity, provide mutual aid and cohesion between Syrians, and bridge relationships with host societies. Finally, in certain cases, these traditions can be harnessed to overcome conflict and tensions between Syrians and members of host societies here the US. In various degrees, they thus contribute to the 
psychological, social, and economic resilience of displaced Syrians. Here we are interested only in the psychological resilience. Folk and religious HEALTH traditions as we have seen are part of the cultural and religious heritage of Syrian; therefore, and as noted in the United Nations Educational, Scientific, and Cultural Organization's (UNE UNESCO) International Council on Monuments and Sites (ICOMOS) paper about the importance of memory in heritage resilience, "The symbolism inherent in heritage is... a powerful means to help victims recover from the psychological impact of disasters... Heritage contributes to social cohesion, sustainable development, and psychological wellbeing. Protecting and preserving heritage promotes resilience" (Swink, 2014).

Resilience, according to the American Psychological Association, is the process of adapting well in the face of adversity, trauma, tragedy, threats or significant sources of stress such as family and relationship problems, serious health problems or workplace and financial stressors. It means "bouncing back" from difficult experiences ("The Road to Resilience"). People develop emotional ecosystems and while those are mostly built around social interactions, emotional ecosystems are also influenced by culture and its physical manifestation. One's physical surroundings and the traditions associated with place are integral to a sound emotional ecosystem. Folk and religious health traditions are strongly associated with the physical manifestation of culture; therefore they occupy a prominent place in the emotional ecosystem influenced by that culture. Folk and religious health habits for Syrians are rooted in the place they lived in (home country), in their homes, and in their social networks (families, neighbors, and friends). When displaced and forced to leave their country, Syrian refugees feel the need 
to preserve these traditions and habits as part of preserving their culture and identity. Dr. Mindy Fullilove writes about such ecosystems and has borrowed a term from gardening, "root shock," to describe "the traumatic stress reaction to the loss of some or all of one's emotional ecosystem." When people are uprooted and displaced and they lose not only their connections to neighbors but also to those elements of familiarity that help to anchor them to a place, their emotional ecosystem suffers. Being able to reconnect with physical manifestations of place helps to stabilize one's stress and minimize the trauma. There is a close relationship between place and nostalgia. Fullilove defines "place" as a setting where disaster-affected people feel that they have a good enough living environment. The perception of disaster-affected people is linked to the surrounding environment through the following three key psychological processes: attachment, familiarity, and identity. Place attachment involves a mutual caretaking bond between a person and a beloved place. Familiarity refers to the processes by which people develop detailed cognitive knowledge of their environs. Place identity is concerned with the extraction of a sense of self based on the places in which an individual spends his/her life. Each of these psychological processes (i.e., attachment, familiarity, and place identity) can be threatened by displacement; consequently problems associated with nostalgia, disorientation, and alienation may ensue (1516). This sense of nostalgia was apparent in many refugees’ responses. Jamila a 51-year-old female from urban Ḥoms states: “folk traditions bring lots of comfort and memories of nice days with parents and family gathering at my home where I used to serve matte (Syrian herbal drink) and used to infuse my house with scents of fresh flowers. I am trying to do the same here to feel 
happy." ICOMOS's session paper "Heritage and Resilience" asserts that cultural heritage as a key component of cultural diversity, is a critical consideration for any strategy to build the resilience of communities (20-21). Several studies have also focused on displaced communities over the long term and found that, even in situations of geographic and/or social dislocation, these communities can display cultural resilience. Refugees and IDPs have turned to various forms of cultural expressions whether tangible or intangible that help them live through disasters. Such forms, according to UNESCO's convention paper "What is Intangible Cultural Heritage", include collective practices of social bonding and remembrance, and the celebration of birth, marriage and other festive events. Moreover, they include individual acts of cultural expression like food, health care, and hygiene habits. Within new environments, the performing arts or crafts skills can furthermore provide a source of livelihood, whereas traditional knowledge may be harnessed for survival (2016). Thus preserving these cultural expressions can have a positive psychological, economic, and social effects on refugees.

Religion too is inseparable from cultural heritage which is embedded in social and cultural practices, representations, a sense of belonging, and identity. Cultural heritage 'moves' with its displaced bearers, who may use it to respond to social, economic, and psychological shocks. In exile, this heritage may be central to the refugees' collective memory, cultural identity, and resilience. "Participation and access to culture and its living expressions, including intangible heritage, can help strengthen people's resilience and sustain their efforts to live through and overcome crisis" ("What is Intangible Cultural Heritage?"). Syrians carry folk and religious health traditions with them as a 
toolkit wherever they settle in the world; thus, this toolkit encompasses representations and expressions of their culture and identity. Religion is a main item in this toolkit. Therefore, practicing Prophetic recommendations and Qur'anic teachings regarding HEALTH and ILLNESS is an expression of identity for many Muslims here for Syrian refugees. Resilience was attributed to faith in God, and Syrian participants were able to attribute to their religion just about any aspect of their lifespan. Individuals sought strength in God's plan on multiple occasions even in illness. They reported that their number one resort when sick is God and prayers. They expressed their faith and patience when sick and some even felt thankful to God for testing them. The refugees in this study used their faith and religious teachings as a means of coping, hope, and finding the optimistic outlook in any given situation. Patience was a key factor in association with coping and resilience. Ethno-cultural and religious health beliefs and practices helped refugees cope with their experiences; it assisted them in reacquiring some of the stability and constancy lost throughout their pre-war lives. So, as conclusion to data analysis for this study, we can say that folk and religious health traditions are a source of comfort and resilience for refugees resettling in new environments and detached from their communities, places, culture, familiarities, and traditions. Thus, I would modify Spector's model calling for implementing the Health Tradition Model not only for obtaining medical pluralism (Spector used 'cultural competence'), but also as a tool of comfort and resilience amid the stressors and discomfort that refugees encounter upon resettlement. 


\section{CHAPTER FIVE}

\section{SUMMARY AND IMPLICATIONS}

Syrian Muslim refugees can be empowered and supported by recognition and validation of their resiliency during the resettlement process. This study has shown that Syrian refugees find significant comfort and measurable happiness in using their folk traditions and abiding by their religious doctrines and practices regarding their health. This study has proved that approaching the refugee resettlement experience should not be exclusively a pessimistic and negative one, focusing on problems, conflicts, pathologies, and stressors, etc. In other words, there is space for hope-infused refugee studies which stress the cultural wealth that refugees bring with them to the host country. In addition, their beliefs, traditions, experiences, etc. could be a major part of the integration strategy they employ after resettlement. Here, I focused on the folk and religious health traditions and beliefs that could be recognized by the US medical system and thus could play an essential role in moving towards a more pluralistic medical system.

In reference to the ongoing refugee crisis, students, researchers, scholars, and other individuals involved in academia should be cognizant of Syrian refugees' religious beliefs and folk traditions as coping mechanisms. The strengths of this population are many, some of which include: spirituality, resilience, and networks of social support. These strengths are fueled by their attachment to religious beliefs and folk traditions which are critical components of their identity. Health care staff can especially build upon these strengths in practice by understanding their ways of treatment and their 
perspectives of Health and Illness, by recognizing their need of emotional support during illness and treatment, by appreciating the role of spirituality and folk health traditions in their treatment, by validating refugees' abilities to stay resilient, and providing reassurance for their support systems. I interviewed seven people who work in the field of refugees' mental and physical health care in Louisville. Two were mental health therapists Nancy and Belinda; when asked what distinguishable things they discovered about Syrians in their way of thinking about health or treatments, they answered that Syrian refugees want to feel better and want help but not necessarily medications or treatments. They feel better when "spending time with families and doing what they used to do in Syria. They like to move their lives there to here." Only these two participants out of the seven interviewed realized the positive role of religion in the lives of Syrian refugees including their health.

These above mentioned needs should be adequately addressed in the US social work and health care policies in order to achieve a successful and effective resettlement experience and at the same time to experience the US not as a melting pot but rather as "chocolate fondue" as Timothy Taylor (2013) suggests. He claims that our different cultural and ethnic backgrounds are the strawberries, pineapple, and cherries, the graham crackers and cookies, the pound cake and brownies, the rice crispy treats and marshmallows, the popcorn and the peppermint sticks, this is how we are dipped in this country.

At a policy level, the results of this study uncovered the notion that refugees entering the United States do get many of their needs addressed, but there is still room for 
improvement and there remain substantial but unrecognized hidden needs. The study proved the urgency of addressing the emotional needs of refugees regarding their health issues in addition to appreciating their holistic view of health and the role of faith when encountering pain. Policies in place for refugees to receive adequate services (besides the usual — food stamps, housing, etc.) could undoubtedly be ameliorated to encompass these needs and thus, to highlight the resilience that refugees implement when facing conflicts or problems.

Researchers could refer to this study in order to expand upon and complement its findings. For future health care research and refugees, problems that Syrian refugees encounter in their experience with US health care system could be analyzed in details. Their comfort and sense of fortitude when using their folk health traditions and when following their religious doctrines regarding health could be subject to more measurable or quantifiable criteria. The incoming Syrian refugee population has not been the focus of much research to date, and these findings lend support to a small but growing body of research about the resources refugees have recourse to as coping mechanisms upon resettlement and to realizing a more pluralistic medical system. Researchers could undeniably utilize these findings in order to assess the role of religious beliefs and folk traditions in the overall health status whether physical or mental of refugees. These findings could open the door for studies about other refugees of different ethnic and religious backgrounds.

I began this study by using Rachel Spector's Health Tradition Model as the theoretical launching point for exploring Syrian refugees' ethno-cultural and religious 
beliefs regarding their health. New findings emerged upon data analysis regarding the positive effect of these beliefs on refugees upon resettlement, the role they play in fortifying refugees with resilience, and some systematic discrepancies in health care encounters between their culture and US. Syrian refugees aim for integration as an acculturative strategy; however this process as mentioned before is a two-way process where the incoming refugees and the host communities are willing to come to a middle point where exchange of beliefs, customs, experiences, skills, knowledge, and traditions serve to enrich the new integrative community. Essentially, integration requires mutual acceptance by both the refugee and the communities in which they live. When asked about the ways we can adopt to better the health encounter between refugees and health care institutions and staff, Lisa one of the nurse practitioners in charge of the Syrian refugees in Louisville 550 Clinics (before it was changed to another name) gave an interesting answer that pinpoints the role of health care staff and the goals they should set for achieving better health care encounters. Her answer highlights the fact that some US health care staff are aware of the deficiencies in this biomedical system. She states:

We need more empathy, care, and concern for refugees. We need to be cognizant of their stressors. We are egocentric, we need to have estimation of ourselves and our weaknesses, we have to move to a learner's posture, where we can learn from them and learn how we can be the channels that move these refugees to better and good health. We need to empower them. I suggest we have holistic clinics for refugees. 
Therefore, integration requires individuals and communities working together to accomplish mutual goals and purposes. To support Syrian refugee resettlement, mutual goals between the refugees, refugee agencies, community partners, health care professionals and systems, and the policies of public institutions need to be identified and put into operation. The desired outcome of integration in Roy's Adaptation Model (1976) is not equilibrium, but rather transformation and growth.

The problems that refugees face upon encountering the health care system in the US are indicative of some degree of difference between their health/illness beliefs and perspectives and the ones practiced by the US biomedical health care system. Therefore, the findings point to the need to implement medical pluralism in the US. Examining the perceptions of participants in this study has given me the opportunity to better understand how refugees view resettlement and how, from their own perspective, they feel more comfortable in handling health issues upon resettlement. Conceptual properties and dimensions of Spector's modified model now has a level of abstraction, substance and meaning. Theoretical comparison is fundamental to perceive the reason behind adopting abductive analysis as my methodology.

\section{Theoretical Backgrounds}

Spector's theory or model of Health Traditions is fundamental to the concept of cultural competence. Examples from different cultures show how to apply the HEALTH Tradition Model and assist the reader (health care staff) to use the model when caring for people from diverse cultural backgrounds. The HEALTH Traditions Model explores what people do from a traditional and/or alternative perspective to maintain HEALTH, 
protect HEALTH or prevent ILLNESS, or restore HEALTH (HEALING). The philosophy of Cultural Care is foundational for applying the HEALTH Traditions Model to cultural competency. Cultural Care is an approach in which HEALTH, ILLNESS, and HEALING are understood holistically. HEALTH is a holistic (physical, mental, and spiritual) balance within the body and with the outside world (natural, communal, and metaphysical). ILLNESS is a state of imbalance within the person (body, mind, and spirit) or environment. HEALING is a phenomenon that restores balance within the

person (body, mind, and spirit) or between the person and the environment. Each of these concepts provides the basis for attending to a person's perspective when it comes to health, illness, and healing. Spector defines cultural and linguistic competency as the ability by health care providers and health care organizations to understand and respond effectively to the cultural and linguistic needs brought to the health care experience (7-8). This cultural care approach recognizes the diversity that exists among the patients.

\section{Theoretical Variation}

Spector's theory focuses on the positive effects of adopting this model in nursing and health care to enhance the health care encounter between US health staff and systems and patients from different ethno-cultural backgrounds. The surprising data I came up with from my interviews is that this model is beneficial not only for attaining a successful health care encounter and thus achieving cultural competency. It is also essential for refugees in particular since they have lost a host of state, social, economic, and familial resources upon displacement and resettlement; therefore their health beliefs and traditions are part of the resources they aim to keep and rely on during times of adversity. Not only 
can this model be adopted by health care professionals, but also social workers and scholars interested in refugee issues and studies. In this way, the approaches to studying the incoming refugees' health issues are not exclusively focused on medical/pathological and problematic issues or are application of Western-designed scales that depict quantitative measures of stress and other mental problems. Also, my point of view here is that Spector's HTM is not essential for achieving cultural competence only, but more comprehensively achieving medical pluralism since nowadays cultural competence is limited to certain bureaucratic and systematic services, mainly translation. Medical pluralism is a more comprehensive term that accommodates many of the assumed principles of cultural competence.

Although rarely stated explicitly, the essential principles of cultural competence are: (1) acknowledgement of the importance of culture in people's lives; (2) respect for cultural differences; and, (3) minimization of any negative consequences of cultural differences. Culturally competent clinicians are supposed to promote these principles by learning about culture, embracing pluralism, and engaging in proactive accommodation. Generally, culturally competent care will advance patient autonomy and justice. In this sense, cultural competence and Western medical ethics are mutually supportive movements. However, Western bioethics and the personal ethical commitments of many health care providers will place limits on the extent to which they will endorse pluralism and accommodation as essential in their practice of cultural competency. Efforts to promote cultural competence in medical education and practice that have blossomed over the past decade have thus focused primarily on the task of providing cultural information 
about various immigrant communities. Although this information can be fruitful to some degree in improving the quality of health care provided for patients of different ethnocultures, there are discernable gaps and risks that need to be addressed and highlighted. Within this frame of cultural competence, the understanding of many cultures tends to be over-simplified. Many stereotypes permeate these cultural profiles. Culture is not a static and timeless thing. It is constantly changing as people make use of their cultural resources in creative and surprising ways (Santiago-Irizarry 1996). Since this the reality in the US health care system today, biomedicine should become as many medical anthropologists have been advocating, only one of the many ethno-medicines from which people are free to choose. People may wish to use biomedicine along with other ethnomedicines. Thus the aim is not to replace biomedicine but rather to augment its effect (Erickson 2016).Therefore, 'medical pluralism' is a more explicit, clear, and comprehensive term than 'cultural competence. As long as medical students are educated to perceive cultural competence as special and quite distinct from the real competence that they need to acquire as future doctors and nurses, the practice of cultural competence will remain undeveloped and not fully realized. Medical competence should be synonymous with cultural competence; therefore, the change should start from educational institutions and medical pluralism should be adopted instead of cultural competence which is narrow and prone to stereotypes, power relations, and interests.

The theoretical approaches that have guided research on the psychological and physical well-being of refugees have mainly highlighted the medical/pathological aspects of refugees' health in addition to some theories focusing on psychosocial stressors. 
Refugees' health is not a field of studies where mental and physical diseases are navigated whether qualitatively or quantitatively. Refugees have voices, demands, have their own beliefs and perspectives regarding their health that need to be voiced, addressed, and recognized. These beliefs and perspectives, once considered and processed by social workers, health care providers, and policy makers can render the resettlement experience less stressful and less exhaustive to both refugees and hosting communities. There are some studies that consider the resilience of refugees and resources they rely on to cope with their new conditions. However, not all people show resiliency in the same way and almost all of the studies focusing on resiliency and coping strategies do not examine religious and folk health traditions as one of the resources refugees rely on to protect and treat their health issues. In many studies the concept of social connections for refugees is recognized and highlighted, but the importance of a mutual accepting relationship among refugees and community partners is not acknowledged. Moreover, development of mutual goals for the refugee and community to facilitate successful refugee resettlement is almost absent from many studies. Culturally sensitive questions and interviews rather than using standardized Western instruments can be more effective in conducting studies about refugees. Although commonalities exist, one cannot assume that what meets the needs of one group will meet the needs of another.

\section{Recommendations}

We have to start going beyond the one-dimensional view of refugees as victims lacking agency who are often portrayed in the literature as bearers of symptoms, coping 
strategies, and stressors and allow them the voice to say what makes them less stressed and more comfortable. Researchers should aim to grasp from these voices the positive optimistic things and useful resources that promote a successful and effective resettlement experience. Instead of looking at deficiencies in these refugee populations, let us pinpoint the deficiencies in our systems, institutions, and policies.

Findings from this study suggest that refugees' identification with their own religious and folk health resources (beliefs, perspectives, traditions, and commodities) can facilitate the resettlement process; whereas constrained access to these resources upon encountering the US health care system can affect their well-being. During the interview period of my study, Syrian refugees Louisville had started to be seen by a Syrian doctor. All of the participants who had met this doctor expressed their comfort, happiness, and relief when being examined and seen by him. This shows the importance of cultural identification in the realm of health. Ryan, Dooley and Benson (2008) argue that refugees become further distressed when the host resettlement society places restrictions on the resources that are required to meet their basic needs. In case of Syrian refugees, these restrictions take the form of unawareness and negligence of their religious and folk health beliefs and perspectives.

Syrian refugees have experienced a multi-faceted loss of resources during their pre-migration phase in the form of death of family members, destruction of their homes, or loss of their safety due to violence and civil unrest. Syrians may continue to experience loss of resources as they migrate across borders to neighboring countries. In this respect, loss is also about losing a sense of belonging, loss of material resources due 
to fleeing unexpectedly, or the inability to obtain employment in the country of asylum. Once they resettle in the US and transition to the post-migration phase, further extensions of loss related to societal constraints on needed resources can severely impact the outcome of the resettlement process, thus affecting their health status whether physical or mental. Transformation and growth can occur when community partners work collaboratively with the refugees to assess their loss, establish goals, and identify the resources needed to help them reach those goals. In so doing, refugees' voices are validated and approaches to them are hope-oriented and empowering. The challenge is to create better policies to make those resources accessible, affordable, and implementable. Tangible support from host communities can foster a sense of hope, comfort, and optimism for Syrian refugees and positively affect their health outcomes and resettlement experience as they establish a sense of belonging in their new social environment. When this occurs, integration of the refugee within the communities in which they live becomes a reality.

This abductive-method research study contributes to the body of knowledge on refugee resettlement by representing new findings particularly about Syrian refugee populations. The basic process of resettlement for Syrian refugees has been relatively unexplored; therefore, this study has narrowed the gap in understanding by highlighting the positive sides of Syrian refugees' resettlement experience and revealing some resources they resort to which provide more comfort and ease stress. These findings can contribute to scholarship in refugee studies and medical anthropology. Essentially, it inspires action for advocacy on behalf of refugees. 
Syrian refugees have distinct cultural and religious characteristics and practices in health that health care professionals should strive to recognize, understand and respect. For example, praying is a religious practice that many Syrians use to nurture their spiritual as well as their physical well-being while managing the stressors of resettlement. Allowing them to pray during health care encounters and facilitating their spiritual practices during hospital stays may reduce tension and anxiety about certain procedures and treatments. Additionally, emotional support is necessary when Syrians verbalize their mental and physical health concerns. Acknowledging spiritual health is critical. Health care outcomes are more effective when staff are informed about the positive role of spirituality in their patients' lives and respect their patients' beliefs and perspectives in health and illness. Allowing them time and space to voice their concerns and acting upon them with mutually developed health care goals will facilitate confidence that their input is valued and respected. Other medical systems besides the biomedical one should be approved and available for people of various ethno-cultural backgrounds to choose from or integrate between. These non-biomedical systems should be implemented encompassing the specific ethno-cultural ways of treatment, diagnosis, prevention, beliefs, and perspectives that are heath-relative. It is critical to provide health care that is holistic for Syrian refugees and many other refugee populations who believe that 'health' is a holistic term encompassing balance in all aspects of the life of a human being.

\section{Limitations}

In any research there are limitations imposed by circumstances. These limitations must be recognized and acknowledged. Due to my previous knowledge of some Syrian 
refugees in community events, filtering of information has been one of the potential weaknesses of the study. Another concern was the fear of exposure. Syrian has a repressive state surveillance and information-gathering system. Syrians often says that the "walls in Syria have ears" and you cannot speak openly even on the phone. Participants may have given a response that they perceived to be socially desirable or "safe" rather than what they actually think, feel, or do. Safety becomes a concern if participants withhold information that they fear might result in retaliation against family members who remain in Syria, or harm that might come to them if their whereabouts were discovered. There is no way to know what information may have been withheld, but the possibility is acknowledged. This is essentially "filtering" their ideas to select only what they want the interviewer to know. Another limitation for my study was that only three participants were less than 30 years old, and these in particular have not shown much reliance on folk and religious health traditions. Future examination of the relationship between age and the usage or resort to these traditions is recommended.

\section{Final Reflection}

During the ten-month period of my study, I experienced compassion stress as I listened to Syrian refugees' stories and analyzed the interviews. I was overcome with emotion when I left some of the interviews and began to cry as I considered the plight of their circumstance. However, this emotional stress motivated me to dig into what renders these refugees more comfortable and less stressful. Despite being culturally closely related to Syrians as I am Lebanese, I learned a lot from them and about them. Syrians refugees I have interviewed mostly were clearly attached to their culture and folk 
traditions. These traditions and beliefs were important resources for them, rendering them resilient and more comfortable upon resettlement with all its stressors.

Recognizing the gaps in the health care-encounter-experiences that impeded successful resettlement for Syrians was alarming to me. I had feelings of sadness, yet anger at the same time when I realized such severe deficiencies exist within the health care system; deficiencies that constrain the availability of resources to meet their basic needs. I feel an overwhelming desire to advocate for change. Conducting this abductive research study was the first step toward change and developing innovative approaches to refugee studies.

Therefore, I have a stronger commitment to continue pursuing a trajectory of refugee research, particularly with Syrian refugees. I am forever grateful for the opportunity to meet, interact, and develop trusting relationships with the participants in this study. I sought to know their stories, perspectives, and beliefs which they willingly shared them with me. As a result, I now better understand these fellow human beings and the hardships they are experiencing. My hope and intent through this completed research is to advocate for greater access and understanding to their resources and empowering support for their resettlement transition. 


\section{REFERENCES}

Abu-Ras, Wahiba and Soleman H. Abu-Bader. "The Impact of the September 11, 2001, Attacks on the Well-Being of Arab Americans in New York City." Journal of Muslim Mental Health, vol. 3, no. 2, 2008, pp. 217-239, doi:10.1080/15564900802487634. Accessed July, 2017.

Achour, M. et al. "Measuring Religiosity and Its Effects on Personal Well-Being: A Case Study of Muslim Female Academicians in Malaysia." J Relig Health, vol. 54, no. 3, 2015, pp. 984-997, doi:10.1007/s10943-014-9852-0. Accessed Oct. 2017.

Adib, Salim M. "From the Biomedical Model to the Islamic Alternative: A Brief Overview of Medical Practices in the Contemporary Arab World." Social science \& medicine, vol. 58, no. 4, 2004, pp. 697-702, doi: https://doi.org/10.1016/S02779536(03)00221-1. Accessed Nov. 2017.

"Admissions \& Arrivals." Refugee Processing Center, U.S Department of State (DOS), Bureau of Population, Refugees, and Migration, Sep 30, 2018, retrieved from: www.wrapsnet.org/admissions-and-arrivals/.

Adra, Hisham. "Syrians Turn to Herbal Remedies As Cost of Medicine Soars." ASHARQ AL-AWSAT, 6 Nov. 2014. Retrieved from: eng-archive.aawsat.com/h-adra/lifestyleculture/syrians-turn-to-herbal-remedies-as-cost-of-medicine-soars. Accessed Jan. 2018.

Ager, Alastair and Alison Strang. "Understanding Integration: A Conceptual Framework." Journal of refugee studies, vol. 21, no. 2, 2008, pp. 166-191, doi:10.1093/jrs/fen016. Accessed Nov. 2017.

Ahn, A. C. et al. "The Limits of Reductionism in Medicine: Could Systems Biology Offer an Alternative?" PLoS Med, vol. 3, no. 6, 2006, p. e208, doi:10.1371/journal.pmed.0030208. Accessed May. 2017.

Ai, Amy L. et al. "Research: The Effect of Religious-Spiritual Coping on Positive Attitudes of Adult Muslim Refugees from Kosovo and Bosnia." The International Journal for the Psychology of Religion, vol. 13, no. 1, 2003, pp. 29-47, doi: 10.1207/S15327582IJPR1301_04. Accessed Nov. 2017.

Alachkar, A. et al. "Traditional Medicine in Syria: Folk Medicine in Aleppo Governorate." Nat Prod Commun, vol. 6, no. 1, 2011, pp. 79-84. Accessed Sep. 2017. 
Al-Ahdab, Fares et al. "Syrians' Alternative to a Health Care System: "Field Hospitals"." Avicenna Journal of Medicine, vol. 4, no. 3, 2014, pp. 51-52, PubMed, doi:10.4103/22310770.133329. Accessed Feb. 2018.

Al-Awadi E., Al-Hashel J., Al-Hajeri D. "Quranic faith-healing practices in Kuwait." Department of Community Medicine, Health Science Center, Kuwait University, 1999. (Unpublished report).

Ali, O. M. et al. "The Imam's Role in Meeting the Counseling Needs of Muslim Communities in the United States." Psychiatr Serv, vol. 56, no. 2, 2005, pp. 202-205, doi:10.1176/appi.ps.56.2.202. Accessed Feb. 2018.

Al-Jawziyya I. Healing with the Medicine of the Prophet. Translated by Jalal AbuAl Rub, Darussalam, 2010.

Al-Khayat, M. "Health as a Human Right in Islam." Health Education Through Religion, vol.9, 2004, pp. 1-42, www.emro.who.int/publications/HealthEdReligion/Index.htm. Accessed Oct. 2017.

Al-Mundharī, Abdul 'Az̄̄īm. Targhib wa-al-Tarhib Min al-Hadith al-Sharif (4 Volums). Dar Ibn Katheer, 2014.

Al-Mustadrak. Translated by SH, Alamdar, Ansariyan Publications, 2003.

Alrawi, Sara, et al. "Traditional Healing Practices among American Muslims: Perceptions of Community Leaders in Southeast Michigan." Journal of Immigrant and Minority Health, vol. 14, no. 3, Aug. 2011, pp. 489-496., doi:10.1007/s10903-011-94950. Accessed Nov. 2017.

Asgary, R. and N. Segar. "Barriers to Health Care Access among Refugee Asylum Seekers." J Health Care Poor Underserved, vol. 22, no. 2, 2011, pp. 506-522, doi:10.1353/hpu.2011.0047. Accessed Feb. 2018.

Ashy, Majed A. "Health and Illness from an Islamic Perspective." Journal of Religion and Health vol. 38, no. 3, 1999, pp. 241-258, https://doi.org/10.1023/A:1022984718794. Accessed Oct. 2017.

Azaizeh, Hassan et al. "The State of the Art of Traditional Arab Herbal Medicine in the Eastern Region of the Mediterranean: A Review." Evidence-based Complementary and Alternative Medicine, vol. 3, no. 2, 2006, pp. 229-235, PMC, doi:10.1093/ecam/nel034. Accessed Oct. 2017.

Bar, Mohammed Ali al-, and Hassan Chamsi-Pasha. Contemporary Bioethics: Islamic Perspective. Springer Open, 2015. 
Barakat, Najieh S. The Adab Al-Tabib of Al-Ruhawi: Its Significance and Relevance to Contemporary Medical Ethics. Kulliyyah of Islamic Revealed Knowledge and Uman Sciences, International Islamic U Malaysia, 2016.

Barnes, D. M. and C. L. Harrison. "Refugee Women's Reproductive Health in Early Resettlement." J Obstet Gynecol Neonatal Nurs, vol. 33, no. 6, 2004, pp. 723-728, doi:10.1177/0884217504270668. Accessed Feb. 2018.

Baum, F. et al. "Social Vaccines to Resist and Change Unhealthy Social and Economic Structures: A Useful Metaphor for Health Promotion." Health Promot Int, vol. 24, no. 4, 2009, pp. 428-433, doi:10.1093/heapro/dap026. Accessed Sep. 2017.

Beiser, M. "Resettling Refugees and Safeguarding Their Mental Health: Lessons Learned from the Canadian Refugee Resettlement Project." Transcult Psychiatry, vol. 46, no. 4, 2009, pp. 539-583, doi: 10.1177/1363461509351373. Accessed Nov. 2017.

Benson, G. Odessa et al. "Religious Coping and Acculturation Stress among Hindu Bhutanese: A Study of Newly-Resettled Refugees in the United States." International Social Work, vol. 55, no. 4, 2011, pp. 538-553, doi: 10.1177/0020872811417474. Accessed April, 2018.

Beresford, M. J. "Medical Reductionism: Lessons from the Great Philosophers." Qjm, vol. 103, no. 9, 2010, pp. 721-724, doi:10.1093/qjmed/hcq057. Accessed Nov. 2017.

Berry, John W. "Acculturation: Living Successfully in Two Cultures." International Journal of Intercultural Relations, vol. 29, no. 6, 2005, pp. 697-712, doi:https://doi.org/10.1016/j.ijintrel.2005.07.013. Accessed Feb. 2018.

Berry, John W. "Immigration, Acculturation, and Adaptation." Applied Psychology, vol. 46, no. 1, 1997, pp. 5-34, doi:doi:10.1111/j.1464-0597.1997.tb01087.x. Accessed Feb. 2017.

Berry, John W. and Bilge Ataca. "Cultural Factors.” Encyclopedia of Stress, Edited by George Fink. Academic Press, 2000, pp. 604-611.

Betancourt, Joseph R. et al. "Defining Cultural Competence: A Practical Framework for Addressing Racial/Ethnic Disparities in Health and Health Care." Public health reports, vol. 118, no. 4, 2003, pp. 293-302, PMC, http://www.ncbi.nlm.nih.gov/pmc/articles/PMC1497553/. Accessed Nov. 2017.

Bruno, A. "U.S. Refugee Resettlement Assistance." Congressional Research Service, Jan. 4, 2011. Retrieved from: https://fas.org/sgp/crs/row/R41570.pdf. Accessed Feb. 2017. 
Campinha-Bacote, Josepha. "The Process of Cultural Competence in the Delivery of Healthcare Services: A Model of Care." Journal of Transcultural Nursing, vol. 13, no. 3, 2002, pp. 181-184, doi: 10.1177/10459602013003003. Accessed May 2017.

Chamsi-Pasha, Hassan and Mohammed A. Albar. "Doctor-Patient Relationship: Islamic Perspective." Saudi Med J, vol. 37, no. 2, 2016, pp. 121-126, PMC, doi:10.15537/smj.2016.2.13602. Accessed June, 2018.

Cohen, Jeffrey H. "Syrian Refugees Next Door?" The Conversation, 1 Apr. 2016. Retrieved from: theconversation.com/syrian-refugees-next-door-56111. Accessed Feb. 2018.

Cohen, S. and T. B. Herbert. "Health Psychology: Psychological Factors and Physical Disease from the Perspective of Human Psychoneuroimmunology." Annu Rev Psychol, vol. 47, 1996, pp. 113-142, doi:10.1146/annurev.psych.47.1.113. Accessed Nov. 2017.

"Constitution of WHO: Principles." WHO. World Health Organization Documents, 45th ed. Geneva, 2005, retrieved from: www.who.int/about/mission/en/. Accessed March 2018.

Corbin, Juliet M, and Anselm L. Strauss. Basics of Qualitative Research: Techniques and Procedures for Developing Grounded Theory. Sage, 2015.

Corvo, Kenneth and Jaia Peterson. "Post-Traumatic Stress Symptoms, Language Acquisition, and Self-Sufficiency:A Study of Bosnian Refugees." Journal of Social Work, vol. 5, no. 2, 2005, pp. 205-219, doi: 10.1177/1468017305054974. Accessed May, 2017.

Cragg, G M, and D J Newman. "Plants as a Source of Anti-Cancer and Anti-HIV Agents." Annals of Applied Biology, vol. 143, no. 2, 2003, pp. 127-133, doi:10.1111/j.1744-7348.2003.tb00278.x. Accessed Nov. 2017.

Cragg, Gordon M. et al. "Impact of Natural Products on Developing New Anti-Cancer Agents." Chemical Reviews, vol. 109, no. 7, 2009, pp. 3012-3043, doi:

10.1021/cr900019j. Accessed Jan. 2018.

Creswell, John W, and Cheryl N. Poth. Qualitative Inquiry \& Research Design:

Choosing Among Five Approaches. Sage, 2018.

Curtis, Sarah, and A R. Taket. Health and Societies: Changing Perspectives. Arnold, 1996.

Denzin, Norman K. "The Art and Politics of Interpretation." The Sage Handbook of Qualitative Research, Edited by Norman Denzin and S Yvonna. Lincoln, 1994, pp. 500515. 
De Vries, J., \& Van Heck, G. L. "The World Health Organization Quality of Life Assessment Instrument (WHOQOL-100): Validation study with the Dutch version." European Journal of Psychological Assessment, vol. 13, no. 3, 1997, pp. 164178. http://dx.doi.org/10.1027/1015-5759.13.3.164. Accessed Nov. 2017.

Doocy, Shannon et al. "Health Service Access and Utilization among Syrian Refugees in Jordan." International Journal for Equity in Health, vol. 15, no. 1, 2016, p. 108, doi:10.1186/s12939-016-0399-4. Accessed Feb. 2018.

Doyle, Eva et al. "Using Community-Based Participatory Research to Assess Health Needs among Migrant and Seasonal Farmworkers." American Journal of Health Education, vol. 37, no. 5, 2006, pp. 279-288, doi:10.1080/19325037.2006.10598916. Accessed Feb. 2018.

Drummond, P. D. et al. "Barriers to Accessing Health Care Services for West African Refugee Women Living in Western Australia." Health Care Women Int, vol. 32, no. 3, 2011, pp. 206-224, doi:10.1080/07399332.2010.529216. Accessed Nov. 2017.

Duncan, G. "Mind-Body Dualism and the Biopsychosocial Model of Pain: What Did Descartes Really Say?" J Med Philos, vol. 25, no. 4, 2000, pp. 485-513, doi:10.1076/0360-5310(200008)25:4;1-a;ft485. Accessed Nov. 2017.

Ebrahimnejad, Hormoz. "What Is 'Islamic' in Islamic Medicine? An Overview." Science between Europe and Asia, edited by Feza Günergun and Dhruv Raina, Springer Netherlands, 2011, pp. 259-270.

El Bizri, Nader. "The Microcosm/Macrocosm Analogy: a Tentative Encounter between Graeco-Arabic Philosophy and Phenomenology." Islamic Philosophy and Occidental Phenomenology on the Perennial Issue of Microcosm and Macrocosm, edited by AnnaTeresa Tymieniecka, Springer, 2011, pp. 3-23.

Engelhardt, Hugo Tristram. The Foundations of Christian Bioethics. Swets \& Zeitlinger Publishers, 2000.

Erickson P., "The healing lessons of ethnomedicine." Understanding and Applying Medical Anthropology, edited by Peter J. Brown and Svea Closser, Routledge, 2016, 192.

Eriksson, Katie and Lindström, Unni. "Abduction-A Way to Deeper Understanding of the World of Caring." Scandinavian journal of caring sciences, vol. 11, no. 4, 1997, pp. 1958.doi: 10.1111/j.1471-6712.1997.tb00455.x. Accessed March 2018.

Ernst, E. and T. J. Kaptchuk. "Complementary Medicine--the Case for Dialogue." J R Coll Physicians Lond, vol. 30, no. 5, 1996, pp. 410-412, retrieved from: https://www.ncbi.nlm.nih.gov/pubmed/8912278. Accessed May, 2018. 
Estes, G. and Zitzow, D. "Heritage Consistency as a Consideration in Counseling Native Americans." ERIC - Education Resources Information Center, Nov. 1980. Retrieved from: eric.ed.gov/?id=ED209035. Accessed Jan. 2017.

Facione, N. C. "The Triandis model for the study of health and illness behavior: A social behavior theory with sensitivity to diversity." Advances in Nursing Science, vol. 15, no. 3, 1993, pp. 49-58, http://dx.doi.org/10.1097/00012272-199303000-00007. Accessed March 2017.

Farage, Samar. "The Ethics of the Physician in the Galeno-Islamic Tradition." Muslim Medical Ethics: From Theory to Practice, edited by Jonathan E. Brockopp and Thomas Eich, University of South Carolina Press, 2008.

Fassaert, T., de Wit, M. A. S., Tuinebreijer, W. C., Knipscheer, J. W., Verhoeff, A. P., Beekman A. T. F. \& Dekker, J. "Acculturation and psychological distress among nonwestern muslim migrants - a population-based survey." International Journal of Social Psychiatry, vol.57, 2011, pp. 132-143, doi: 10.1177/0020764009103647. Accessed Feb. 2018.

Fernando, Suman. Mental Health, Race and Culture. Palgrave Macmillan, 2010.

Fontanarosa, P. B. and G. D. Lundberg. "Alternative Medicine Meets Science." Jama, vol. 280, no. 18, 1998, pp. 1618-1619. Accessed May, 2018.

Foucault, Michel. The Archaeology of Knowledge, translated by AM Sheridan Smith. New York: Pantheon, 1972.

Fullilove, M. T. "Psychiatric Implications of Displacement: Contributions from the Psychology of Place." Am J Psychiatry, vol. 153, no. 12, 1996, pp. 1516-1523, doi:10.1176/ajp.153.12.1516. Accessed June, 2018.

Galdo, Anna. "Welfare in Mediterranean Countries: the Syrian Arab Republic." UNPAN, 2012, pp. 1-19. Retrieved from:

unpan1.un.org/intradoc/groups/public/documents/CAIMED/UNPAN018931.pdf.

Accessed May, 2018.

Galen. Method of Medicine. Edited by Ian Johnston and G. Horsley. Harvard University Press, 2011.

Gordon, Milton M. Assimilation in American Life: The Role of Race, Religion and National Origins. 2010.

Gorske, Tad T, and Steven R. Smith. Collaborative Therapeutic Neuropsychological Assessment. Springer, 2010. 
Goyette, Jared. "Canada is Just Better at Welcoming Syrian Refugees, but the US is Trying to Do More." Public Radio International, April, 2016. Retrieved from:

www.pri.org/stories/2016-04-05/canada-just-better-welcoming-syrian-refugees-us-tryingdo-more. Accessed Feb. 2018.

Greenstone, Gerry. "The history of bloodletting." $B C M J$, vol. 52, no. 1, 2010, pp.12-14, https://www.bcmj.org/premise/history-bloodletting. Accessed May, 2018.

Guruge, S. and N. Khanlou. "Intersectionalities of Influence: Researching the Health of Immigrant and Refugee Women." Can J Nurs Res, vol. 36, no. 3, 2004, pp. 32-47. Accessed May, 2017.

Gutas D., Greek Thought, Arabic Culture: The Graeco-Arabic Translation Movement in Baghdad and Early 'Abbasaid Society (2nd-4th/5th-10th c.). Routledge, 2012.

Guyatt et al. "Evidence-Based Medicine. A New Approach to Teaching the Practice of Medicine." Jama, vol. 268, no. 17, 1992, pp. 2420-2425, doi:10.1001/jama.1992.03490170092032. Accessed Nov. 2017.

Hassan, Ghayda et al. "Culture, Context, and the Mental Health and Psychosocial Wellbeing of Syrians: A Review of Mental Health and Psychosocial Support staff working with Syrians Affected by Armed Conflict.” UNHCR: Geneva 2015, pp.1-50. Retrieved from: http://www.unhcr.org/en-us/protection/health/55f6b90f9/culture-contextmental-health-psychosocial-wellbeing-syrians-review-mental.html. Accessed Feb. 2018.

Hein, Jeremy. "Refugees, Immigrants, and the State." Annual Review of Sociology, vol. 19, 1993, pp. 43-59. JSTOR, JSTOR, www.jstor.org/stable/2083380. Accessed Oct. 2017.

"Heritage and Resilience: Issues and Opportunities for Reducing Disaster Risks." UNISDR. Global Platform for Disaster Risk Reduction, 2013. Retrieved from: www.unisdr.org/we/inform/publications/33189. Accessed May, 2018.

Hermansen, Marcia. "Dimensions of Islamic Religious Healing in America." Religion and Healing in America, edited by Linda Barnes and Susan Sered. Oxford University Press, 2004, pp. 407-423.

Hoberman, John M. Black and Blue: The Origins and Consequences of Medical Racism. Uni of California Press, 2016.

"Holistic Medicine: What It Is, Treatments, Philosophy, and More." WebMD, June, 2017, Retrieved from: www.webmd.com/balance/guide/what-is-holistic-medicine\#1. Accessed July, 2018. 
Hua, Miao et al. "Integrating Traditional Chinese Medicine into Chinese Medical Education Reform: Issues and Challenges." International Journal of Medical Education, vol. 8, 2017, pp. 126-127, PMC, doi:10.5116/ijme.58e3.c489. Accessed May, 2018.

Immigration, Refugees and Citizenship Canada. "Welcome Refugees: Key Figures." Canada.ca, 27 Feb. 2017. Retrieved from: www.canada.ca/en/immigrationrefugees-citizenship/services/refugees/welcome-syrian-refugees/key-figures.html. Accessed May, 2018.

Inhorn, Marcia C. America's Arab Refugees: Vulnerability and Health on the Margins. Stanford University Press, 2018.

Inhorn, M. C. and G. I. Serour. "Islam, Medicine, and Arab-Muslim Refugee Health in America after 9/11." Lancet, vol. 378, no. 9794, 2011, pp. 935-943, doi:10.1016/s01406736(11)61041-6. Accessed Oct. 2017.

Jāmi 'At-Tirmidhi 6 Volumes: Vol 1 to 6 Arabic and English. Translated by Abu Khaliyl, Daruusalam, 2014.

Javier, Hope. "The Four Humours Theory." ESSAI, vol. 12, no. 21, 2014, pp. 7274, https://dc.cod.edu/essai/vol12/iss1/21. Accessed Feb. 2018.

Jorden, Skye et al. "Supportive and Unsupportive Social Interactions in Relation to Cultural Adaptation and Psychological Distress among Somali Refugees Exposed to Collective or Personal Traumas." Journal of Cross-Cultural Psychology, vol. 40, no. 5, 2009, pp. 853-874, doi:10.1177/0022022109339182. Accessed March 2018.

Josselson, Ruthellen. Interviewing for Qualitative Inquiry: A Relational Approach. Guilford Publications, 2013.

Kamperman, A. M., Komproe, I. H., \& de Jong, J. T. V. M. "Migrant mental health: A model for indicators of mental health and health care consumption." Health Psychology, vol. 26, no.1, Jan.2007, pp. 96-104, http://psycnet.apa.org/buy/2006-23340-012. Accessed March, 2018.

Kardia, S. L. et al. "Family-Centered Approaches to Understanding and Preventing Coronary Heart Disease." Am J Prev Med, vol. 24, no. 2, 2003, pp. 143-151, https://www.ncbi.nlm.nih.gov/pubmed/12568820. Accessed Oct. 2017.

Keyes, E. F. and C. F. Kane. "Belonging and Adapting: Mental Health of Bosnian Refugees Living in the United States." Issues Ment Health Nurs, vol. 25, no. 8, 2004, pp. 809-831, doi: 10.1080/01612840490506392. Accessed Oct. 2017.

Khan, Faroque Ahmed. "Approaching Modern Technological Challenges through the Traditions of Ibn Sina (980-1036)." Journal of the Islamic Medical Association of North America, vol. 40, no. 1, 2008, pp. 15-22, doi:10.5915/40-1-5280. Accessed Feb. 2018. 
Kherallah, Mazen et al. "Health Care in Syria before and During the Crisis." Avicenna Journal of Medicine, vol. 2, no. 3, 2012, pp. 51-53, PMC, doi:10.4103/22310770.102275. Accessed March, 2018.

Kia-Keating, M. and B. H. Ellis. "Belonging and Connection to School in Resettlement: Young Refugees, School Belonging, and Psychosocial Adjustment." Clin Child Psychol Psychiatry, vol. 12, no. 1, 2007, pp. 29-43, doi: 10.1177/1359104507071052. Accessed Nov. 2017.

Kleinman, Arthur. Patients and Healers in the Context of Culture: An Exploration of the Borderland between Anthropology, Medicine, and Psychiatry Vol.3. U of California $\mathrm{P}, 1981$.

Koenig, Harold G. "Religion and Medicine I: Historical Background and Reasons for Separation." The International Journal of Psychiatry in Medicine, vol. 30, no. 4, 2000, pp. 385-398, doi:10.2190/2rwb-3ae1-m1e5-tvhk. Accessed Oct. 2017.

Koenig, Harold G., and Saad Al Shohaib. Health and Well-Being in Islamic Societies. Springer, 2014.

Kroo, Adrienn and Henriett Nagy. "Posttraumatic Growth among Traumatized Somali Refugees in Hungary." Journal of Loss and Trauma, vol. 16, no. 5, 2011, pp. 440-458, doi:10.1080/15325024.2011.575705. Accessed March 2018.

Larson, J. S. "The Conceptualization of Health." Med Care Res Rev, vol. 56, no. 2, 1999, pp. 123-136, doi:10.1177/107755879905600201. Accessed Feb. 2018.

"Legal Status of Traditional Medicine and Complementary/Alternative Medicine: A Worldwide Review: Eastern Mediterranean: Syrian Arab Republic." Essential Medicines and Health Products Information Portal, 2001, WHO, retrieved from: apps.who.int/medicinedocs/en/d/Jh2943e/6.11.html\#Jh2943e.6.11. Accessed March 2018.

Leslie, Charles. "Medical Pluralism in World Perspective [1]." Social Science \& Medicine. Part B: Medical Anthropology, vol. 14, no. 4, 1980, pp. 191-195, doi: https://doi.org/10.1016/0160-7987(80)90044-7. Accessed May, 2018.

Lindberg, David C. The Beginnings of Western Science: the European Scientific Tradition in Philosophical, Religious, and Institutional Context, Prehistory to A.D. 1450. International Society for Science and Religion, 2008.

Lindeberg, Staffan et al. "Biological and Clinical Potential of a Palaeolithic Diet." Journal of Nutritional \& Environmental Medicine, vol. 13, no. 3, 2003, pp. 149-160, doi:10.1080/13590840310001619397. Accessed Feb. 2018. 
Livingston, James D. et al. "A Tale of Two Cultures: Examining Patient-Centered Care in a Forensic Mental Health Hospital." The Journal of Forensic Psychiatry \& Psychology, vol. 23, no. 3, 2012, pp. 345-360, PMC, doi:10.1080/14789949.2012.668214. Accessed Feb. 2018.

Lock, Margaret M., and Vinh-Kim Nguyen. An Anthropology of Biomedicine. Wiley, 2018.

Lovering, S. "The Crescent of Care: A Nursing Model to Guide the Care of Muslim Patients." Cultural Competence in Caring for Muslim Patients, edited by Hussein Rassool. Palgrave Macmillan, 2014, pp. 104-120.

MacFarquhar, Neil. "Syrian Opposition Is Hobbled by Deep Divisions." The New York Times - Breaking News, World News \& Multimedia, 23 Feb. 2012. Retrieved from: www.nytimes.com/2012/02/24/world/middleeast/syrian-opposition-is-hobbled-by-deepdivisions.html. Accessed Feb. 2018.

Malkki, Liisa H. "Speechless Emissaries: Refugees, Humanitarianism, and Dehistoricization." Cultural Anthropology, vol. 11, no. 3, 1996, pp. 377-404. JSTOR, JSTOR, www.jstor.org/stable/656300. Accessed May, 2018.

Martin, Emily. The Woman in the Body: A Cultural Analysis of Reproduction: with a New Preface. Beacon Press, 2001.

Melzack, R. and P. D. Wall. "Pain Mechanisms: A New Theory." Science, vol. 150, no. 3699, 1965, pp. 971-979, doi: 10.1126/science.150.3699.971. Accessed Oct. 2017.

Mershed, Mania et al. "Healthcare Financing in Syria: Satisfaction with the Current System and the Role of National Health Insurance - a Qualitative Study of Householders' Views." The International Journal of Health Planning and Management, vol. 27, no. 2, 2012, pp. 167-179, doi:10.1002/hpm.2102. Accessed Jan. 2018.

Mghir, R. et al. "Depression and Posttraumatic Stress Disorder among a Community Sample of Adolescent and Young Adult Afghan Refugees." J Nerv Ment Dis, vol. 183, no. 1, 1995, pp. 24-30, http://dx.doi.org/10.1097/00005053-199501000-00005. Accessed Nov. 2017.

Miller, K. E. and A. Rasmussen. "War Exposure, Daily Stressors, and Mental Health in Conflict and Post-Conflict Settings: Bridging the Divide between Trauma-Focused and Psychosocial Frameworks." Soc Sci Med, vol. 70, no. 1, 2010, pp. 7-16, doi:10.1016/j.socscimed.2009.09.029. Accessed Nov. 2017.

Miller, K. E. et al. "Bosnian Refugees and the Stressors of Exile: A Narrative Study." Am J Orthopsychiatry, vol. 72, no. 3, 2002, pp. 341-354. Accessed Feb. 2017. 
"Mortality over the Twentieth Century in Australia: Trends and Patterns in Major Causes of Death, Table of Contents." Australian Institute of Health and Welfare, 2006. www.aihw.gov.au/reports/australias-health/mortality-twentieth-century-australiatrends/contents/table-of-contents. Accessed Feb. 2018.

Morris, Meghan D. et al. "Healthcare Barriers of Refugees Post-Resettlement." Journal of community health, vol. 34, no. 6, 2009, pp. 529-538, PMC, doi:10.1007/s10900-0099175-3. Accessed Feb. 2018.

Museru, O. I. et al. "Hepatitis B Virus Infection among Refugees Resettled in the U.S.: High Prevalence and Challenges in Access to Health Care." J Immigr Minor Health, vol. 12, no. 6, 2010, pp. 823-827, doi:10.1007/s10903-010-9335-7. Accessed Feb. 2018.

Nabolsi, M. M. and A. M. Carson. "Spirituality, Illness and Personal Responsibility: The Experience of Jordanian Muslim Men with Coronary Artery Disease." Scand J Caring Sci, vol. 25, no. 4, 2011, pp. 716-724, doi:10.1111/j.1471-6712.2011.00882.x. Accessed Feb. 2018.

Nassar-McMillan, Sylvia C. and Julie Hakim-Larson. "Counseling Considerations among Arab Americans." Journal of Counseling \& Development, vol. 81, no. 2, 2003, pp. 150159, doi:doi:10.1002/j.1556-6678.2003.tb00236.x. Accessed Feb. 2018.

"No Escape for Syrians Seeking Safety Six Years After First Protests." Oxfam GB, 13 Mar. 2017. Retrieved from: www.oxfam.org.uk/media-centre/press-

releases/2017/03/no-escape-for-syrians-seeking-safety-six-years-after-first-protests. Accessed Feb. 2018.

Noah, Timothy. "A Short History of Health Care." Slate Magazine, March 13, 2007. Retrieved from http://www.slate.com/news-and-politics/2007/03/a-short-history-ofhealth-care.html. Accessed March, 2018.

Norris, A. E. et al. "Premigration Persecution, Postmigration Stressors and Resources, and Postmigration Mental Health: A Study of Severely Traumatized U.S. Arab Immigrant Women." J Am Psychiatr Nurses Assoc, vol. 17, no. 4, 2011, pp. 283-293; discussion 294-286, doi:10.1177/1078390311408900. Accessed Feb. 2017.

Oh, Y. et al. "Acculturation, Stress, and Depressive Symptoms among Korean Immigrants in the United States." J Soc Psychol, vol. 142, no. 4, 2002, pp. 511-526, doi: 10.1080/00224540209603915. Accessed Oct. 2017.

O'Mahony, J. and T. Donnelly. "Immigrant and Refugee Women's Post-Partum Depression Help-Seeking Experiences and Access to Care: A Review and Analysis of the Literature." J Psychiatr Ment Health Nurs, vol. 17, no. 10, 2010, pp. 917-928, doi:10.1111/j.1365-2850.2010.01625.x. Accessed Nov. 2017. 
Padela, Aasim I. et al. "American Muslim Perceptions of Healing: Key Agents in Healing, and Their Roles." Qualitative health research, vol. 22, no. 6, 2012, pp. 846-858, PMC, doi:10.1177/1049732312438969. Accessed Oct. 2017.

Papademetriou, Demetrios G., Richard Alba, Nancy Foner, and Natalia BanulescuBogdan. "Managing Religious Difference in North America and Europe in an Era of Mass Migration." Migrationpolicy.org, 11 July 2016. Retrieved from: www.migrationpolicy.org/research/managing-religious-difference-north-america-andeurope-era-mass-migration. Accessed Feb. 2018.

Pavlish, C. L. et al. "Somali Immigrant Women and the American Health Care System: Discordant Beliefs, Divergent Expectations, and Silent Worries." Soc Sci Med, vol. 71, no. 2, 2010, pp. 353-361, doi:10.1016/j.socscimed.2010.04.010. Accessed Nov. 2017.

Penninx, R. "Integration. The role of communities, institutions, and the state." Migration Policy Institute. Oct 1, 2013, retrieved from: https://www.migrationpolicy.org/article/integration-role-communities-institutions-andstate. Accessed Nov. 2017.

Philips, A.A.B. The Exorcist Tradition in Islam. Edited by R. Ansary. Al Hidaayah Publishing \& Distribution, 2007.

Pormann, Peter E., and Emilie Savage-Smith. Medieval Islamic Medicine. Edinburgh Univ. Press, 2010.

Portes, Alejandro, and Rubén G. Rumbaut. Immigrant America: A Portrait. University of California Press, 2014. ProQuest Ebook Central, https://ebookcentral-proquestcom.echo.louisville.edu/lib/louisville/detail.action?docID=1711065. Accessed September, 2018.

Rang, H. P., and M. Maureen Dale. Rang and Dale's Pharmacology. 7th ed. Elsevier Churchill Livingstone, 2012.

Rashidi, A. and S. S. Rajaram. "Culture Care Conflicts among Asian-Islamic Immigrant Women in Us Hospitals." Holist Nurs Pract, vol. 16, no. 1, 2001, pp. 55-64, PubMed, doi: 10.1097/00004650-200110000-00010. Accessed Oct. 2017.

Rasmussen, A. et al. "Rates and Impact of Trauma and Current Stressors among Darfuri Refugees in Eastern Chad." Am J Orthopsychiatry, vol. 80, no. 2, 2010, pp. 227-236, doi:10.1111/j.1939-0025.2010.01026.x. Accessed Feb. 2017.

Rassool, G. Hussein. Cultural Competence in Caring for Muslim Patients. Palgrave Macmillan, 2014. 
Redfield, Robert et al. "Memorandum for the Study of Acculturation." American Anthropologist, vol. 38, no. 1, 1936, pp. 149-152, http://www.jstor.org/stable/662563. Accessed Oct. 2017.

Reese Masterson, Amelia et al. "Assessment of Reproductive Health and Violence against Women among Displaced Syrians in Lebanon." BMC women's health, vol. 14, no. 25, 2014, pp. 1-8, PubMed, doi:10.1186/1472-6874-14-25. Accessed Jan. 2018.

Regenmortel, Marc H. V. Van. "Reductionism and Complexity in Molecular Biology." EMBO Reports, vol. 5, no. 11, 2004, pp. 1016-1020, PMC, doi:10.1038/sj.embor.7400284. Accessed Oct. 2017.

Riholm, Maj-Britt. "Theory Development and the Logic of Discovery." International Journal of Human Caring, vol. 14, no. 3, 2010, pp. 35-41, doi: 10.20467/10915710.14.3.35. Accessed March 2017.

"The Road to Resilience." American Psychological Association, http://www.apa.org, www.apa.org/helpcenter/road-resilience.aspx. Accessed May, 2018.

Rohmann, Chris. A World of Ideas: A Dictionary of Important Theories, Concepts, Beliefs, and Thinkers. Ballantine Books, 2000.

Roy, Callista. The Roy Adaptation Model. Pearson, 2009.

Rumbaut, Rubén G. "Assimilation of Immigrants." International Encyclopedia of the Social \& Behavioral Sciences, vol.2, no. 2, 2015, pp. 81-87. Retrieved from: https://papers.ssrn.com/sol3/papers.cfm?abstract_id=2595896. Accessed Oct. 2017.

Ruhil, Rohini. "Medical Pluralism in India and Its Integration into State Health Services System." AYUSHDHARA, vol. 2, no.5, 2015, pp. 309-314, Academia, retrieved from: https://www.researchgate.net/publication/292971294_MEDICAL_PLURALISM_IN_IN DIA_AND_ITS_INTEGRATION_INTO_STATE_HEALTH_SERVICES_SYSTEM. Accessed March, 2018.

"Rules Regarding Looking, Touching and Examining." Al-Islam.org, www.alislam.org/islamic-rulings-medical-issues-sayyid-ali-khamenei/rules-regarding-lookingtouching-and-examining. Accessed May, 2018.

Ruthven, Malise. Islam: A Very Short Introduction. Oxford University Press, 2012.

Ryan D, Dooley B, Benson C. "Theoretical perspectives on post-migration adaptation and psychological well-being among refugees: Towards a resource-based model." Journal of Refugee Studies, vol. 21, no. 1, 2008, pp. 1-18, doi: 10.1093/jrs/fem047. Accessed Oct. 2017. 
Sachedina, Abdulaziz A. Islamic Biomedical Ethics: Principles and Application. Oxford Univ. P, 2012.

Saha, Somnath et al. "Patient Centeredness, Cultural Competence and Healthcare Quality." Journal of the National Medical Association, vol. 100, no. 11, 2008, pp. 12751285, PMC, retrieved from: http://www.ncbi.nlm.nih.gov/pmc/articles/PMC2824588/. Accessed Sep. 2017.

Saḥ̄ḥ Bukhārī (Nine Volums). Tranlsated by Mohammad Muhsin Khan, Darussalam, 2014.

Saḥịh Muslim. Translated by Nasiruddine al Khattab, Darussalam, 2007.

Saldaña, Johnny. The Coding Manual for Qualitative Researchers. Sage, 2016.

Saniotis, Arthur. "Islamic Medicine and Evolutionary Medicine: A Comparative Analysis." Journal of the Islamic Medical Association of North America, vol. 44, no. 1, 2012, pp: 1-9, doi:10.5915/44-1-8780. Accessed Oct. 2017.

Schweitzer, Robert et al. "Trauma, Post-Migration Living Difficulties, and Social Support as Predictors of Psychological Adjustment in Resettled Sudanese Refugees." Australian and New Zealand Journal of Psychiatry, vol. 40, no. 2, 2006, pp. 179-187, doi:10.1080/j.1440-1614.2006.01766.x. Accessed Feb. 2018.

Schweitzer, R. et al. "Coping and Resilience in Refugees from the Sudan: A Narrative Account." Aust N Z J Psychiatry, vol. 41, no. 3, 2007, pp. 282-288, doi:10.1080/00048670601172780. Accessed Feb. 2018.

Seabrook J. "The unprivileged: A hundred years of their ideas about health and illness." Concepts of Health, Illness and Disease: A Comparative Perspective, edited by C. Currer C and M. Stacey. New York: Berg, 1986.

Shank, Gary. "The Extraordinary Ordinary Powers of Abductive Reasoning." Theory \& Psychology, vol. 8, no. 6, 1998, pp. 841-860, doi:10.1177/0959354398086007. Accessed March 2017.

Shaw, Susan J. "The Logic of Identity and Resemblance in Culturally Appropriate Health Care." Health, vol. 14, no. 5, 2010, pp. 523-544, doi:10.1177/1363459309360973. Accessed Feb. 2018.

Sigerist, Henry E. A History of Medicine. Early Greek, Hindu, and Persian Medicine. NY: Oxford University Press, 1961.

Simich, L. et al. "Social Support and the Significance of Shared Experience in Refugee Migration and Resettlement." West J Nurs Res, vol. 25, no. 7, 2003, pp. 872-891, doi: 10.1177/0193945903256705. Accessed May 2017. 
Spector, Rachel E. Cultural Diversity in Health \& Illness. $7^{\text {th }}$ ed. Prentice Hall Health, 2009.

Strang, Alison and Alastair Ager. "Refugee Integration: Emerging Trends and Remaining Agendas." Journal of refugee studies, vol. 23, no. 4, 2010, pp. 589-607, doi: 10.1093/jrs/feq046. Accessed Oct. 2017.

Strijk, P. J. et al. "Health and Social Needs of Traumatized Refugees and Asylum Seekers: An Exploratory Study." Perspect Psychiatr Care, vol. 47, no. 1, 2011, pp. 4855, doi:10.1111/j.1744-6163.2010.00270.x. Accessed Nov. 2017.

Sunan Abu Dawud (Five Volumes). Translated by Yaser Qadhi, Darussalam, 2008.

Sunan An Nasā'i (Six Books). Translated by Nasiruddin Al-Khattab, Darussalam, 2007.

Sunan Ibn Mäjah (Five Volumes). Translated by Nasiruddin Al-Khattab, Darussalam, 2007.

Sweeney, K. and D. Kernick. "Clinical Evaluation: Constructing a New Model for PostNormal Medicine." J Eval Clin Pract, vol. 8, no. 2, 2002, pp. 131-138, doi:10.1107/s0108768107031758/bs5044sup1.cif. Accessed Feb. 2018.

Swink, Rodney. "The Importance of Memory and Place in Heritage

Resilience." US/ICOMOS, 15 Aug. 2016. Retrieved from: www.usicomos.org/theimportance-of-memory-and-place-in-heritage-resilience/. Accessed May, 2018.

"Syria's Civil War Explained from the Beginning." Al Jazeera, 21 Feb. 2018. Retrieved from: www.aljazeera.com/news/2016/05/syria-civil-war-explained-

160505084119966.html. Accessed Nov. 2017.

"Syria Refugee Crisis: is Your Country Doing Its Fair Share?" Oxfam International, 16 Dec. 2016. Retrieved from: www.oxfam.org/en/campaigns/rights-crisis-lebanon-jordancrisis-syria/syria-refugee-crisis-your-country-doing-its-fair. Accessed Feb. 2018.

"2014 Syrian Arab Republic Humanitarian Assistance Response Plan (SHARP) - Syrian Arab Republic." ReliefWeb, 2014. Retrieved from: reliefweb.int/report/syrian-arabrepublic/2014-syrian-arab-republic-humanitarian-assistance-response-plan-sharp. Accessed March, 2018.

Syrian Ministry of Health. "Morbidity \& Mortality." Ministry of Health, 2015. Retrieved from: www.moh.gov.sy/Default.aspx?tabid=254\&language=en-US. Accessed March, 2018.

Syrian Ministry of Health. "Health Indicators." Ministry of Health, 2015. Retrieved from: http://www.moh.gov.sy/Default.aspx?tabid=248\&language=en-US\#8. Accessed March, 2018. 
Taylor, Janelle S. "Confronting "Culture" in Medicine's "Culture of No Culture"." Academic Medicine, vol. 78, no. 6, 2003, pp. 555-559, retrieved from:

https://www.ncbi.nlm.nih.gov/pubmed/12805033. Accessed Nov. 2017.

Taylor, Timothy. "OPINION EXCHANGE | Analogies for America: Beyond the Melting Pot." Star Tribune, 29 June 2013, www.startribune.com/analogies-for-america-beyondthe-melting-pot/213593491/. Accessed June, 2018.

Tedeschi, Richard G. and Lawrence G. Calhoun. "Target Article: "Posttraumatic Growth: Conceptual Foundations and Empirical Evidence"." Psychological Inquiry, vol. 15, no. 1, 2004, pp. 1-18, doi:10.1207/s15327965pli1501_01. Accessed Feb. 2018.

Thagard, Paul. "The Concept of Disease: Structure and Change." Nature of Concepts, edited by Philip Van Loocke, Routledge, 2014.

Thomas, F. C. et al. "Resilience of Refugees Displaced in the Developing World: A Qualitative Analysis of Strengths and Struggles of Urban Refugees in Nepal." Confl Health, vol. 5, no. 1, 2011, p. 20, doi:10.1186/1752-1505-5-20. Accessed Feb. 2017.

Timmermans, Stefan and Iddo Tavory. "Theory Construction in Qualitative Research:From Grounded Theory to Abductive Analysis." Sociological Theory, vol. 30, no. 3, 2012, pp. 167-186, doi:10.1177/0735275112457914. Accessed Feb. 2017.

UNHCR. "Syria Regional Refugee Response" Operational Portal, May, 2018. Retrieved from: data2.unhcr.org/en/situations/Syria. Accessed Oct. 2018.

UNICEF. "Uprooted: The Growing Crisis for Refugee and Migrant Children." UNICEF, Sep. 2016, pp. 1-140. Retrieved from:

https://www.unicef.org/publications/index_92710.html. Accessed Feb. 2018.

University of Louisville, Global Health Center Kentucky Office for Refugees. "Kentucky Refugee Health Assessment Report," 2016, pp.1-48. Retrieved from:

https://louisville.edu/medicine/departments/medicine/divisions/infectiousdiseases/refugee -health/services/SRH2015.pdf. Accessed Feb. 2017.

U.S. Department of Health and Human Services, Centers for Disease Control and Prevention. "Syrian Refugee Health Profile." Jan. 2017, pp. 1-20. Retrieved from: https://www.cdc.gov/immigrantrefugeehealth/pdf/syrian-health-profile.pdf. Accessed Feb. 2017.

Wacholder, S., N. Rothman, and N. Caporaso. "Population Stratification in Epidemiologic Studies of Common Genetic Variants and Cancer: Quantification of Bias." Journal of the National Cancer Institute, vol. 92, no. 14, 2000, pp. 1151-1158., doi:10.1093/jnci/92.14.1151. Accessed Nov. 2017. 
Wahoush, Ellen O. "Reaching a Hard-to-Reach Population Such as Asylum Seekers and Resettled Refugees in Canada." Bulletin of the World Health Organization, vol. 87, no. 8, 2009, pp. 568-568, PMC, doi:10.2471/BLT.08.061085. Accessed Nov. 2017.

Walton LM, Akram F, and Hossain F. "Health Beliefs of Muslim Women and Implications for Health Care Providers: Exploratory Study on the Health Beliefs of Muslim Women." Online Journal of Health Ethics, vol. 10, no. 2, 2014, pp. 5-39, WorldCat.org, doi.org/10.18785/ojhe.1002.05. Accessed May, 2018.

Weissbecker, Inka and A. Leichner "Addressing Mental Health Needs Among Syrian Refugees." Middle East Institute, 22 Sept. 2015, www.mei.edu/content/article/addressing-mental-health-needs-among-syrian-refugees. Accessed Feb. 2018.

"What is Intangible Cultural Heritage?" UNESCO, Intangible Heritage, 2016. Retrieved from: http://ich.unesco.org/en/what-is-intangible-heritage-00003. Accessed May, 2018.

WHO. “Global Health Observatory (GHO) Data: Syrian Arab Republic.” WHO, 2018. Retrieved from: apps.who.int/nha/database/Country_Profile/Index/en. Accessed Feb, 2018.

WHO. "HeRAMS Annual Report 2015 | Syrian Arab Republic." WHO EMRO, 10 Mar. 2016. Retrieved From:www.emro.who.int/syr/information-resources/herams2015-reports.html. Accessed Feb. 2018.

WHO. "WHO Response to the Syrian Crisis - Regional Situation Report, January 2015 Syrian Arab Republic." ReliefWeb, Jan. 2015. Retrieved from:reliefweb.int/report/syrianarab-republic/who-response-syrian-crisis-regional-situation-report-january-2015. Accessed March 2018.

Yosef, A. R. "Health Beliefs, Practice, and Priorities for Health Care of Arab Muslims in the United States." J Transcult Nurs, vol. 19, no. 3, 2008, pp. 284-291, doi:10.1177/1043659608317450. Accessed Oct. 2017.

Zong, Jie, Jeanne Batalova, Jie Zong, and Jeanne Batalova. "Syrian Refugees in the United States." Migration Policy Institute, 2 Mar. 2017. Retrieved from: www.migrationpolicy.org/article/syrian-refugees-united-states. Accessed Feb. 2018. 


\section{Appendices}

\section{Appendix 1}

\section{Interview Questions}

1) What does health mean to you?

2) Is health related to physical or mental realm?

3) What does illness mean to you and how do you react to it?

4) What do you do to protect your health?

5) When you say "I have pain in my heart", what do you mean by that?

6) What do you do if you notice any change in your health?

7) From where do you get health care here?

8) When sick whom do you resort to first and second?

9) How do you generally evaluate the health care resources and services here?

10) Do you feel depressed when sick here?

11) What thoughts come to your mind when you are sick here?

12) When sick do you prefer to be alone or with family or people?

13) Do you fear death when sick or when feeling pain?

14) What problems do you encounter in the health care system here?

15) What thing you wish is available in the health care system here?

16) Are there any special food and home treatments you opt for when sick here?

17) Do your religious and folk health practices have any impact on you? If yes explain

18) From which region in Syria are you?

19) What is your ethnicity? 
20) What is your education level?

21) How long have you been here in US?

22) How old are you?

23) Where do you feel more comfortable: at the primary care physician's clinic, specialist's clinic, or ER?

24) How do you evaluate the health care system in Syria or the former country you lived in?

25) Why did you come to the US? 
Appendix 2

IRB Approval

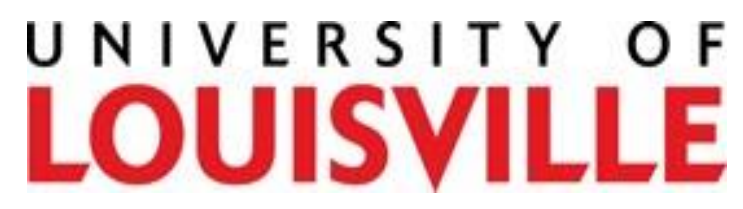

Human Subjects Protection Program Office MedCenter One - Suite 200

501 E. Broadway

Louisville, KY 40202-1798

Office: 502.852.5188 Fax: 502.852.2164
DATE:

TO:

IRB NUMBER:

STUDY TITLE:

January 29, 2018

Julie Peteet, PhD

17.0688

Arab Islamic and Folk Health Model: A New and Empowering

Perspective of the Syrian Refugees' Resettlement in the United

States.

REFERENCE \#: $\quad 654517$

IRB STAFF CONTACT: Jackie Powell, CIP

852-4101

The amendment request was received by the Human Subjects Protection

Program Office and reviewed by the HSPPO staff and was found to be complete. The following documents have been approved:

\begin{tabular}{|l|l|l|}
\hline \multicolumn{2}{|l|}{ Submission Components } & Outcome \\
\hline Form Name & Version & Approved as Submitted \\
\hline $\begin{array}{l}\text { Request Application, } \\
\text { Protocol, or Document } \\
\text { Change }\end{array}$ & Version 1.0 & \\
\hline
\end{tabular}




\begin{tabular}{|c|c|c|c|}
\hline IRB Study Application & \multicolumn{2}{|c|}{ Version 1.2} & Approved as Submitted \\
\hline \multicolumn{4}{|l|}{ Study Consent Form } \\
\hline Title & Version \# & Version Date & Outcome \\
\hline $\begin{array}{l}\text { clean copy of } \\
\text { informed consent }\end{array}$ & Version 3.0 & 01/26/2018 & Approved \\
\hline $\begin{array}{l}\text { clean copy of } \\
\text { healthcare consent }\end{array}$ & Version 3.0 & $01 / 26 / 2018$ & Approved \\
\hline
\end{tabular}

The modifications include:

University of Louisville hospital has been removed as a study site and Med Center one has been added.

If you have any questions, please contact the Human Subjects Protection Program Office at hsppofc@louisville.edu.

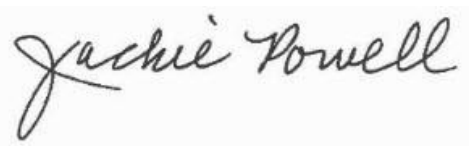

Jackie Powell, CIP

Senior IRB Analyst

Social/Behavioral/Education Institutional Review Board 


\title{
CURRICULUM VITAE
}

\author{
Ghina Kheir \\ Email Address: ghina.kheir@gmail.com
}

\section{Education}

2018 Ph.D. Department of Comparative and Global Humanities. University of Louisville

Louisville, $K Y$

2010 MA. English Language and Literature. Balamand University

Lebanon

2004 BA. English Language and Literature. Lebanese University

Lebanon

Graduated with distinction

\section{Academic and Teaching Interests:}

Health and medical pluralism, refugee studies, bioethics, religion, Arabic literature, and Middle Eastern studies.

Title of Dissertation: ARAB-ISLAMIC AND FOLK HEALTH MODELS: NEW PERSPECTIVES ON SYRIAN REFUGEE RESETTLEMENT IN THE US

\section{Professional Experience}

Kentucky Refugee Ministries

Louisville, $K Y$

Internship in Cultural Orientation and ESL, January -March 2017

Faculty of Business and Economical Sciences at the Lebanese University

Lebanon

ESL teacher, April 2007 to July 2009 


\title{
Deir Ammar Vocational School
}

LebanonESL teacher for Accounting and Computer Science Students, January 2004 to January 2009

\section{Rawdat EI Fayhaa Secondary School}

Lebanon

English Teacher for Grades 2 and 4, October 2006 to March 2008

\author{
Faculty of Law and Political Sciences at the Lebanese University \\ Lebanon \\ ESL Teacher, October 2008 to June 2009
}

\section{Quantum Learning Center}

Lebanon

ESL Teacher, May 2006 to November 2006

\section{Certifications and Awards}

- Doctoral Dissertation Completion Award, Fall 2018

- Teaching License, Massachusetts Department of Education in English as a Second Language, 2011

- Honors in recognition of outstanding academic achievement at Tripoli Evangelical School

- Awards in poetry and translation contests at Lebanese University 2003, 2004

- "Diplome d'Études en Langue Française" from "Centre Culturel Française " (CCF) 2004

\section{Competencies and Skills}

- Passionate about cross-cultural issues especially between the West and the Arab and Muslim world

- Highly interested in social and humanitarian work

- Skillful in classroom management and motivating students

- Interactive teaching/learning 
- Excellent classroom management

- Computer proficient

- Creative lesson plan development

- Interdisciplinary teaching

- Effectively work with parents

- Positive reinforcement for others

- Proficient in the IRB process

\section{Language Proficiency:}

Arabic (fluent)

English (fluent)

French (intermediate)

Spanish (reading and speaking)

\section{$\underline{\text { Referees }}$}

- Prof.Julie Peteet Studies

Professor of Anthropology and the director of the Middle East and Islamic

Program at University of Louisville

Department of Anthropology, Lutz Hall 239

Phone:502-852-6864

Email: jpeteet@1ouisville.edu

- Prof.Simona Bertacco

Director of Graduate Studies in the Department of Comparative Humanities at University of Louisville

Phone: (502) 852-7161

Email: simona.bertacco@louisville.edu 